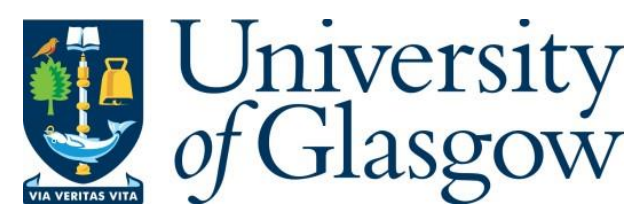

Abánades Lázaro, I. and Forgan, R. S. (2019) Application of zirconium MOFs in drug delivery and biomedicine. Coordination Chemistry Reviews, 380, pp. 230-259.

There may be differences between this version and the published version. You are advised to consult the publisher's version if you wish to cite from it.

http://eprints.gla.ac.uk/172244/

Deposited on: 30 October 2018

Enlighten - Research publications by members of the University of Glasgow

http://eprints.gla.ac.uk 


\title{
Application of Zirconium MOFs in Drug Delivery and Biomedicine
}

\author{
Isabel Abánades Lázaro and Ross S. Forgan*
}

WestCHEM, School of Chemistry, University of Glasgow, University Avenue, Glasgow, G12 8QQ, UK.

E-mail: Ross.Forgan@glasgow.ac.uk

Web: http://www.forganlab.com

\begin{abstract}
Nanoparticulate metal-organic frameworks (MOFs) have the requisite high storage capacities, tailorable structures, ease of functionalisation, and excellent biocompatibilities for application as nanoscale drug delivery devices (DDSs). Zirconium MOFs in particular combine optimal stability towards hydrolysis and postsynthetic modification with low toxicity, and so are particularly suited for biological applications. This review covers the use of $\mathrm{Zr}$ MOFs as DDSs with focus on the different physical properties that makes them attractive for use. The various methods for modifying the surfaces of $\mathrm{Zr}$ MOFs are described with pertinent examples of the resulting enhancements in aqueous stability, colloidal dispersion, and stimuli-responsive drug release. The in vitro and in vivo application of $\mathrm{Zr}$ MOFs for photodynamic therapy and drug delivery are discussed with respect to the structural features of the MOFs and their surface functionality, and perspectives on their future applications and analogous hafnium MOFs are given.
\end{abstract}

Keywords: metal-organic frameworks; drug delivery; zirconium; biomedicine; in vivo; in vitro; imaging 
Table of Contents:

1. Introduction

2. Structures and Syntheses of Zirconium MOFs

3. Surface Functionalisation of Zirconium MOFs

3.1. Coordination Modulation

3.2. Postsynthetic Coordination

3.3. Postsynthetic Covalent Modification

3.4. Postsynthetic Noncovalent Modification

4. Colloidal Dispersion and Stability of Zirconium MOFs

5. Controlling Cargo Release

6. In Vitro Studies of Zirconium MOFs

6.1. Enhancing and Targeting Cellular Uptake of MOFs

6.2. Endocytosis Mechanisms

6.3. Biocompatibility of Zr MOFs

6.4. Photodynamic Therapy with Zr MOFs

6.5. Drug Delivery from Zr MOFs

7. In Vivo Studies of Zirconium MOFs

8. Conclusions

9. Acknowledgements

10. Abbreviations and Acronyms

11. References 


\section{Introduction}

Since it is estimated that at least one third of the population of developed countries will be diagnosed with cancer at some point in their lives [1], innovative and efficient cancer diagnosis and treatment have become major priorities for the scientific community. In this respect, drug delivery - the use of new technologies to selectively deliver therapeutic cargoes to particular areas of the body for treatment - has emerged. Drug Delivery Systems (DDSs) can stabilise and direct drugs to damaged tissues, minimising side effects while maximising treatment efficiency [2-5]. However, drawbacks such as uncontrollable drug release [6,7], usually as a consequence of carrier degradation [8], or accumulation in the body, often due to macrophage recognition [9-12] and to low carrier degradation [13, 14], can hinder the clinical application of DDSs.

Metal-organic frameworks (MOFs) are a new generation of materials composed of metal ions or clusters linked by multitopic organic ligands, forming extended network structures [15]. Their remarkable porosity, together with their high thermal and chemical stabilities and structure tailorability, makes them attractive for a wide variety of applications, including in healthcare [16]. MOFs offer several advantages over current DDSs, which are often purely organic or inorganic. The former (liposomes or polymers), although more biocompatible, usually present lower drug payloads [17-19], while the latter (gold, iron and silica nanoparticles among others), can offer notably higher drug loadings but are less biocompatible, and their low degradation rate can result in accumulation in the liver or spleen, potentially inducing unwanted side effects (Figure 1) [20-22].
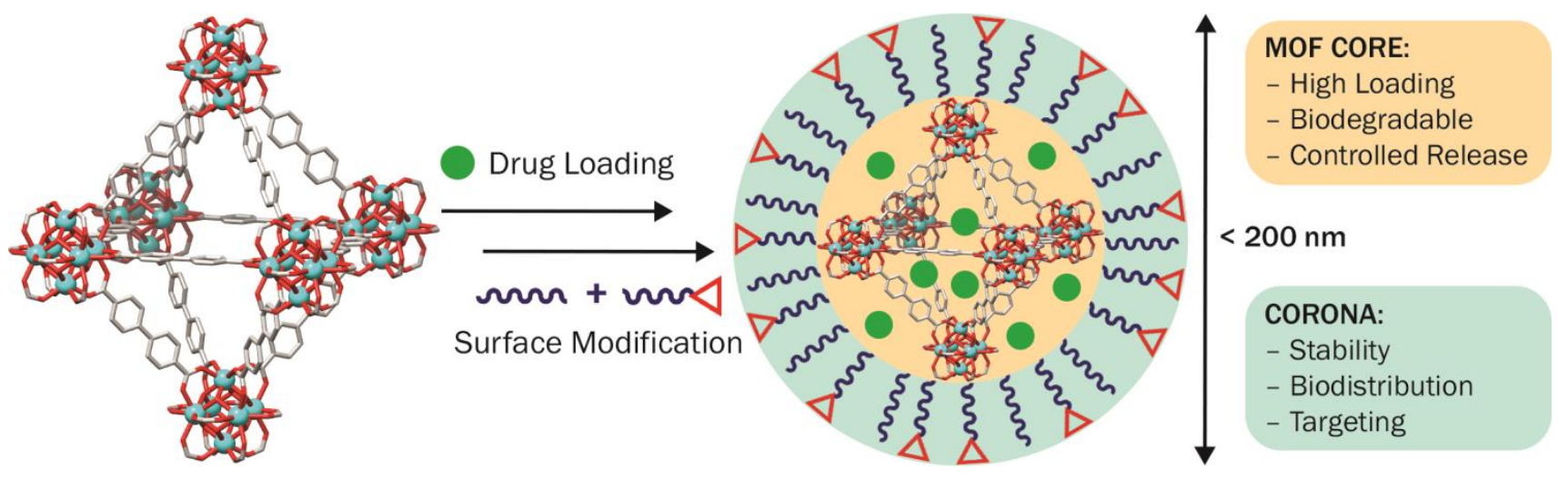

Figure 1. Schematic showing the ideal properties of a MOF-based drug delivery system, using the structure of UiO-67, $\left[\mathrm{Zr}_{6} \mathrm{O}_{4}(\mathrm{OH})_{4}(\mathrm{bpdc})_{6}\right]_{n}$ (bpdc $=4,4^{\prime}$-biphenyldicarboxylate) as an example. 
The organic/inorganic nature of MOFs has positioned them as an attractive alternative to the drawbacks that nanomedicine is currently facing, as it offers almost unlimited possibilities to design desired structures through metal-linker chemistry and postsynthetic modification in order to enhance their drug delivery properties, such as high drug loadings, controllable release of the drug, low cytotoxicity, appropriate colloidal stability and degradation rates, efficient cell internalisation, and anticancer cell selectivity [23-25]. As well as drug delivery, significant efforts have been made to interface MOFs with biological entities [26, 27], for example encapsulating enzymes for catalysis [28], viruses for room temperature vaccines [29], and even living cells [30] within MOF scaffolds.

Since Ferey and co-workers reported the first study of iron-based MOFs for applications in biomedicine [31], a tremendous amount of work has emerged towards developing the great potential for various applications of nanoparticulate MOFs (NMOFs) in healthcare [16, 32-36] Iron MOFs are probably the most widely studied materials for healthcare applications to date, because iron is well tolerated, with a $50 \%$ lethal dose $\left(L_{50}\right)$ of $30 \mathrm{gkg}^{-1}$ when orally administered to rats, while their high porosity enables very high drug loadings [31, 37-41]. Interest in zirconium-based MOFs [42] for biomedical applications has increased of late as zirconium is also a biocompatible metal: the human body typically contains about $300 \mathrm{mg}$ of zirconium, and the recommended daily ingestion is $4.15 \mathrm{mg}$ per day [43]. The $L_{50}$ of zirconyl acetate in rats, as determined by in vivo experiments, has been found to be $4.1 \mathrm{gkg}^{-}$ ${ }^{1}$, which is lower but still comparable to iron [44]. Additionally, the hard Lewis acid/base coordination nature of the $\mathrm{Zr}$-carboxylate bonds can render them more chemically and mechanically stable than iron MOFs and other high valent materials [45-47], facilitating postsynthetic functionalisation without compromising materials properties [48] maintaining excellent porosity and molecular storage capacities [49] and ultimately resulting in higher physiological stability [50]. In this review, we describe the various efforts to develop Zr MOFs as DDSs, and in biomedicine in general. The differing structures and functionalisation protocols for $\mathrm{Zr}$ MOFs are highlighted, in particular focussing on external surface modification and the subsequent effects on properties such as stability and dispersion. In vitro and in vivo applications of Zr MOFs are described in the context of structure-property relationships, and future research directions are discussed. 


\section{Structures and Syntheses of Zirconium MOFs}

The first Zr MOFs were reported by Lillerud et al. in 2008 [51]. The UiO series of MOFs, where $\mathrm{UiO}$ stands for Universitetet i Oslo, consists of materials where $\left[\mathrm{Zr}_{6} \mathrm{O}_{4}(\mathrm{OH})_{4}\left(\mathrm{RCO}_{2}\right)_{12}\right]$ octahedral clusters link linear dicarboxylate ligands into extended, highly porous networks with overall ideal formula $\left[\mathrm{Zr}_{6} \mathrm{O}_{4}(\mathrm{OH})_{4}(\mathrm{~L})_{6}\right]_{\mathrm{n}}$. These $\mathrm{Zr}_{6}$ clusters and derivatives serve as inorganic secondary building units (SBUs) in the vast majority of $\mathrm{Zr}$ MOFs reported to date [42].

The first MOF of the series, UiO-66, in which the linker is 1,4-benzene dicarboxylate (BDC), exhibits a pristine surface area of $1200 \mathrm{~m}^{2} \mathrm{~g}^{-1}$ and a pore volume of $0.5 \mathrm{ccg}^{-1}$. Its octahedral and tetrahedral pores have sizes of 11 and $8 \AA$, respectively, with pore windows of 3 and $5 \AA$ [51]. A range of ligands has been used to form an isoreticular series [51-53], with porosity increasing with ligand length (Figure 2a) until interpenetration occurs with phenylene-bisethynylbenzoate linkers $[54,55]$. The use of dicarboxylate linkers with anchored pendant functionalities along with the excellent chemical stabilities of the series has allowed various postsynthetic modification (PSM) protocols to be developed to include diverse functionality $[48,52,56]$. Zirconium MOFs containing tricarboxylate or tetracarboxylate linkers have also been synthesised. For example, planar tetracarboxylates (Figure $2 b$ ) such as tetrakis(4carboxyphenyl)porphyrin (TCPP), when combined with 12-connected hexagonal $\mathrm{Zr}_{6}$ SBUs gives PCN-223 and with 6-connected $\mathrm{Zr}_{6}$ SBUs gives PCN-224; in these cases, additives to syntheses tune the formation of the different MOFs $[57,58]$. Similarly, the structurally related 1,3,6,8(tetrakis ( $p$-benzoate)pyrene ligand, when linked by 8-connected $\mathrm{Zr}_{6}$ SBUs, leads to both NU-901 and NU-1000 MOFs [59-61]. Zr MOFs are robust enough to allow incorporation of multiple related ligands into the same topology - the so-called mixed linker approach and also doping of alternative metal cations in place of the $\mathrm{Zr}^{4+}$ units. As such, a wide variety of other Zr MOFs are known [42], but this review shall focus on the above examples (Figure $2 \mathrm{c})$, which have been used in biomedicinal applications.

The synthesis of Zr MOFs is usually carried out under solvothermal conditions [62-66], although other synthetic routes have also been reported [42, 67-69]. Solvothermal synthesis is sensitive to several factors, such as $\mathrm{pH}$, concentration, temperature, pressure, reaction time, and stoichiometry, among others, which can be tuned to adjust the crystallisation process and obtain MOFs of various sizes. The coordination modulation protocol, first reported by Fischer and co-workers for Zn MOFs [70], in which monodentate ligands (modulators) with similar chemical functionality to the multidentate organic linkers are 
introduced to the synthetic process, has been widely adopted as a tool to control size and enhance properties such as crystallinity and porosity in Zr MOFs [42, 63].

a)

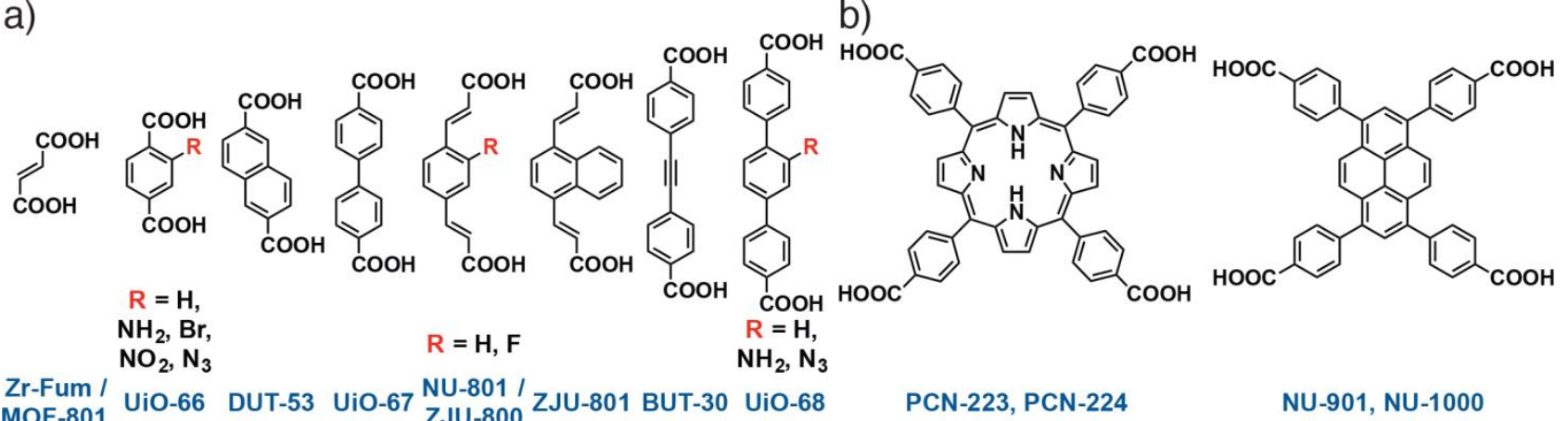

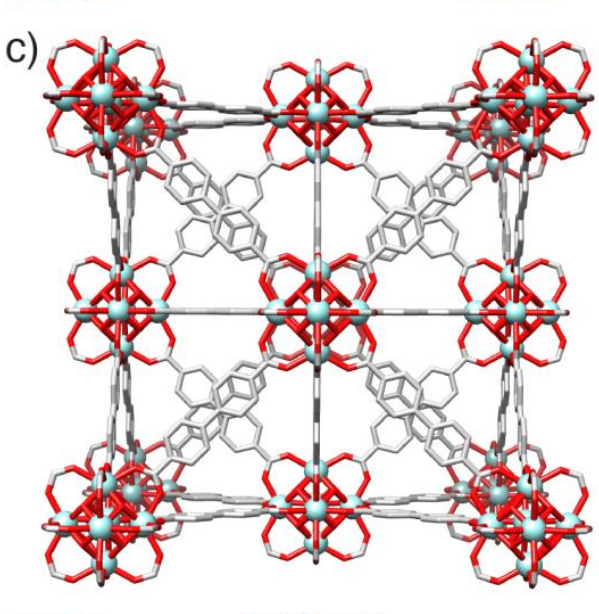

MOF:

UiO-67

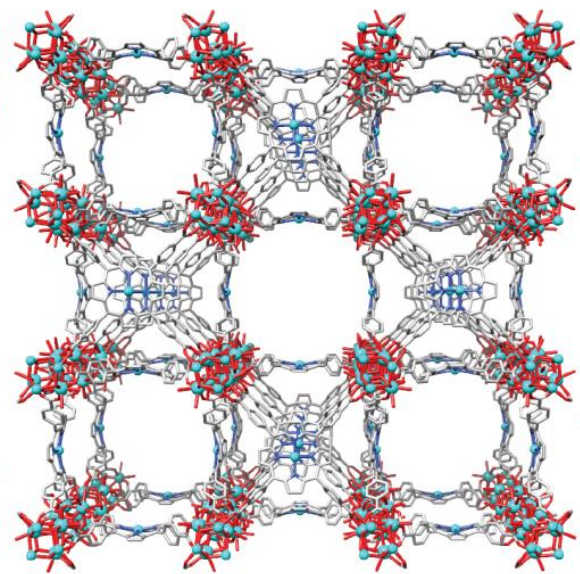

PCN 224

$2.1 \mathrm{~nm}$

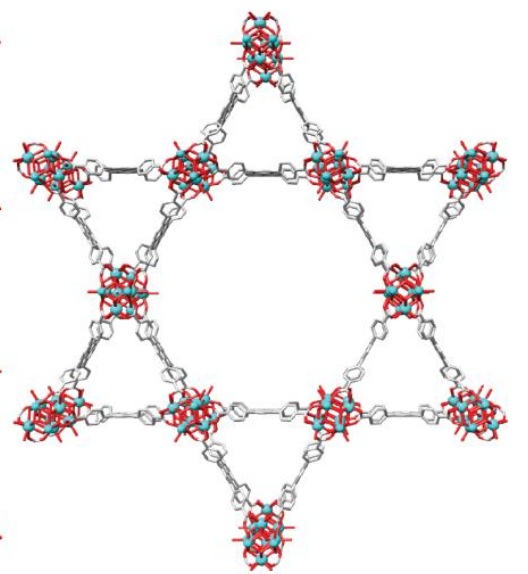

NU-1000

Figure 2. Chemical structures of a) dicarboxylate ligands incorporated into UiO-66 topology MOFs and b) tetracarboxylate ligands incorporated into Zr MOFs. c) Packing diagrams derived from crystal structures of classes of $\mathrm{Zr}$ MOFs discussed in this review.

In this process, the monotopic ligands compete with the multitopic bridging MOF linkers for the metal coordination sites during crystallization, typically enhancing crystallinity, and acting in two different ways. On the one hand, if the modulator acts as a crystal growth promoter, the size of the crystal will depend on its concentration during synthesis $[63,66,71]$. On the other hand, if it acts as capping agent, its functionality can be confined to the surface, being permanently coordinated to metal sites and thus inhibiting crystal growth (Figure 3a) [72-74]. Therefore, this technique can be wisely used to control not only the particle size of the MOFs - scaling down the size of DDSs to <200 $\mathrm{nm}$ is imperative for intravenous administration in order to ensure unhindered circulation around small capillaries [75] - but also the surface chemistry during the synthetic process. Modulators can also induce missing linker and missing cluster defects in Zr MOFs, by capping SBUs and replacing multidentate ligands 
throughout the bulk of the material, with a close correlation observed between modulator $\mathrm{p} K_{\mathrm{a}}$ and defect induction [76]. Defects can modify a number of physical properties, including porosity, and chemical and mechanical stability (Figure 3b) [77].
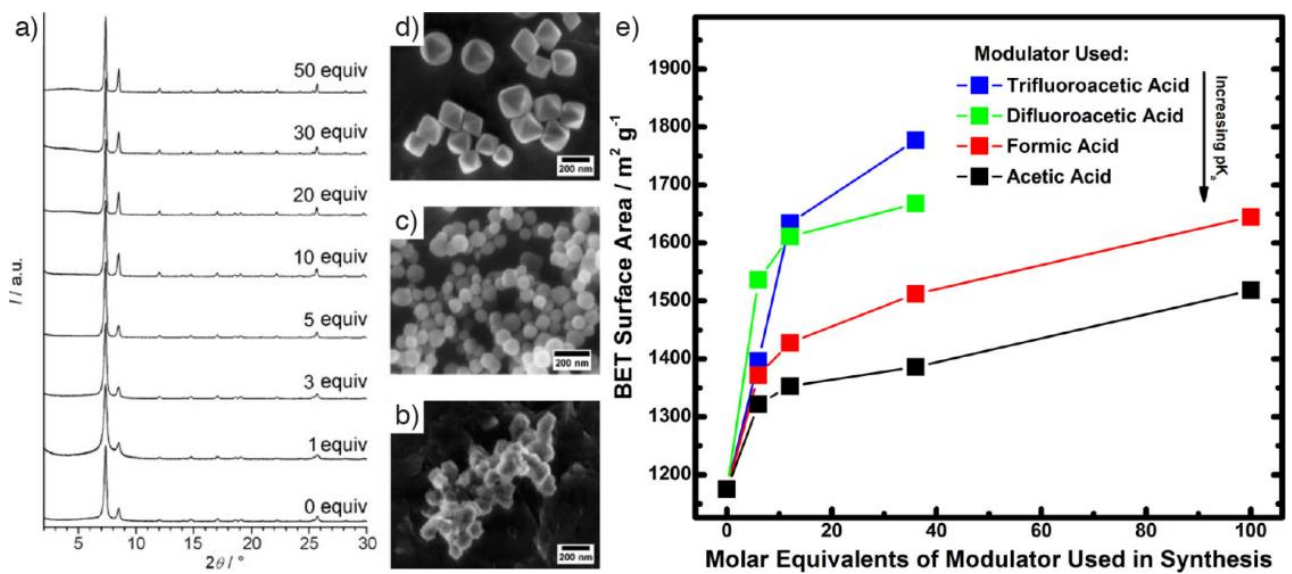

Figure 3. The effect of coordination modulation on the synthesis of UiO-66. a) PXRD patterns when benzoic acid is used as a modulator, showing increases in crystallinity. Scanning electron microscopy (SEM) images of UiO-66 prepared with b) 0 equivalents, c) 10 equivalents, and d) 30 equivalents of benzoic acid modulator, showing particle size control. Modified with permission from ref [63] copyright (2016) John Wiley and Sons. e) Increases in Brunauer-Emmett-Teller (BET) surface areas calculated from $\mathrm{N}_{2}$ adsorption isotherms for modulated UiO-66, with decreasing modulator $\mathrm{p} K_{\mathrm{a}}$ inducing a greater number of defects and thus higher surface area. Defect-free UiO-66 is expected to have a BET surface area of $\sim 1200 \mathrm{~m}^{2} \mathrm{~g}^{-1}$. Modified with permission from ref [76] copyright (2016) American Chemical Society.

Using modulators in the synthesis of $\mathrm{Zr}$ MOFs is now commonplace, with many groups exploiting the control of particle size and surface chemistry it facilitates [42]. 


\section{Surface Functionalisation of Zirconium MOFs}

The surface chemistry of a given DDS governs its interaction with the media, improving stability and dispersion, and potentially allowing the drug to cross physiological barriers while providing the possibility of targeted carriers. As such, surface modification is of great interest for the development of efficient MOF-based DDSs, however, the multiple synthetic steps synthesis, drug loading and surface modification - and the requirement for orthogonality between them, can hinder their efficient manufacture. Surface modification of MOFs [56] can be performed during synthesis, by the coordination modulation (CM) protocol as described above, or postsynthetically (PS). Postsynthetic surface modification can be categorised into (i) coordinative PSM, whereby the coordination chemistry of metal clusters at the particle surface is used to attach functionality, for example by surface ligand exchange, or (ii) covalent PSM, usually performed using the linker functionality as a platform for further reactions, such as click chemistry.

Characterisation of the chemistry at the external surfaces of MOFs is complicated by the surface comprising a small fraction of the bulk material, although general guidelines can be followed. Nuclear magnetic resonance (NMR) spectroscopy of digested samples can give insights into the composition of the sample; the molar ratio of surface components compared to the linker can be estimated based on the intensities of resonances assigned to protons of both the linker and surface reagents, although defectivity hampers efforts to obtain mass fractions of surface functionality. Thermogravimetric analysis (TGA) can provide information on the gravimetric content and nature of the coating. If new mass loss events are observed at a higher temperature than those of free surface reagents, coordinative attachment to the $\mathrm{Zr}$ positions rather than electrostatic or Van der Waals forces (physisorption) is suggested. Similarly, the shifting of characteristic signals in Fourier transform infrared (FT-IR) spectra resulting from the coordination of surface reagents, and/or appearance of new signals corresponding to coordination bonds between $\mathrm{Zr}$ and surface reagents, indicate attachment through coordination. Porosity should not be significantly affected by surface functionalisation, although addition of mass at the surfaces may result in lower gravimetric gas uptake and surface areas. If the modified MOF has much lower porosity (or is nonporous), it is an indication that the surface reagents are also coordinated in the inner porosity or simply stored in the pores as guests. Additionally, large surface units such as polymers may block pores or induce new features in isotherms due to kinetic effects. Dynamic light scattering (DLS) and zeta potential measurements can give information on changes in size, dispersion and surface chemistry in solution. In the solid state, scanning electron microscopy (SEM) may also show the physical effects of surface modification - large polymers may 
induce "rounding" at particle surfaces - while energy-dispersive X-ray spectroscopy (EDX) and photoelectron spectroscopy (XPS) can give chemical information. It is important to note that in order to confirm surface coating content and mode, the correlation of a number of techniques is required.

\subsection{Coordination Modulation}

Examples of surface modification of Zr MOFs performed during the synthetic process are quite limited, despite the possibility of one-pot syntheses of functionalised nanoparticles. We have developed versatile and reproducible protocols based on coordination modulation [73]. Introducing functionalised monocarboxylic acids as modulators, for example $p$-azidomethyl benzoic acid (L1) or p-propargyloxy benzoic acid (L2), during synthesis results in their attachment at surface and defect sites, providing surface-coated MOFs ready for further functionalisation by "click" chemistry. This procedure is also compatible with the anticancer metabolic probe molecule, dichloroacetic acid (DCA), being used as a co-modulator of UiO66 , resulting in the formation of well dispersed nanoparticles containing both the anticancer drug $(\sim 20 \% \mathrm{w} / \mathrm{w})$ and the functionalised modulator. Extending the protocol to isoreticular $\mathrm{Zr}$ MOFs - including UiO-66 and its bromo, amino and nitro derivatives, and extended structures DUT-52 and UiO-67 - results in 100 nm particles of DCA@UiO-66 derivatives and microcrystals of DCA@DUT-52 and DCA@UiO-67 when $\mathrm{ZrCl}_{4}$ is the metal precursor, and mesoporous<20 nm DCA@UiO-66 derivatives and 200 nm DCA@DUT-52 and DCA@UiO-67 when $\mathrm{ZrOCl}_{2}$ is used as the metal precursor. The high porosity of the DCA modulated samples, due to DCA attachment to the inner and outer surface at defect sites $(\sim 20 \% w / w)$, allowed the loading of a second drug, the well-known anticancer drug 5fluorouracil (5-FU), into the pores of the isoreticular MOFs to create dual DDSs [78].

In principle, any carboxylate-containing molecule can act as a modulator of Zr MOFs, and we have also coordination modulation to introduce the biomolecules folic acid and biotin to the surfaces of UiO-66, with or without DCA as co-modulator, during the synthetic process [74]. Folic acid, in particular, could be incorporated in quantities up to $28 \% w / w$, likely as it contains multiple carboxylate units, potentially acting as a linker (the so-called mixed-linker approach) as well as a surface ligand (Figure 4). However, the length mismatch between folic acid and BDC will result in significant defectivity in the resulting material. 


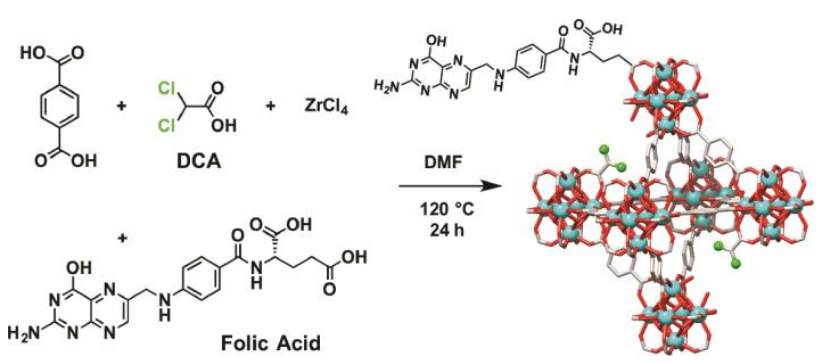

Figure 4. Schematic synthesis of UiO-66 modulated by dichloroacetic acid and folic acid, showing incorporation of both modulators at defect and surface sites.

Utilising modulators with more than one carboxylate unit results in incorporation throughout the structure; if there is a size mismatch with the linker, this presumably occurs at defect sites and coordinated to $\mathrm{Zr}_{6}$ clusters, as well as at the surface. This approach serves to trap the functional modulator within the structure, a method that has been exploited to prepare agents for photodynamic therapy (PDT). Zn-DTPP- $\mathbf{I}_{2} @ U$ UiO-66, where DTPP- $\mathrm{I}_{2}$ is the bisiodo, bis-carboxy porphyrin di(4-carboxyphenyl)-10,20-bis(4-lodophenyl)porphine, was

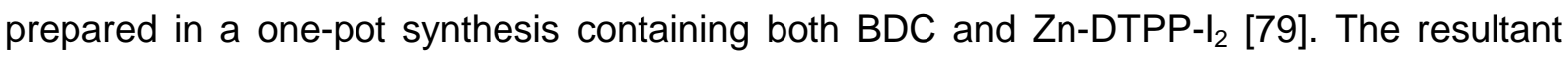
MOF contains $1.4 \% \mathrm{w} / \mathrm{w}$ of porphyrin linker, as determined by inductively coupled plasma optical emission spectrometry (ICP-OES), which is well-distributed across $\sim 100 \mathrm{~nm}$ nanoparticles, as determined by energy-dispersive X-ray (EDX) spectroscopic mapping. As the porphyrin is considerably longer than the BDC linker, it is likely incorporation occurs at defect sites throughout the MOF; the authors demonstrated that carboxylates are essential for the porphyrin linker incorporation, as a control one-pot synthesis performed with porphyrin with esters in the place of carboxylates, together with UiO-66 starting materials, resulted in no porphyrin linker incorporation, suggesting attachment through carboxylate units rather than pore localisation.Zn-DTPP- $\mathrm{I}_{2} @ U \mathrm{UiO}-66$ was found to be porous $\left(\mathrm{S}_{\mathrm{BET}}=901\right.$ $\mathrm{m}^{2} \mathrm{~g}^{-1}$ ) albeit with a lower surface area than expected for pristine UiO-66 $\left(\mathrm{S}_{\mathrm{BET}} \sim 1200 \mathrm{~m}^{2} \mathrm{~g}^{-1}\right)$. Controls in which the porphyrin linker was introduced postsynthetically showed only $0.06 \%$ $w / w$ incorporation, likely as surface decoration.

Dong et al. used a similar strategy to prepare TCCP@UiO-66, with incorporation of 2.9\% $w / w$ of the porphyrin estimated by UV/Vis spectroscopy, and with good porosity $\left(\mathrm{S}_{\mathrm{BET}}=1051\right.$ $\mathrm{m}^{2} \mathrm{~g}^{-1}$ ) [80]. The higher porphyrin loading compared to Zn-DTPP-I $@$ @iO-66 could be attributed to the additional carboxylate groups of TCCP (four) compared to Zn-DTPP-I 2 (two) promoting incorporation and coordination to $\mathrm{Zr}_{6}$ clusters. Other groups have prepared this material as a control sample, with similar results. Park et al. have taken a similar approach to prepare their own sample of TCCP@UiO-66 as well as incorporating a photoswitchable, 
dicarboxylato dithienylethene molecule, 1,2-bis(5-(4-carboxyphenyl)-2-methylthien-3yl)cyclopent-1-ene (BCDTE) in a range of ratios to form BCDTE@UiO-66, again for PDT [81]. A UiO-68 derivative, where the linker, 4,4'-(9,10-anthracenediyl)benzoic acid, is an annihilator was prepared containing a palladium porphyrin, $\mathrm{Pd}(\mathrm{II})-\mathrm{TCPP}$, used as a photosensitiser, in a similar synthesis. Self-assembly of Pd(II)-TCPP@UiO-68 could be finetuned to modify the ratio of linker to photosensitizer in the structure by varying their ratio during synthesis. The MOF was used for triplet-triplet annihilation upconversion (TTA-UC)based imaging, and the MOF with the highest content of Pd(II)-TCPP was the most efficient in the TTA-UC process, as determined by luminescence spectra [82].

These examples illustrate the potential of coordination modulation for MOF-based DDSs, with the possibility of size and surface chemistry control exercised by multiple modulators, as well as using drug molecules as modulators to ensure their high loading. Multitopic modulators raise the prospect of defect encapsulation of functional molecules.

\subsection{Postsynthetic Coordination}

Zirconium MOFs can be functionalised through coordination of moieties to $\mathrm{Zr}_{6}$ SBUs; nucleophilic functional groups such as carboxylates [83], phosphates [84], imidazoles [85], and thiols[80], among others have been used to confine functionalities to the surfaces of preformed Zr MOFs (Figure 5a). This mode of PSM typically requires size selectivity in order to address only the outer MOF surface, as if the reagents can penetrate the porosity, the inner surface of the MOF can also be functionalised during the process. The new surface reagent may coordinate to unsaturated Zr SBUs or displace surface linkers in a process that has also been termed surface ligand exchange (SLE). Examples are listed in Table 1.

Wang et al. have shown that a carboxyl-functionalised diiodo-substituded BODIPY (I2-BDP) can be postsynthetically incorporated onto the surfaces of UiO-66, by heating the two in $N, N$ dimethylformamide (DMF) at $65^{\circ} \mathrm{C}$ for $24 \mathrm{~h}$, without compromising the topology or porosity of the crystal [86]. The optical properties of the BODIPY functionality led to the MOF being studied for photodynamic therapy (PDT) and thus it was termed UiO-PDT. Comprehensive characterisation showed that the content of I2-BDP in the $70 \mathrm{~nm}$ nanoparticles of UiO-66PDT was around $30 \% \mathrm{w} / \mathrm{w}$, with the measured BET surface area of $1422 \mathrm{~m}^{2} \mathrm{~g}^{-1}$ confirming the anchoring of I2-BDP at the external surfaces rather than loading in the pores. 
Table 1. Examples of Zirconium MOFs functionalised by postsynthetic surface coordination.

\begin{tabular}{|c|c|c|c|c|c|c|}
\hline MOF & $\begin{array}{l}\text { Surface } \\
\text { Coating }\end{array}$ & $\begin{array}{c}\text { Modification } \\
\text { Protocol }\end{array}$ & Drugs & Name During Review & $\begin{array}{l}\text { Enhanced } \\
\text { Properties }\end{array}$ & Ref \\
\hline UiO-66 & I2-BDP & $\begin{array}{l}\text { PS carboxylate } \\
\text { coordination }\end{array}$ & $\begin{array}{l}\text { Linker singlet } \\
\text { oxygen } \\
\text { generation }\end{array}$ & UiO-PDT & $\begin{array}{c}\text { Cell } \\
\text { internalisation; } \\
\text { Cytotoxicity }\end{array}$ & {$[86]$} \\
\hline UiO-66 & $\begin{array}{l}\text { Heparin (Hep) } \\
\text { Folic acid (FA) } \\
\text { Biotin (Biot) }\end{array}$ & SLE & $\begin{array}{l}\text { Dichloroacetic } \\
\text { acid (DCA) }\end{array}$ & $\begin{array}{c}\text { UiO-66-Hep (PS) } \\
\text { UiO-66-FA (PS) } \\
\text { UiO-66-Biot (PS) }\end{array}$ & $\begin{array}{l}\text { Dispersion; } \\
\text { Stability; } \\
\text { Cell uptake }\end{array}$ & [74] \\
\hline PCN-224 & Folic acid (FA) & $\begin{array}{l}\text { PS carboxylate } \\
\text { coordination }\end{array}$ & $\begin{array}{l}\text { Linker singlet } \\
\text { oxygen } \\
\text { generation }\end{array}$ & PCN-224-FA & $\begin{array}{l}\text { Drug release; } \\
\text { Cell uptake; } \\
\text { Therapeutic } \\
\text { efficiency }\end{array}$ & [83] \\
\hline UiO-66 & $\begin{array}{c}\text { Flavin } \\
\text { mononucleotide } \\
\text { (FMN) }\end{array}$ & $\begin{array}{l}\text { PS phosphate } \\
\text { coordination }\end{array}$ & $\begin{array}{l}\text { Alendronate } \\
\text { (AL) }\end{array}$ & AL-UiO-66-FMN & $\begin{array}{l}\text { pH-responsive } \\
\text { drug release; } \\
\text { Cytotoxicity }\end{array}$ & {$[84]$} \\
\hline $\begin{array}{l}\text { UiO-68- } \\
\mathrm{NH}_{2}\end{array}$ & SiRNA & $\begin{array}{l}\text { PS phosphate } \\
\text { coordination }\end{array}$ & Cis-platin & SiRNA@UiO-Cis & $\begin{array}{l}\text { Dispersion; } \\
\text { Cell uptake; } \\
\text { Gene silencing; } \\
\text { Overcome cis- } \\
\text { platin resistance }\end{array}$ & [87] \\
\hline $\begin{array}{l}\text { UiO-66 } \\
\text { UiO-67 } \\
\text { BUT-30 }\end{array}$ & $\begin{array}{l}\text { 1,2-dioleosyl-sn- } \\
\text { glycero-3- } \\
\text { phosphate } \\
\text { (L-DOPA) }\end{array}$ & $\begin{array}{l}\text { PS phosphate } \\
\text { coordination }\end{array}$ & - & $\begin{array}{l}\text { DOPA-UiO-66 } \\
\text { DOPA-UiO-67 } \\
\text { DOPA-BUT-30 }\end{array}$ & Dispersion & [88] \\
\hline PCN-223 & $\begin{array}{l}\text { Phospholipid } \\
\text { bilayers (PBLs) } \\
\text { DOPC/DOPC }\end{array}$ & $\begin{array}{l}\text { 1. PS phosphate } \\
\text { coordination } \\
\text { 2. Self-assembly }\end{array}$ & $\begin{array}{l}\text { Linker singlet } \\
\text { oxygen } \\
\text { generation }\end{array}$ & $\begin{array}{c}\text { PCN-223@DOPC } \\
\text { PCN-223@DOPC/DOPC }\end{array}$ & $\begin{array}{l}\text { Stability towards } \\
\text { phosphate; } \\
\text { Dispersion; } \\
\text { Intracellular bio } \\
\text { stability }\end{array}$ & {$[90]$} \\
\hline Zr-fum & $\begin{array}{l}\text { His-tagged } \\
\text { peptides }\end{array}$ & $\begin{array}{l}\text { PS imidazole } \\
\text { coordination }\end{array}$ & $\begin{array}{l}\text { Pro-apoptosis } \\
\text { peptides }\end{array}$ & Zr-fum-peptide & $\begin{array}{c}\text { Cell uptake; } \\
\text { Cytotoxic effect }\end{array}$ & [85] \\
\hline UiO-66 & TPP-SH & $\begin{array}{l}\text { PS thiol } \\
\text { coordination }\end{array}$ & $\begin{array}{l}\text { Linker singlet } \\
\text { oxygen } \\
\text { generation }\end{array}$ & UiO-66-TPP-SH & $\begin{array}{c}\text { Cell } \\
\text { internalisation; } \\
\text { Cytotoxicity }\end{array}$ & [74] \\
\hline
\end{tabular}

We have recently reported the use of surface ligand exchange (SLE) for the direct postsynthetic coordination of biomolecules to UiO-66 zirconium units [74]. Postsynthetic coordination of heparin (an anticoagulant containing sulfate coordinating groups), folic acid (a cancer targeting unit containing two carboxylic acid groups) and biotin (a vitamin with wide uses in biomedicine, which possess one carboxylic acid group) to the surfaces of UiO-66 nanoparticles, which had first been addressed with an azide functionalised carboxylatecontaining modulator (L1) during synthesis using the coordination modulation process, is facile [73]. Coordination was proven to occur on the outer surface without major pore blockage (as determined by $\mathrm{N}_{2}$ adsorption and desorption experiments) displacing the modulator anchored to zirconium SBUs present on the outer surface, and yielding UiO-66FA (PS), UiO-66-Biot (PS) and UiO-66-Hep (PS), where PS stands for postsynthetic. PCN224 has been also coated with folic acid through postsynthetic coordination chemistry, in order to study the targeting properties of the material, PCN-224-FA, when applied to PDT, as the porphyrin linker has intrinsic optical properties [83]. 
In 2014, Lin and Shi independently reported the use of phosphate groups to coordinate biomolecules to the available zirconium clusters on the surfaces of MOFs [84, 87]. Shi et al. took advantage of the affinity of the $\mathrm{Zr}$ SBUs of UiO-66 for phosphates to attach the aminobiphosphonate drug Alendronate $(\mathrm{AL})$ for the treatment of bone cancer. The resultant MOF, AL-UiO-66, had very high drug loadings $(51.4 \%$ w/w) [84]. The sample was fully characterised and showed a drastic decrease in porosity after loading, while FT-IR spectra showed shifting of characteristic vibration bands for $\mathrm{AL}$ and new signals attributed to $\mathrm{P}-\mathrm{O}-\mathrm{Zr}$ stretching. The combination of the results suggests that $A L$ was coordinated to the $\mathrm{Zr}$ positions in the outer and inner surface of the MOF, which was confirmed by O1s XPS spectra of the materials, explaining the high drug payloads as a consequence of the high affinity of the $\mathrm{Zr}_{6}$ clusters for towards AL. The authors also functionalised the surface of UiO66 with fluorescent flavin mononucleotide (FMN, the phosphorylated form of vitamin B2) using the same principle, thus forming UiO-66-FMN, which was used to explore intracellular imaging. The difference in size of flavin mononucleotide compared to alendronate ensured that the flavin was confined to the surface as it could not penetrate the porosity.

Lin and co-workers studied the attachment of small interfering RNA (siRNA), through the phosphate groups present on its backbone, to the $\mathrm{Zr}^{4+}$ cations on the surface of UiO-68- $\mathrm{NH}_{2}$ after loading the pores with a cis-platin prodrug. The authors further used this highly specialised MOF, named siRNA-UiO-Cis, for siRNA and cis-platin co-delivery [87]. Later, Mirkin and co-workers studied the use of phosphate coordinating groups in order to functionalise the surface of three different zirconium MOFs, UiO-66, UiO-67, and BUT-30 (in the latter (4,4'-ethylene-1,2-diyl)dibenzoic acid is the MOF linker), with a phospholipid through PSM [88]. Importantly, in this isoreticular family of MOFs the density of zirconium clusters present at the surface decreases as the length of organic linker increases, and thus the content of 1,2-dioleoyl-sn-glycero-3-phosphate (DOPA), determined by ICP-MS, is higher for DOPA-UiO-66 and lower for DOPA-BUT-30. Similarly, the surface selectivity of the functionalisation, driven by the size of the DOPA units, was confirmed when smaller DOPA-functionalised nanoparticles of each MOF, in which the surface to bulk ratio is higher, have higher DOPA content. In other words, it was found that DOPA density correlates with the density of metal nodes in the outer surface. The samples were fully characterised, showing that after DOPA functionalisation the MOFs maintained their porosity, with FT-IR shifts again suggesting $\mathrm{Zr}-\mathrm{O}-\mathrm{P}$ coordination. 


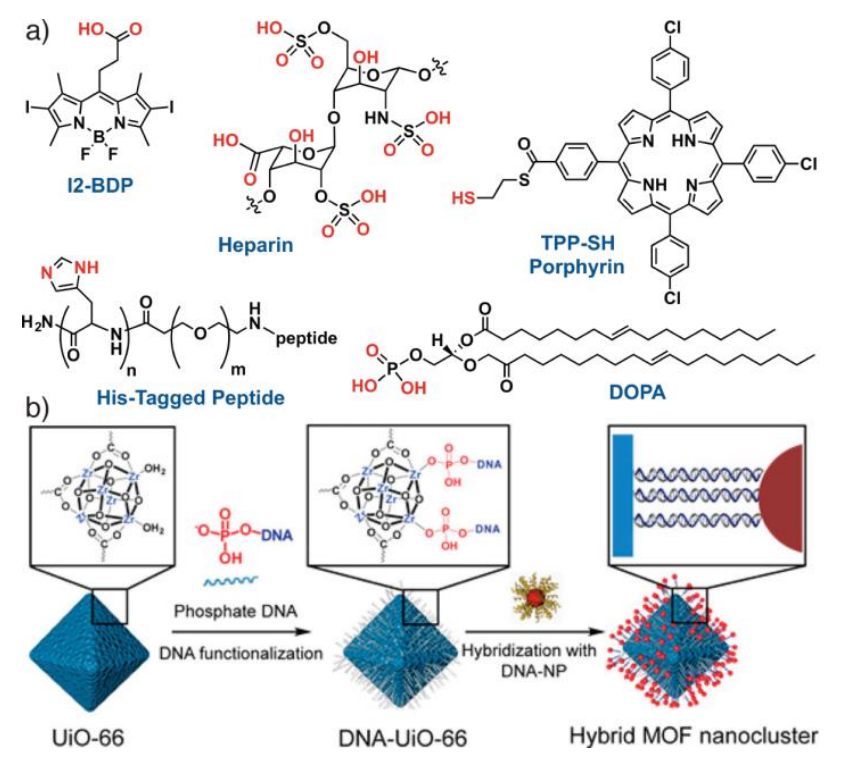

Figure 5. a) Examples of chemical structures of reagents with differing coordination units that have been incorporated onto the surfaces of Zr MOFs by postsynthetic coordination. b) Scheme illustrating a general strategy for coordination of DNA to the surfaces of Zr MOFs through terminal phosphate groups. Modified with permission from ref [89] copyright (2017) American Chemical Society.

This protocol was later extended by Mirkin et al. into a general procedure for functionalising $\mathrm{Zr}$ MOFs with oligonucleotides through phosphate coordination (Figure 5b) [89]. A number of $\mathrm{Zr}$ MOFs with different topologies and connectivity were examined, and a correlation was again found between surface SBU density and surface oligonucleotide coverage. The connectivity of the $\mathrm{Zr}$ SBU also mediates surface coverage; MOFs with more highly connected clusters have more surface defects due to coordinative unsaturation, allowing greater binding of surface phosphates. The oligonucleotide coating was used to hybridise UiO-66 with gold nanoparticles through self-assembly of complementary DNA strands.

The zirconium-phosphate interaction has also been exploited for the synthesis of $\mathrm{Zr}$-based MOFs grafted with phospholipid bilayers (PBLs) [90]. In this case, the porphyrinic MOF PCN223 was synthesised by triethylamine (TEA) modulation, where variation of the quantity of TEA and acetic acid added to the MOF synthesis achieves particle size-control. PSM of PCN-223 with 1,2-dioleoyl-sn-glycero-3-phosphocholine (DOPC) was carried out first in $\mathrm{CHCl}_{3}$ in order to create a monolayer via coordination, forming nanoPCN-223@DOPC, which was further coated with cholesterol and DOPC, creating a hydrophobic system in which coated MOFs and DOPC chains self-assemble into supported MOF-PBLs, so called nanoPCN-223@DOPC/DOPC. The formation of PBLs was confirmed by negative staining with uranyl acetate, due to strong interaction between phosphate and uranyl groups, among 
other characterisation techniques such as FT-IR spectroscopy, zeta potential measurement and X-ray photoelectron spectroscopy (XPS) [91].

Besides phosphate groups, the use of imidazole coordinating agents has recently been reported for the UiO-66 series MOF linked by the endogenous ligand fumarate, so-called $\mathbf{Z r}$ fum, also reported as MOF-801 [85]. Once more, the use of a Lewis base, in this case the imidazole groups present in terminal oligohistidine sequences (His-tags) of several peptide, was used to decorate Zr-MOFs surface with biomolecules. The strength of peptide binding to the MOF increased with the number of histidine residues in the peptide, and thus the authors used a series of peptides containing six histidine residues $\left(\mathrm{H}_{6}\right.$-Tags) to coat the surface of Zr-fum with a range of bioactive molecules.

A thiol functionalised porphyrin, 5-(4-(S-ethylthiolester)thiocarbonylphenyl)-10,15,20-tris(4chlorophenyl)-porphyrin (TPP-SH), has been coordinated to the surface of UiO-66 (140 nm), by immersion of the MOF in a dichloromethane solution of TPP-SH to generate UiO-66-TPPSH. Porphyrin loading was found to be $3.2 \% w / w$, determined by UV/Vis spectroscopy, and loading of the thiol functionalised porphyrin was found to be much more efficient than loading the analogous monocarboxylate porphyrin, suggesting the thiol group is an effective anchoring unit [80].

\subsection{Postsynthetic Covalent Modification}

Surface functionalisation can also be achieved through covalent postsynthetic modification, through chemical transformation of pendant functionalised groups present in the organic linkers of MOFs (Table 2). MOFs linked by 2-aminoterephthalic acid have long been utilised for postsynthetic modification through reaction at the amine moiety, with UiO-66- $\mathbf{N H}_{\mathbf{2}}$ being a prime example $[52,53]$. Poly ( $N$-isopropylacrylamide) (PNIPAM) chains have been attached to the amino groups present in UiO-66- $\mathrm{NH}_{2}$ through amide coupling with polymer chains terminated with activated $\mathrm{N}$-hydroxysuccinimide (NHS) esters (Figure 6a), forming the surface functionalised UiO-66-PNIPAM, as the polymer chains are too large to penetrate the porosity [92]. 

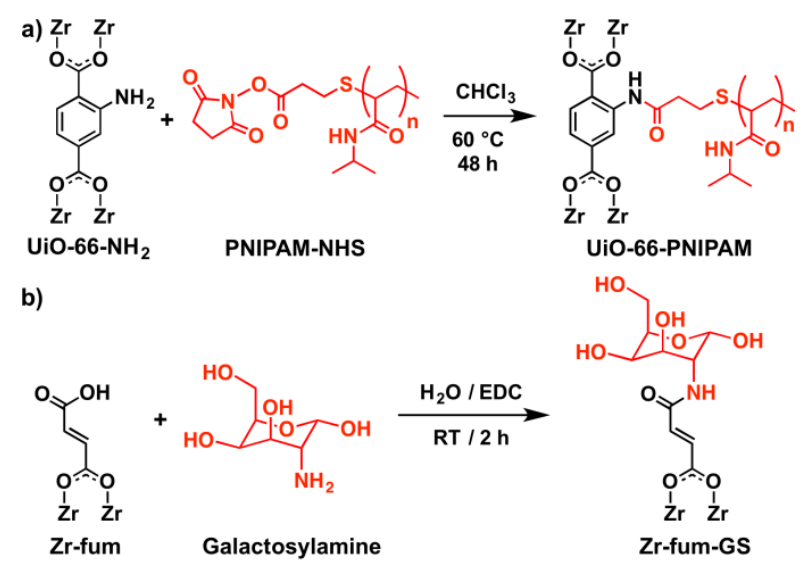

b)
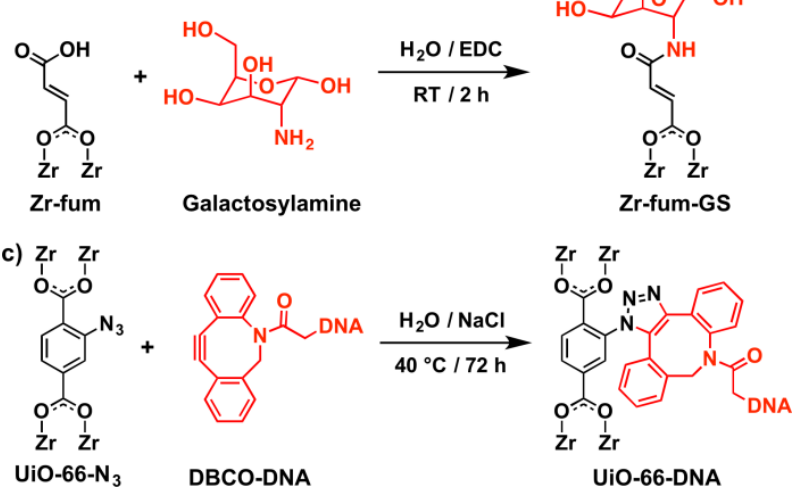

Figure 6. Postsynthetic covalent modification of a) UiO-66- $\mathrm{NH}_{2}$ with PNIPAM through NHS-mediated amide coupling, b) Zr-fum with galactosylamine through EDC-mediated amide coupling with terminal carboxylates, and c) UiO-66- $\mathrm{N}_{3}$ with DNA by strain-promoted azide-alkyne cycloaddition.

Yang and co-workers reported the use of the pendant amino groups of UiO-66- $\mathrm{NH}_{2}$ to covalently attach positively charged quaternary ammonium salts $(Q)$ by amide formation, to serve as threads for pseudorotaxanes at the MOF surface, reporting conversion of $41 \%$ of the amino groups, although some coordination of the threads through a carboxylate group is also evident in the ${ }^{1} \mathrm{H}$ NMR spectra of acid-digested samples. The authors used supramolecular chemistry to cap the positively charged surface moieties of $\mathrm{UiO}-66-\mathrm{NH}-\mathrm{Q}$ with the negatively charged decacarboxylato-pillar[5]arene (CP5), forming UiO-66-NH-QCP5 capped, which possesses [2]pseudorotaxanes as stimuli-responsive elements for triggered drug release [93]. Distinguishing capping CP5 from CP5 that is adsorbed to the SBUs at the surface through its carboxylate units is, however, troublesome.

It has been reported that both folic acid (FA) and 5-carboxyfluorescein (5-FAM) can be dually covalently coupled to $\mathrm{UiO}-66-\mathrm{NH}_{2}$ using the amide coupling reagent $\mathrm{N}$-(3dimethylaminopropyl)- $N$-ethylcarbodiimide (EDC) in aqueous suspensions containing the drug 5-fluorouracil, forming drug-loaded UiO-66- $\mathrm{NH}_{2}$-FA-5-FAM [94]. Again, distinguishing the formation of a covalent linkage between the MOF and the free carboxylate-containing reagents from postsynthetic coordination is difficult, with IR spectroscopy used in this report; mass spectrometry would provide more compelling evidence of the covalent conjugation. 
Table 2. Literature examples of Zirconium MOFs functionalised by postsynthetic covalent modifications.

\begin{tabular}{|c|c|c|c|c|c|c|}
\hline MOF & Surface Coating & $\begin{array}{l}\text { Modification } \\
\text { Protocol }\end{array}$ & Drugs & Name During Review & $\begin{array}{l}\text { Enhanced } \\
\text { Properties }\end{array}$ & Ref \\
\hline $\begin{array}{l}\text { UiO-66- } \\
\mathrm{NH}_{2}\end{array}$ & PNIPAM-NHS & Amide coupling & $\begin{array}{l}\text { Resoruflin } \\
\text { Caffeine } \\
\text { Procainamide }\end{array}$ & UIO-66-PNIPAM & $\begin{array}{l}\text { On-off } \\
\text { temperature } \\
\text { release }\end{array}$ & [92] \\
\hline $\begin{array}{l}\text { UiO-66- } \\
\mathrm{NH}_{2}\end{array}$ & $\begin{array}{l}\text { 1. Quaternary } \\
\text { ammonium salts } \\
\text { 2.Carboxylato- } \\
\text { pillar[5]arene (CP5) }\end{array}$ & $\begin{array}{l}\text { 1. Amide coupling } \\
\text { 2. Supramolecular } \\
\text { chemistry }\end{array}$ & $\begin{array}{c}\text { 5-Fluorouracil } \\
(5-\mathrm{FU})\end{array}$ & $\begin{array}{c}\text { UiO-66-NH-Q-CP5 } \\
\text { capped }\end{array}$ & $\begin{array}{l}\text { Multi-stimuli } \\
\text { responsive } \\
\text { drug release }\end{array}$ & $\begin{array}{l}{[93],} \\
{[99]}\end{array}$ \\
\hline $\begin{array}{l}\text { UiO-66- } \\
\mathrm{NH}_{2}\end{array}$ & $\begin{array}{c}\text { Folic acid (FA) } \\
\text { 5-Carboxyfluorescein } \\
\text { (5-FAM) }\end{array}$ & Amide coupling & 5-FU & $\begin{array}{c}\text { UiO-66- } \mathrm{NH}_{2}-\mathrm{FA}-5- \\
\text { FAM }\end{array}$ & $\begin{array}{l}\text { Targeted drug } \\
\text { delivery }\end{array}$ & [94] \\
\hline $\begin{array}{l}\text { UiO-67 } \\
\text { Zr-fum }\end{array}$ & Galactosylamine & Amide coupling & - & $\begin{array}{l}\text { UiO-67-GS } \\
\text { Zr-fum-GS }\end{array}$ & $\begin{array}{l}\text { Dyes } \\
\text { encapsulation; } \\
\text { Imaging }\end{array}$ & [95] \\
\hline UiO-66 & PEG-NH ${ }_{2}$ & Amide couping & $\begin{array}{l}\text { Mn-doped for } \\
\text { microwave } \\
\text { therapy }\end{array}$ & $\begin{array}{l}\text { Mn-doped } \\
\text { UiO-66-PEG }\end{array}$ & $\begin{array}{l}\text { Anticancer } \\
\text { targeting; } \\
\text { ROS } \\
\text { production }\end{array}$ & [96] \\
\hline UiO-66- $\mathrm{N}_{3}$ & 1. DBCO-DNA & 1. SPAAC & - & UiO-66-DNA & $\begin{array}{l}\text { Stability and } \\
\text { dispersion }\end{array}$ & [97] \\
\hline $\mathrm{UiO}-68-\mathrm{N}_{3}$ & $\begin{array}{l}\text { 1. DBCO-DNA } \\
\text { 2. Complementary } \\
\text { DNA sequences }\end{array}$ & $\begin{array}{l}\text { 1. SPAAC } \\
\text { 2. DNA } \\
\text { hybridisation }\end{array}$ & $\begin{array}{l}\text { Doxorubicin } \\
\quad(\mathrm{DOX}) \\
\text { Methylene blue } \\
\text { Rhodamine 6G }\end{array}$ & UiO-68-N ${ }_{3}$-DNA & $\begin{array}{l}\text { Stimuli } \\
\text { responsive } \\
\text { release; } \\
\text { Anticancer } \\
\text { targeting }\end{array}$ & [98] \\
\hline UiO-66-L1 & $\begin{array}{c}\text { Propargyl-PEG550; } \\
\text { Propargyl-PEG2000; } \\
\text { Propargyl-Poly-L- } \\
\text { Lactide }\end{array}$ & $\begin{array}{l}\text { Click modulation } \\
\text { (CuAAC) }\end{array}$ & DCA & $\begin{array}{l}\text { UiO-66-L1-PEG550 } \\
\text { UiO-66-L1-PEG2000 } \\
\text { UiO-66-L1-PolyLact }\end{array}$ & $\begin{array}{l}\text { Stability and } \\
\text { dispersion; } \\
\text { Therapeutic } \\
\text { efficiency }\end{array}$ & [73] \\
\hline UiO-66-L2 & Azide-PNIPAM & $\begin{array}{l}\text { Click modulation } \\
\text { (CuAAC) }\end{array}$ & DCA & UiO-66-L2-PNIPAM & $\begin{array}{l}\text { Stability and } \\
\text { dispersion; } \\
\text { Therapeutic } \\
\text { efficiency }\end{array}$ & [73] \\
\hline
\end{tabular}

Postsynthetic surface modification based on condensation between terminal carboxylates of the framework ligands and amine functionalities of the surface reagents has also been reported. For example, galactosylamine has been coupled to terminal carboxylates of the linkers at the surfaces of UiO-67 and Zr-fum also using EDC as a coupling agent (Figure 6b), albeit with some loss of crystallinity of the samples [95], and amine-terminated poly(ethylene glycol) has been coupled to Mn-doped UiO-66, prepared by addition of $\mathrm{MnCl}_{2}$ to a typical UiO-66 solvothermal synthesis, in a similar manner, to form Mn-doped UiO-66-PEG [96]. Again, these MOFs were characterised by IR spectroscopy after the functionalisation protocol, making covalent bond formation difficult to determine, although coordination of terminal primary amines is less likely than terminal carboxylates. 
In 2014, Mirkin et al. synthesised a UiO-66 analogue containing an azide group on its linker, UiO-66- $\mathbf{N}_{3}$, and subsequently covalently attached dibenzylcyclooctyne (DBCO) functionalised DNA to the MOF through copper-free, strain-promoted azide-alkyne cycloaddition (SPAAC) (Figure 6c) [97]. Through radiolabelling, the authors confirmed that PSM occurs only on the outer surface, as expected due to size-selectivity. Recently, Willner and co-workers reported the synthesis of UiO-68- $\mathrm{N}_{3}$ by postsynthetic transformation of UiO68- $\mathrm{NH}_{2}$, and also utilised the azide functionality to attach DBCO-functionalised DNA sequences through SPAAC. Sequential addition of a single oligonucleotide strand on the MOF surface followed by hybridisation with complementary strands allows incorporation of a diverse range of surface functionality, including $\mathrm{pH}$-responsive sequences, aptamers, and DNAzymes [98].

We have introduced the concept of chemical transformations of functionalised modulators incorporated into UiO-66 at defect sites. Azide and propargyl-functionalised modulators located at the surfaces of UiO-66 were postsynthetically attached to various functionalised oligomers and polymers through copper(I)-catalysed azide-alkyne cycloaddition (CuAAC, Figure 7) [73, 74]. The polymers included poly(ethylene glycol) (PEG) chains of different lengths, poly-L-lactide terminated with propargyl groups, and PNIPAM terminated with azide groups, thus forming the surface functionalised UiO-66-L1-PEG550, UiO-66-L1-PEG2000, UiO-66-L1-PolyLact and UiO-66-L2-PNIPAM. Attachment was proved to occur only on the outer surface, without pore blockage, while covalent bond formation was confirmed by ESIMS analysis of digested samples. Additionally, controls in which the nanoparticles were stirred with the polymers without the presence of the $\mathrm{Cu}(\mathrm{I})$ catalyst showed no polymer conjugation or adsorption, confirming the nature of the attachment to be covalent.

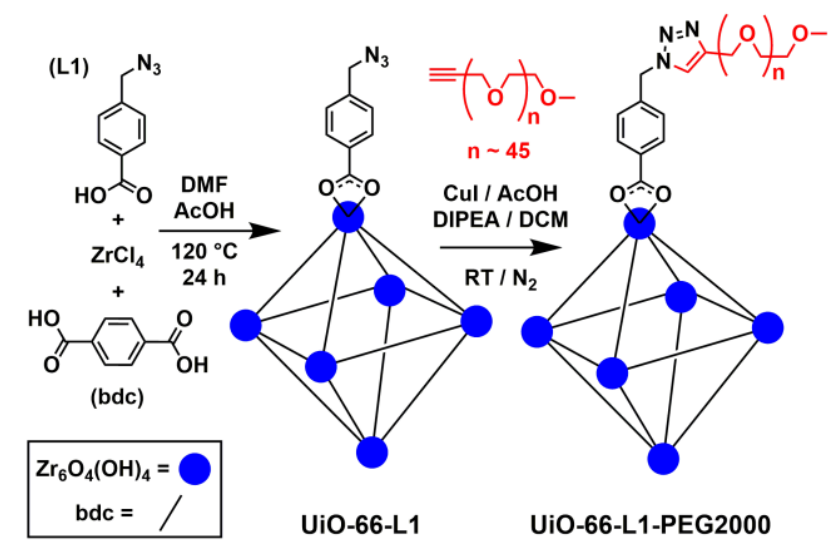

Figure 7. Schematic of the "click modulation" process to selectively surface modify UiO-66 with poly(ethylene glycol) chains. Modified with permission from ref [73] copyright (2017) Elsevier. 


\subsection{Postsynthetic Noncovalent Modification}

Controlled supramolecular interactions can also be used to further surface modify MOFs (Table 3). Hong et al. reported the synthesis of a radiolabelled version of UiO-66 ( ${ }^{89} \mathrm{Zr}$-UiO66), which they functionalised with pyrene-derived PEG (Py-PGA-PEG) through $\pi-\pi$ stacking interactions with the organic linkers of UiO-66 (Figure 8) [100]. The pyrene-derived PEG chains contained a terminal maleimide residue, which was used to further functionalise the MOF with a nucleolin-targeting peptide (F3) through postsynthetic addition to one of its cysteine residues. The authors found that the PEG units, due to their flexible structure, were partially blocking the porosity of the MOF, as a consequence of $\pi-\pi$ stacking with organic linkers present inside the structure. They postulated that to control the distribution of PEG on the MOF's surface, covalent attachment might be needed.

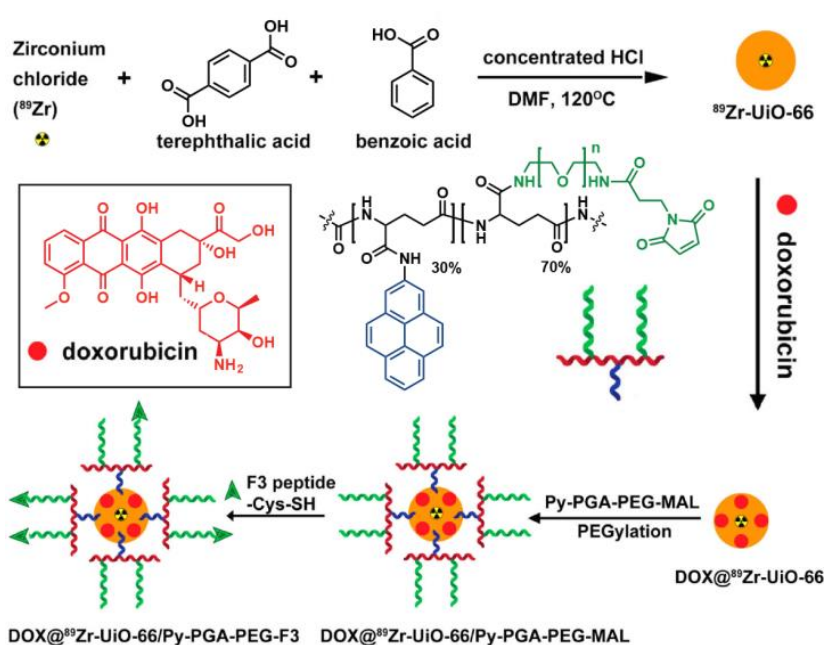

Figure 8. Schematic self-assembly of radiolabelled UiO-66, followed by drug loading, noncovalent postsynthetic functionalisation, and peptide incorporation. Modified with permission from ref [100] copyright (2017) American Chemical Society.

Other approaches, such as liposome encapsulation [101] or silica coating and subsequent surface functionalisation based on reactions with silica siloxane groups, have also been reported for other MOF systems [3, 102]. Although silica coating provides further stability under simulated physiological conditions, higher cytotoxic effects and a higher accumulation in the body are common drawbacks of this approach. To the best of our knowledge, this approach has not been used for the surface functionalisation of zirconium MOFs, possibly because their water stability is higher than for other MOF systems. Zr MOFs coated with poly( $\xi$-caprolactone) in the form of microparticles have recently been reported [103]. The authors investigated UiO-66 and UiO-67 microencapsulation with a copolymer of poly( $\xi$ - 
caprolactone) and D-a-tocopherol polyethylene glycol 1000 succinate (PCL-TPGS), a derivate of vitamin E and PEG. Large quantities of drug-loaded MOFs were successfully incorporated into micron-scale polymer spheres.

Table 3. Literature examples of Zirconium MOFs functionalised by noncovalent modifications or multiple protocols.

\begin{tabular}{|c|c|c|c|c|c|c|}
\hline MOF & Surface Coating & $\begin{array}{c}\text { Surface } \\
\text { Modification } \\
\text { Protocol }\end{array}$ & Drugs & $\begin{array}{l}\text { Name during the } \\
\text { review }\end{array}$ & $\begin{array}{l}\text { Enhanced } \\
\text { Properties }\end{array}$ & Ref \\
\hline $\begin{array}{c}{ }^{89} \mathrm{Zr} \mathrm{UiO}- \\
66\end{array}$ & $\begin{array}{l}\text { 1. Pyrene-derived PEG } \\
\text { (py-PGA-PEG) with } \\
\text { maleimide residue } \\
\text { 2. F3 Targeting peptide }\end{array}$ & $\begin{array}{l}\text { 1. } \pi-\pi \text { interaction } \\
\text { 2. Maleimide-thiol } \\
\text { coupling }\end{array}$ & DOX & $\begin{array}{c}{ }^{89} \mathrm{Zr-UiO-66-Py-} \\
\text { PGA-PEG-F3 }\end{array}$ & $\begin{array}{c}\text { pH-responsive } \\
\text { drug release; } \\
\text { Positron emission } \\
\text { tomography (PET) }\end{array}$ & [100] \\
\hline $\begin{array}{l}\mathrm{UiO}-66 \\
\mathrm{UiO}-67\end{array}$ & $\begin{array}{c}\text { Modified poly( }(\xi- \\
\text { caprolactone) (PCL- } \\
\text { TPGS) }\end{array}$ & Microencapsulation & $\begin{array}{l}\text { Paclitaxel } \\
\text { Cis-platin }\end{array}$ & $\begin{array}{l}\text { UiO-66 -PCL-TPGS } \\
\text { UiO-67 -PCL-TPGS }\end{array}$ & $\begin{array}{l}\text { Prolonged drug } \\
\text { release }\end{array}$ & [103] \\
\hline PCN-224 & $\begin{array}{c}\text { 1. } \mathrm{N}_{\alpha}, N_{\alpha^{-}} \\
\text {bis(carboxymethyl)-I- } \\
\text { lysine } \\
\text { 2. DNA } \\
\text { 3. } \mathrm{NaFY}_{4}: \mathrm{Yb} / \mathrm{Er} \text { UCNPS }\end{array}$ & $\begin{array}{l}\text { 1. PS coordination } \\
\text { of carboxylates } \\
\text { 2. Amide coupling } \\
\text { 3. SPAAC } \\
\text { 4. DNA hybridisation }\end{array}$ & - & PCN-224-UCNP & Targeted PDT & [104] \\
\hline
\end{tabular}

Finally, a combination of the coordination, covalent, and supramolecular approaches has been used to functionalise PCN-224. The amino acid $N_{\alpha}, N_{\alpha}$-bis(carboxymethyl)-I-lysine was attached to the surface by coordination of its three carboxylates, followed by covalent amide conjugation to a bifunctional linker with an activated $\mathrm{N}$-hydroxysuccinimide (NHS) ester and a DBCO unit. Subsequent SPAAC allowed conjugation of azide-modified DNA, complementary strands of which were attached to lanthanide-based upconverting nanoparticles (UCNPs). Complementary base-pair recognition resulted in the formation of MOF-UCNP composites that were used for PDT [104]. There are clearly a number of protocols for modifying the outer surfaces of MOF nanoparticles, both during and after synthesis, and that are compatible with cargo loading. Each method has its own particular advantages, but a comprehensive comparison of the different protocols, with respect to efficacy, surface coverage, and stability, has not been carried out, and would greatly inform the disparate groups working in this area. 


\section{Colloidal Dispersion and Stability of Zirconium MOFs}

To ensure the safe and efficient use of MOFs in medicinal applications, they must be stable towards aggregation and hydrolysis in aqueous solvents. Good water dispersion is vital for in vivo treatment, as blood is an aqueous, phosphate-containing fluid, and aggregation could result in harmful capillarity blockage. As zirconium has a greater affinity for phosphates than for carboxylates, phosphates present in the body can also attack the zirconium positions, inducing degradation and thus resulting in uncontrollable release of the drug, negating the drug delivery effect [45]. It is, however, important to take into account that the ultimate aggregation that NMOFs will suffer in the blood current is difficult to predict. In vitro studies using phosphate buffered saline (PBS, which has a higher phosphate concentration than typically found in blood) or water as dispersants have been widely used in order to evaluate their behaviour in aqueous media, as well as the effect of the presence of phosphates on their colloidal stability. Other dispersants, such as growth media, serum, or PBS spiked with diverse proteins, have been exploited to study the presence of blood containing proteins in the dispersion of NMOFs [41].

Fairen-Jimenez et al. have recently studied the colloidal stability of the UiO-66 family of $\mathrm{Zr}$ MOFs using dynamic light scattering (DLS) in PBS and growth media. It was found that all the MOFs aggregate significantly in PBS, whereas no major aggregation was found when the MOFs were dispersed in growth media, possibly as a consequence of the formation of a protein corona on the surface of the NMOFs [105]. This phenomenon has also been observed for other MOF systems $[41,106]$. Rapid degradation of benzoic acid modulated UiO-66 in PBS at pH 7.4 was observed by UV/visible spectroscopy, releasing $80 \%$ of the terephthalic acid linker during the first hour, but not in water, where less than $10 \%$ of the linker was released after 7 days. The samples were characterised after different exposure times in PBS, confirming the formation of a phosphate corona by FT-IR spectroscopy, as a consequence of phosphate attacking the $\mathrm{Zr}$ units and displacing the linkers. Similar high degradation rates in PBS were found for other members of the UiO-66 isoreticular series, which could result in unwanted uncontrollable release of drugs. We have observed slightly slower degradation kinetics for $\mathrm{AcOH}$ modulated $\mathrm{UiO}-66$, which took $8 \mathrm{~h}$ of immersion in PBS to release $80 \%$ of the bdc linker, suggesting modulators may play some role in stability to phosphate-induced degradation [73].

Surface modifications are known to play a crucial role in the hydrolytic stability and colloidal dispersion of MOFs and DDSs in general, as they govern the interactions with the media in which DDSs are dispersed and can shelter the $\mathrm{Zr}_{6}$ SBUs from attack by nucleophilic ions 
such as phosphate. For example, UiO-66- $\mathbf{N}_{3}$ nanoparticles in water aggregate quickly upon $\mathrm{NaCl}$ addition, however, UiO-66- $\mathbf{N}_{3}$-DNA conjugated nanoparticles are colloidally stable in aqueous solutions of up to $0.4 \mathrm{M} \mathrm{NaCl}$, possibly due to the steric and electrostatic barriers provided by the DNA surface coating [97]. Surface modification with the phospholipid LDOPA can even enable the dispersion of hydrophilic Zr MOFs in low polarity media such as $\mathrm{CHCl}_{3}$. Thus, UiO-66-DOPA, UiO-67-DOPA and BUT-30-DOPA migrated from the aqueous to the organic phase upon liquid-liquid extraction (Figure 9) [88].

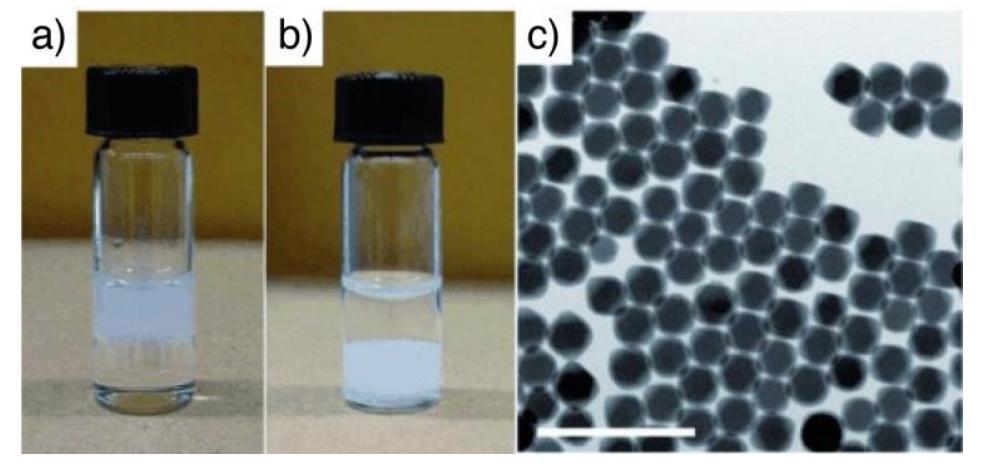

Figure 9. Images of a) bare Zr MOF nanoparticles suspended in water, and b) DOPA-coated Zr MOF transferred to $\mathrm{CHCl}_{3}$. c) SEM image of UiO-66-DOPA dropcast from $\mathrm{CHCl}_{3}$. Scale bar $1 \mu \mathrm{m}$. Modified with permission from ref [88] copyright (2015) John Wiley and Sons.

The effect of incorporating phospholipid mono- and bilayers into MOFs was investigated through examining the colloidal stability and dispersion of bare PCN-223 nanoparticles, nanoPCN-223@DOPC and nanoPCN-223@DOPC/DOPC in a series of solvents, such as water, PBS and biological growth media [90]. The hydrodynamic size of bare nanoPCN-223 drastically increased with time in water and more importantly in PBS, indicating significant aggregation. As a consequence of phosphate attack, $90 \%$ of the linker was released from bare nanoPCN-223 in the first hour of PBS exposure. Upon the first coating with the phospholipid DOPC, PCN-223@DOPC was found to be highly hydrophobic and aggregated in water, likely due to the acyl chains of DOPC. In contrast, the MOFs coated with phospholipid bilayers did not significantly aggregate in water or PBS over a period of 7 days, highlighting the power of surface modifications. Both mono- and bi-layer coated nanoparticles were stable towards common cations and anions, as well as in serum. PCN223 coated with PBLs releases less than $3 \%$ of the organic linker after 7 days in PBS, strongly suggesting that PBLs act as a barrier to block phosphate attack, with PBL coatings even providing additional resistance towards $\mathrm{H}_{2} \mathrm{O}_{2}$. The combination of polymer-coating and the high coverage provided by the postsynthetic coordination protocol ensures excellent stability. 
We have investigated the aggregative behaviour of a range of polymer-coated UiO-66 derivatives, finding that after covalent surface PEGylation, UiO-66-L1-PEG550 and UiO-66L1-PEG2000 were well dispersed in PBS, with average hydrodynamic diameters close to the ones measured by SEM [73]. Enhancements in the stabilities of the PEGylated MOFs in PBS were also achieved. An induction time was found, during which PEGylated samples did not undergo notable linker release; only $35 \%$ of BDC was released after $3 \mathrm{~h}$, and crystallinity was not affected. Importantly, after $24 \mathrm{~h}$ of exposure nearly all the linker had been released, indicating that although an initial stability enhancement is found - possibly as a consequence of the PEG coating initially hindering phosphate attack - full degradation will occur (Figure 10), which is vital for clearance in vivo. Significant enhancements in polydispersity and stability were also found when UiO-66 was functionalised with poly-Llactide and PNIPAM through the same methodology, although coordination of heparin to the surface through its sulfate units did not notably improve dispersion [74].
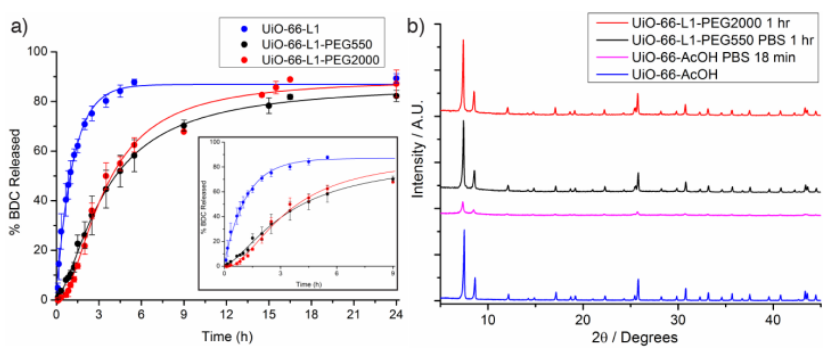

Figure 10. a) Degradation profiles monitoring linker release by UV/Visible spectroscopy and b) powder X-ray diffraction analysis showing an enhancement in the stability of UiO-66 in PBS when coated with poly(ethylene glycol) chains. Used with permission from ref [73] copyright (2017) Elsevier.

We have also investigated the stability of UiO-66 samples functionalised by introducing folic acid or biotin as modulators in one-pot syntheses, and compared them to the analogous samples functionalised by postsynthetic coordination, allowing comparison of stability enhancements endowed by differing functionalisation protocols. The samples prepared by postsynthetic coordination had a greater induction time in which degradation was slower than the samples synthesised by one-pot coordination modulation, possibly due to more complete coordination of surface $\mathrm{Zr}$ units. However, after the induction period, the samples synthesised by coordination modulation had lower degradation rates, and all biotin and folic acid functionalised samples were more stable towards PBS than bare UiO-66. 
Hong and co-workers found slight changes in aggregative behaviour when UiO-66 was dispersed in water before and after supramolecular Py-PGA-PEG functionalisation. The hydrodynamic diameter of bare UiO-66 ( 220 nm) was slightly higher than the size observed by SEM, and increased further for UiO-66-Py-PGA-PEG-F3 ( 250 nm) [100]. These results suggest that, although many factors are involved in controlling the aggregative behaviour of MOFs, surface functionalisation through covalent attachment might be more efficient at enhancing colloidal stability of UiO-66 than using $\pi-\pi$ interactions, possibly due to the higher stability of the coating using the former protocol.

Mirkin and co-workers have recently reported that the monocarboxylic acid modulator used during UiO-66 synthesis plays a crucial role in the MOFs polydispersity [107]. Modulators with lower $\mathrm{p} K_{\mathrm{a}}$ values are more likely to be deprotonated during synthesis, and so increased competition with the organic linker for the zirconium positions induces the formation of defects (see for example, Figure 3b). These defects increase the surface charge (measured by zeta potential), thus increasing the repulsion between nanoparticles and enhancing their colloidal stability. UiO-66 samples modulated by formic acid $\left(\mathrm{p} K_{\mathrm{a}}=3.8\right)$, dichloroacetic acid $\left(p K_{a}=1.4\right)$ and trifluoroacetic acid $\left(p K_{a}=1.1\right)$ were colloidally stable in water, as determined by DLS, and did not show any aggregation by scanning tunnelling electron microscopy (STEM). In contrast, when acetic acid $\left(\mathrm{p} K_{\mathrm{a}}=4.8\right)$ is used as a modulator for the synthesis of UiO-66 (the BDC linker has a first $p K_{a}$ of 3.5 and a second of 4.8) the resultant particles were considerably aggregated.

In the course of our own research, we independently realised that DCA, a molecule with anticancer activity, could be deliberately incorporated into UiO-66 in significant amounts $(20 \% \mathrm{w} / \mathrm{w})$ during synthesis, as a consequence of its lower $\mathrm{p} K_{\mathrm{a}}$ value [73]. This protocol was further explored introducing functionalised modulators (azide, or propargyl benzoic acid derivatives) or biomolecules (folic acid, biotin) together with DCA as the co-modulator, yielding DCA@UiO-66-modulator (CM) in one simple synthetic step. In correlation with the observations by Mirkin, the hydrodynamic diameters of the various MOFs in PBS and water were close to those determined by SEM, again showing little aggregation when DCA is used as co-modulator, in contrast to $\mathrm{AcOH}$ modulated $\mathrm{UiO}-66$ [74].

The biodegradation of Mn-doped UiO-66-PEG has been investigated in artificial lysosomal fluid $(\mathrm{pH} 4.5)$ to mimic intracellular conditions upon different soaking times (1, 9, 12 and 24 h) [96]. Although after $9 \mathrm{~h}$ the morphology of the MOF is significantly altered, as confirmed by TEM imaging, some Bragg reflection peaks can still be observed by PXRD analysis of dried samples, which completely disappear after $24 \mathrm{~h}$, suggesting that the MOF can degrade 
in vivo after performing its task. The authors observed that after one hour the MOFs start to aggregate, with complete agglomeration after $9 \mathrm{~h}$.

The stability of MOFs towards phosphates depends on many factors, but clearly surface coating is one of the most important, as it can shelter metal clusters from phosphate attack. Compared to the amount of work that has been performed to determine and to enhance the drug release kinetics of $\mathrm{Zr}$ MOFs, there are few studies in the literature that discuss the degradation kinetics of the $\mathrm{Zr}$ MOF itself, despite the fact that the drug release will, in part, be a consequence of carrier degradation. It is evident that both hydrolytic stability and colloidal dispersion are closely related; notable improvements in both are possible through surface functionalisation based on phosphate coordination and covalent postsynthetic modification. The use of a low $\mathrm{p} K_{\mathrm{a}}$ modulator during the synthesis of $\mathrm{UiO}$ series MOFs significantly enhances their colloidal dispersion; it may be expected that this will also enhance hydrolytic stability by increasing the strengths of the bonds between the $\mathrm{Zr}$ SBUs and the carboxylates of the linkers [108]. 


\section{Controlling Cargo Release}

For DDSs to be effective, premature release of therapeutic cargo should be minimised, allowing the drug to travel to the location of the disease within the body before delivering the payload. For MOFs, release of cargo can occur by diffusion out of the pores or through degradation of the MOF itself, with unwanted early release - the so-called "burst release" phenomenon - a major issue to overcome. The chemical stability and ease of functionalisation of $\mathrm{Zr}$ MOFs has facilitated the development of many strategies to allow controlled or even stimuli-responsive cargo release. As hydrolytic stability is implicit in control of cargo release, similar protocols to those discussed in Section 4 have been employed to overcome burst release in Zr MOFs.

Attaching cargo to the surfaces and defect sites of Zr MOFs by coordination provides the possibility of $\mathrm{pH}$ or phosphate induced cleavage and release. For example, Lachelt and coworkers studied the release of fluorescent peptides, attached to Zr-fum surfaces using Histag imidazole coordination, into HEPES buffered glucose (HBG) at different $\mathrm{pH}$ values over $24 \mathrm{~h}$ by photometric determination (Figure 11) [85]. HBG does not contain phosphates, so the role of $\mathrm{pH}$ can be assessed independently. At $\mathrm{pH} 7.4$ the coating was stable, while at $\mathrm{pH}$ 5 the peptide was partially released, and at $\mathrm{pH} 3$ was completely cleaved from the surface of $\mathrm{Zr}$-fum. Although the imidazoles present in histidine residues have $\mathrm{p} K_{\mathrm{a}}$ values around 6 , and thus detachment at $\mathrm{pH} 5$ due to imidazole protonation would be expected to be more pronounced, the authors suggest that incomplete detachment could be due to the lowered effective $\mathrm{p} K_{\mathrm{a}}$ value when His-tags are attached to the zirconium units.

a)
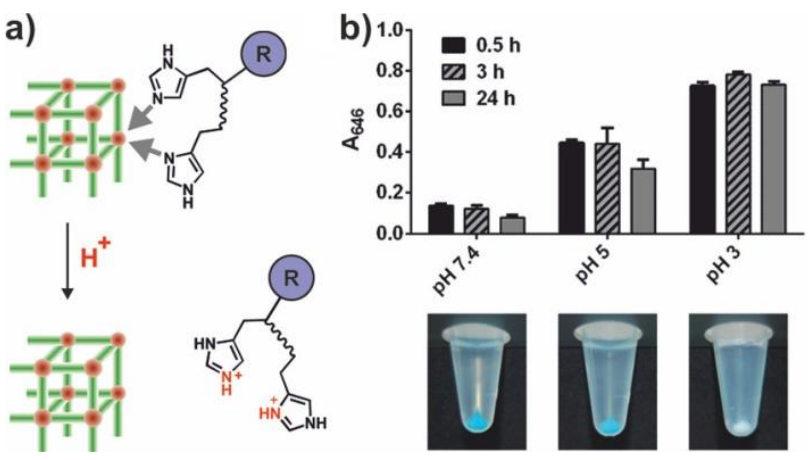

Figure 11. a) Schematic release of his-tagged peptides from $\mathrm{Zr}$-fum by decreasing $\mathrm{pH}$. b) Assessment of $\mathrm{pH}$ induced released peptides by absorbance at $\lambda=646 \mathrm{~nm}$, with photographic images showing decrease in colour as peptide is release. Modified with permission from ref [85] copyright (2017) American Chemical Society. 
The coordination of the drug Alendronate through its phosphate groups to UiO-66 results in $\mathrm{pH}$ responsive drug release from UiO-66-AL, which released $43 \%$ of $\mathrm{AL}$ in $\mathrm{PBS}$ at $\mathrm{pH} 7.4$ over $60 \mathrm{~h}$, and $59 \%$ of $\mathrm{AL}$ under the same conditions but at $\mathrm{pH} 5.5$ [84]. In this case, the release at $\mathrm{pH} 7.4$ is likely a consequence of phosphate substitution, which is somewhat enhanced at $\mathrm{pH}$ 5.5. Since the $\mathrm{p} K_{\mathrm{a}}$ of alendronate is lower than free phosphate, the less pronounced release rates at $\mathrm{pH} 5.5$ might be a consequence of the equilibrium between protonated and non-protonated alendronate and phosphates.

If molecular cargo is tightly bound by the host MOF then temperature can be used to induce its release. Jiang et al. compared the release of the drug diclofenac sodium (DS) from the UiO series MOF NU-801 (3,3'-(1,4-phenylene)diacrylic acid linker) with a derivative containing a central 1,4-naphthyl spacer, ZJU-801.[109] Release of the drug from DS@NU801 into PBS was characterised by a burst release, with only a slight enhancement as temperature was increased from $25{ }^{\circ} \mathrm{C}$ to $60{ }^{\circ} \mathrm{C}$, and $80 \%$ release at $37^{\circ} \mathrm{C}$ in $24 \mathrm{~h}$. In contrast, DS@ZJU-801 releases only 25\% of its cargo at $37{ }^{\circ} \mathrm{C}$ in $24 \mathrm{~h}$, but is completely evacuated over the same time period at $60{ }^{\circ} \mathrm{C}$. The difference in release is ascribed to enhanced $\pi-\pi$ stacking between ZJU-801 and DS.

Physically modifying drug-loaded MOFs to sterically protect the surface from hydrolysis is also an effective approach to control drug release (Table 4). Fairen-Jimenez et al. have applied an amorphisation approach to trap calcein, a model drug molecule, within UiO-66 by grinding. Full release of calcein from amorphous UiO-66 took 30 days rather than two days for crystalline UiO-66 (Figure 12a) [110], and 15 days instead of two for amorphous UiO-66$\mathrm{NH}_{2}$ [105]. Similarly, the release of (DS) from ZJU-800, a member of the UiO series linked by 3,3'-(2-fluoro-1,4-phenylene)diacrylic acid, was monitored in PBS by Jiang et al [111]. DS was loaded into ZFU-800 up to $59 \% \mathrm{w} / \mathrm{w}$, and its release in PBS $(\mathrm{pH} 7.4)$ at $37^{\circ} \mathrm{C}$ displayed a burst effect, with an immediate $10 \%$ release, followed by full release over two days. The effect of pressure on the drug release kinetics was investigated by applying different pressures (10 MPa and $30 \mathrm{MPa}$ ) to drug loaded samples for one minute, compacting the MOFs into slices, which were further broken for the drug release experiments. The authors observed a 2.5 fold decrease in the release rates for the lower pressure, maintaining the release up to 5 days, and when the higher pressure was applied, the release was prolonged to 8 days, with no burst release for either sample (Figure 12b). Whilst bulk crystallinity was maintained, pressure-induced amorphisation at particle surfaces could sufficiently block pores and slow down release. 
Table 4. Postsynthetic treatment of Zr MOFs to enhance drug release kinetics. ${ }^{[a]}$

\begin{tabular}{|c|c|c|c|c|}
\hline MOF & $\begin{array}{c}\text { Drug/ } \\
\text { Biomolecule }\end{array}$ & Treatment & Applications & Ref \\
\hline UiO-66 & Calcein & $\begin{array}{l}\text { Mechanical } \\
\text { amorphisation }\end{array}$ & $\begin{array}{c}\text { Prolonged release from } 2 \text { to } 30 \\
\text { days in PBS }\end{array}$ & [110] \\
\hline $\begin{array}{c}\text { UiO-66-X } \\
\text { DUT-52 } \\
\text { UiO-67 }\end{array}$ & $\begin{array}{l}\text { Calcein } \\
\alpha-\mathrm{CHC}\end{array}$ & $\begin{array}{l}\text { Mechanical } \\
\text { amorphisation }\end{array}$ & $\begin{array}{l}\text { Prolonged release in PBS; } \\
\text { Enhanced cytotoxicity }\end{array}$ & [105] \\
\hline ZJU-800 & $\begin{array}{c}\text { Diclofenac } \\
\text { disodium (DS) }\end{array}$ & $\begin{array}{l}\text { Pressure } \\
\text { application }\end{array}$ & Pressure-controlled release & [111] \\
\hline $\begin{array}{l}\mathrm{NU}-1000 \\
\mathrm{NU}-901\end{array}$ & $\begin{array}{l}\text { Calcein } \\
\alpha-\mathrm{CHC}\end{array}$ & $\begin{array}{l}\text { Temperature } \\
\text { treatment }\end{array}$ & $\begin{array}{l}\text { Prolonged release in PBS; } \\
\text { Enhanced cytotoxicity }\end{array}$ & [112] \\
\hline
\end{tabular}

${ }^{[a]}$ Some examples of incorporation of stimuli-responsive release mechanisms on the surfaces of $\mathrm{Zr}$ MOFs are given in Table 2.

Thermal amorphisation has been also investigated to prolong the drug release times of NU1000 and NU-901 [112]. These zirconium MOFs have remarkably high storage capacities with calcein loadings of $41.6 \% \mathrm{w} / \mathrm{w}$ and $37.0 \% \mathrm{w} / \mathrm{w}$, respectively - due to their high porosity $\left(\mathrm{S}_{\mathrm{BET}}=2320\right.$ and $2500 \mathrm{~m}^{2} \mathrm{~g}^{-1}$, respectively), but their larger pore cavities can at the same time result in rapid drug release. Calcein was confirmed to be located in the pores, as the loaded samples had drastically reduced porosities. Temperature treatment $\left(180{ }^{\circ} \mathrm{C}\right)$ was performed in order to collapse the structure and to hinder calcein release through the pore cavity. In contrast to the mechanical amorphisation protocols performed on the UiO-66 family $[105,110]$, although the intensity of the Bragg peaks had decreased, they could still be observed clearly in the PXRD pattern, indicating only partial structure collapse.
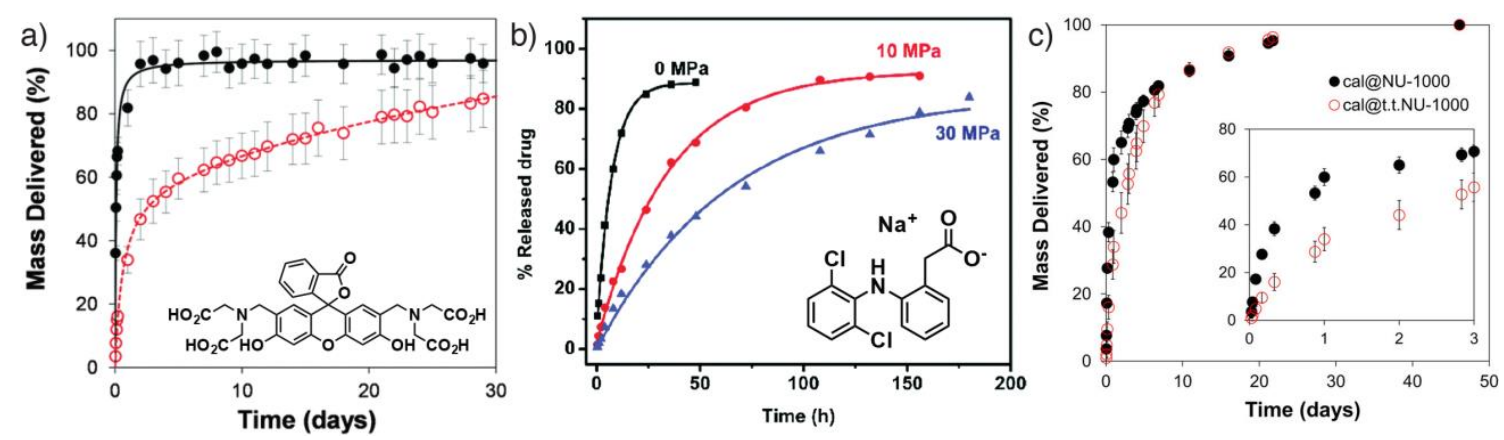

Figure 12. Release profiles of a) calcein from pristine (filled symbols) and amorphised (empty symbols) UiO-66, b) diclofenac sodium from ZJU-800 treated at different pressures, and c) calcein from pristine (filled symbols) and temperature amorphised (empty symbols) NU-1000. Modified with permission from a) ref [110] copyright (2015) The Royal Society of Chemistry, b) ref [111] copyright (2016) Royal Society of Chemistry, and c) ref [112] copyright (2017) American Chemical Society. 
The effect of thermal treatment on the drug release kinetics was clear; after $4 \mathrm{~h}$ cal@NU1000 had released $\sim 28 \%$ of its calcein, but after thermal treatment only $10 \%$ was released in the same time period. The release kinetics were slowed to the seventh day, when the profiles for thermally amorphised and pristine calcein-loaded NU-1000 overlap at around $80 \%$ release, and continue to release the full amount up to seven weeks (Figure 12c). On the other hand, only a minor effect on calcein release kinetics was found upon thermal treatment of NU-901.

Encapsulation of MOF nanoparticles in polymer microspheres can also control release. UiO66 and UiO-67 were loaded with cisplatin (4.8\% w/w and $1 \% \mathrm{w} / \mathrm{w}$, respectively) and taxol $(14 \% w / w$ and $10 \% w / w$, respectively) before microencapsulation in modified poly $(\xi-$ caprolactone), and their release kinetics in PBS (pH 7.4) were investigated [103]. Burst release of cisplatin from uncoated $\mathrm{UiO}-66$ and $\mathrm{UiO}-67$ was observed $(70 \%$ and $90 \%$ release, respectively, after $5 \mathrm{~h}$ of exposure) followed by slow release of the remainder, either as a consequence of the majority of the drug being bound to the surfaces of the MOFs rather than stored in their pores, or to carrier instability. Similar burst release (50-60\%) of taxol was observed from the bare MOFs. The burst effect was considerably reduced after microencapsulation of the nanoparticles for both drugs, with a more pronounced effect for cisplatin, which showed sustained release for 18 days.

In Section 4, a number of examples were detailed where incorporation of surface functionality blocked phosphate-induced degradation; surface units can also block the release of cargo molecules until certain external stimuli are applied. We have shown that calcein release from UiO-66 can be controlled by postsynthetic covalent PEGylation through click chemistry at functionalised modulators [73]. Release profiles into PBS, measured by UV/Vis spectroscopy, showed that unfunctionalised cal@UiO-66-L1 released all its calcein in 2 days at $\mathrm{pH} 7.4$, but cal@UiO-66-L1-PEG2000 only released $~ 30 \%$ of loaded calcein under the same conditions. We hypothesise that when UiO-66 is coated by PEG chains, once the phosphates diffuse through the protecting coating and begin to displace the polymer and calcein attached to the surface, a phosphate corona that hinders further calcein release is formed. Bare and coated samples release $\sim 90 \%$ of the loaded calcein in PBS at pH 5.5 after only ten hours, with the lower $\mathrm{pH}$ conditions allowing displacement of surface phosphates and the remainder of the calcein. This behaviour allows $\mathrm{pH}$-responsive release of calcein from cal@UiO-66-L1-PEG2000 upon addition of acid (Figure 13); the lower pH of some cancer cells could allow this to be a mechanism for controlled delivery and release of anticancer therapeutics. 


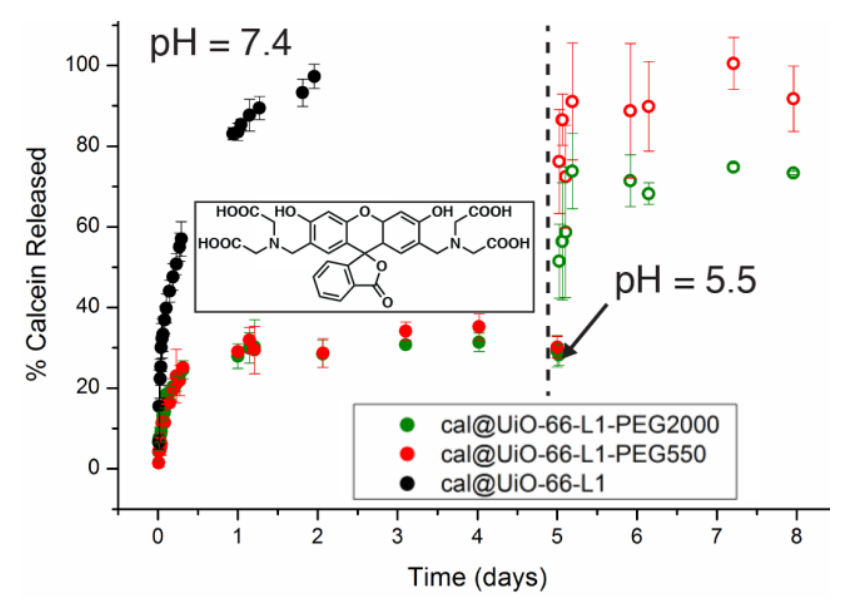

Figure 13. $\mathrm{pH}$ responsive release of calcein from PEGylated UiO-66 samples. Modified with permission from ref [73] copyright (2017) Elsevier.

PNIPAM is thermosensitive polymer, which is adopts a closed, globular mode at higher temperatures, and opens to a coil formation at lower temperatures. Thus, Kokado and Sada reported the on-off thermoresponsive release of three different molecules - resorufin, caffeine and procainamide - from UiO-66-PNIPAM in water [92]. The release kinetics at 25 ${ }^{\circ} \mathrm{C}$ were slightly improved compared to the precursor UiO-66- $\mathrm{NH}_{2}$, to which PNIPAM was attached by amide formation, which released $\sim 95 \%$ of resorufin after a few hours. Drug release from the PNIPAM-functionalised MOF was pronounced at $25^{\circ} \mathrm{C}$, when the polymer is in its open coil form, exhibiting a burst release of more than $50 \%$ of the different molecules in the first few hours and $80-90 \%$ release after one day. The release kinetics were remarkably reduced at $40{ }^{\circ} \mathrm{C}$, with an initial release of only $10-20 \%$ of the cargo molecules in the first hour, with no subsequent release. As the drugs were loaded after PSM, the small amount of drug released initially at $40^{\circ} \mathrm{C}$ could be a consequence of minor surface drug location. By changing the temperature during the course of the drug release experiment, UiO-66-PNIPAM drug release was switched on and off by external stimulus (Figure 14a). It is important to point out that this temperature responsive behaviour was only achieved when the degree of PNIPAM coating was high enough to ensure significant surface coverage, as a sample with only $4.2 \% \mathrm{w} / \mathrm{w}$ PNIPAM did not present thermoresponsive behaviour. 

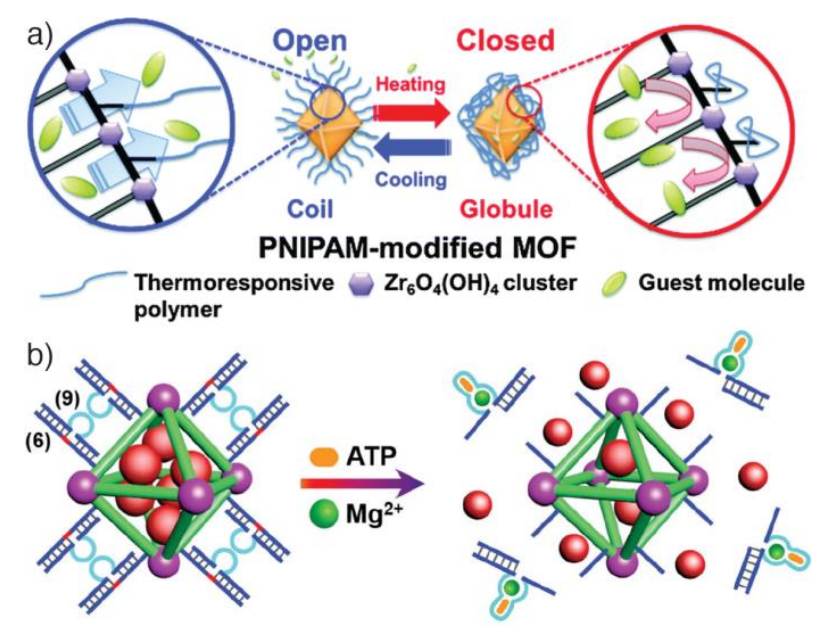

Figure 14. a) Schematic showing temperature induced release of cargo from UiO-66-PNIPAM. Modified with permission from ref [92] copyright (2015) The Royal Society of Chemistry. b) Schematic showing $\mathrm{Mg}^{2+}$ and adenosine triphosphate (ATP) induced release of cargo from UiO-68 functionalised with metal-sensitive DNAzymes. Modified with permission from ref [98] copyright (2017) The Royal Society of Chemistry.

Willner et al. studied the reorganisation of DNA on the surface of UiO-68- $\mathrm{N}_{3}$ in response to $\mathrm{pH}$ and metal ions as mechanisms for the release of doxorubicin (DOX) and methylene blue [98]. To induce $\mathrm{pH}$ responsive release, cytosine-rich DNA sequences were attached to the surface of UiO-68- $\mathrm{N}_{3}$ by SPAAC, and the authors attributed the enhanced release of cargo into PBS at $\mathrm{pH} 5$ compared to that at $\mathrm{pH} 7.4$ to the reorganisation of the cytosine-rich DNA into an i-motif structure that allowed cargo to be released, rather than linker deprotonation and structure decomposition. Metal ion responsive release was probed by attaching metalion-dependent catalytic nuclei acid sequences - so-called "DNAzymes" - through hybridisation with pre-installed surface sequences. Upon metal-ion binding, these DNAzymes are released from the MOF and should result in uncapping and release of trapped cargo, in this case the dyes rhodamine $6 \mathrm{G}$ and methylene blue, as well as doxorubicin.

The release of rhodamine $6 \mathrm{G}\left(\mathrm{Mg}^{2+}\right)$ and methylene blue $\left(\mathrm{Pb}^{2+}\right)$ from UiO-68- $\mathrm{N}_{3}-\mathrm{DNA}$ was induced by the presence of the metal ions in a concentration and time dependent manner. The doxorubicin-loaded MOF was functionalised with DNA containing both an $\mathrm{Mg}^{2+}$ dependent DNAzyme sequence and an adenosine triphosphate (ATP) aptamer unit, based on the fact that ATP concentrations are higher in cancerous cells than healthy ones (Figure 14b). Release was only slightly enhanced upon increase of $\mathrm{Mg}^{2+}$, but a two-fold increase was promoted through cooperation of $\mathrm{Mg}^{2+}$ and ATP addition. It should be noted that the 
phosphate units of ATP may also become involved with coordination to the $\mathrm{Zr}_{6}$ SBUs at the surface of the MOF.

Yang and co-workers studied the stimuli-responsive release of 5-fluorouracil (5-FU) from pseudorotaxane capped 5-FU@UiO-66-NH-Q-Cp5 capped in aqueous solution in response to changes in $\mathrm{pH}$, temperature, and the presence of various concentrations of $\mathrm{Ca}^{2+}$ [99] and $\mathrm{Zn}^{2+}$ ions [93], which have high affinity for decacarboxylato-pillar[5]arene (CP5), the macrocyclic component of the capping pseudorotaxanes. The capped MOF released around $10 \%$ of 5 - FU at $\mathrm{pH} 7.4\left(25-37^{\circ} \mathrm{C}\right)$ after one hour, and lower $\mathrm{pH}$ values resulted in an increase of the drug release rate, with $60 \%$ of drug released at $\mathrm{pH} 2$ over the same time frame, likely due to hydrolytic cleavage of the surface functionality. Increased temperature also resulted in a more pronounce release rate. Because of the favourable binding between $\mathrm{Ca}^{2+}$ and the carboxylate-functionalised CP5 macrocycle, 5-FU release from 5-FU@UiO-66NH-Q-Cp5 capped was triggered in a stimuli-responsive manner by increasing $\mathrm{Ca}^{2+}$ concentration [99], releasing the full amount of the drug for $\mathrm{Ca}^{2+}$ concentrations of $600 \mathrm{mM}$ in two hours. Significantly lower $\mathrm{Zn}^{2+}$ concentrations (10 nM) were sufficient to achieve $75 \%$ release in one hour [93]. Control experiments without CP5 capping resulted in total drug release after 2 days, indicating that the CP5 molecule hinders cargo release, although it is difficult to distinguish if the molecule acts as the wheel of a pseudorotaxane or simply a surface-adsorbed cap, or indeed both.

We can observe that in general all zirconium MOFs have $\mathrm{pH}$-responsive drug release as a consequence of hydrolysis, which is favourable for anticancer treatment, as the cytoplasm of cancer cells is generally more acidic than for healthy cells [113]. If we compare the release kinetics of different drugs from $\mathrm{UiO}-66$, it comes to mind that cargo attached to the $\mathrm{Zr}$ clusters (such as Alendronate) are released with a more favourable rate than molecules stored in the pores (such as caffeine or resorufin). The importance of surface coating is obvious and has different effects depending on its nature. For example, surface coatings which can compete with phosphates during degradation highly enhance the stability of the samples through coordinative competition, and protecting polymers attached to the surfaces of NMOFs also sterically protect them from degradation, although to a lower extent, as once the coating has been displaced, degradation occurs at a normal rate. Protocols to collapse the porosity of MOFs around loaded molecules - such as mechanical amorphisation, temperature treatment, or applied pressure - have also induced more desirable release fates, although their effect on colloidal stability is not pronounced, indicating that surface coatings are more suitable to enhance both stability and dispersion. Thus, an appropriate strategy could be to perform surface coating after amorphisation. 


\section{In Vitro Studies of Zirconium MOFs}

To be efficient DDSs, MOFs should be easily internalised by the cells that they are aiming to treat, and able to release their cargo in intracellular conditions. Importantly, the DDS should avoid immune system recognition, and thus not be internalised by immune system cells such as macrophages. Nanoparticle uptake depends on many factors, including size, morphology and surface chemistry among others [114-116], and attempts have been made to enhance uptake and also control the endocytosis mechanisms of MOFs. Fluorescent linkers, surface functionality, or cargo molecules are usually used to monitor endocytosis of MOFs through confocal microscopy and/or fluorescence-activated cell sorting (FACS). It is also possible to quantify MOF content in cells through elemental analysis of $\mathrm{Zr}$.

\subsection{Enhancing and Targeting Cellular Uptake of MOFs}

A number of protocols have been investigated to enhance the uptake of MOFs, and/or their cargo, by different cell lines, as well as induce particular intracellular localisation, and to target certain diseases. Different groups have found that uptake of MOF nanoparticles by cells occurs rapidly. Xie and co-workers investigated internalisation of UiO-PDT by B16F10 mouse melanoma cells for different incubation times (0.5, 2 and $4 \mathrm{~h})$ using FACS, and compared it with the mean fluorescence intensity when cells were incubated with the same concentration of free linker (I2-BDP), which exhibits characteristic fluorescence [86]. A doseresponsive behaviour for the uptake of both was found, being higher ( 1.5 fold increase at $2 \mathrm{~h}$ incubation time) in the case of UiO-PDT. By confocal fluorescence microscopy it was observed that the red fluorescence was mainly located in the cytoplasm of B16F10 cells for both cases. Internalisation of UiO-66-FMN by HepG2 human liver carcinoma cells has been investigated after 4 and $12 \mathrm{~h}$ incubation time, finding that after $4 \mathrm{~h}$ more than $80 \%$ of the cell population have high mean fluorescent intensity, while after $12 \mathrm{~h}$ only a slightly increase is found [84]. These results indicate that UiO-66-FMN cell uptake occurs rapidly during the first $4 \mathrm{~h}$, after which the cell uptake rate decreases. Through confocal microscopy, high green fluorescence in the cells cytoplasm was observed.

Zhou and co-workers investigated HeLa human cervical cancer cells uptake of a porphyrinic MOF (PCN-224) by varying particle size, with the aim to enhance internalisation and cytotoxicity through passive targeting [83], based on the fact that nanoparticles accumulate in cancer tissue due to the enhanced permeability and retention (EPR) effect [117]. The authors analysed the zirconium content by ICP-MS of digested cells, which were incubated 
with samples of the MOF of varying size $(30,60,90,140$, and $190 \mathrm{~nm})$ over different times $(0-40 \mathrm{~h})$. The highest cell uptake was found for nanoparticles of $90 \mathrm{~nm}$ diameter, and generally reached a plateau after $12 \mathrm{~h}$ of incubation. Confocal microscopy showed the NMOF was located in both the lysosomes and mitochondria, while no nucleus co-localisation was found.

Incubation of HeLa cells with porphyrin-coated UiO-66-TPP-SH and TCPP@UiO-66 (15 $\mu \mathrm{gmL}^{-1}$ ) for only $2 \mathrm{~h}$ resulted in fluorescence located in the cytoplasm, suggesting that both MOFs have good membrane permeability. However, red fluorescence was also observed in the cytoplasm after incubation with free TPP-SH, suggesting passive diffusion of the free porphyrin, which would also occur if the surface ligands detach from the MOFs prior to endocytosis [80]. Similarly, after just one hour of incubation of HepG2 cells with the porphyrin-containing Zn-DTPP-I2@UiO-66 (10 $\left.\mathrm{mgmL}^{-1}\right)$, confocal microscopy showed fluorescence associated with the porphyrin to be located in the cytoplasm [79].

Surface modification has been used to enhance endocytosis efficiency and tune the cell uptake routes of MOFs. We have found that functionalisation of UiO-66 with polar pendant moieties $\left(\mathrm{Br}, \mathrm{NO}_{2}, \mathrm{NH}_{2}\right)$ enhances uptake by HeLa cells compared to less polar derivatives such as DUT-52 and UiO-67 [118]. Mirkin et al. incubated UiO-66-DNA with HeLa cells for $24 \mathrm{~h}$, with fluorescent Tamra functionality on the DNA showing that conjugation to the MOF results in enhanced uptake of the DNA sequence. ICP-MS analysis of the zirconium content of the cells showed enhanced uptake for the UiO-66-DNA conjugates compared to bare MOFs, which was more remarkable for $19 \mathrm{~nm}$ sized nanoparticles than for $14 \mathrm{~nm}$ nanoparticles [97].

The intracellular bio-stability of PCN-223 has been investigated by quantification of linker release inside cells [90]. The authors incubated HeLa and human hepatocarcinoma SMMC7721 cells with bare nanoPCN-223, PCN-223@DOPC/DOPC and TCPP, the linker of the NMOF, which is itself fluorescent and thus allows tracking of MOFs inside the cells (Figure 15). Passive uptake of free TCPP leads to low, well-distributed red fluorescence confined to the cytoplasm, while when cells were incubated with solutions of the bare MOF, only traces of nanoPCN-233 were observed as well-defined dots in the lysosomal locations inside the cells. Free TCPP located uniformly in the cell could also be observed, indicating possible degradation of the MOF sample in growth media, presumably due to the presence of phosphates in the media. In contrast, they found that PBL-coated nanoPCN-223 is only located in the lysosomes with no evidence of released TCPP in the cytoplasm. FACS showed that although TCPP undergoes passive diffusion into the cell and the mean 
fluorescence intensity is similar to bare nanoPCN-223, after coating with PBLs the cell uptake efficiently is enhanced $\sim 1.7$ fold within the first $4 \mathrm{~h}$ of incubation, as no increase in fluorescence was found after longer incubation times of 12 and $24 \mathrm{~h}$.

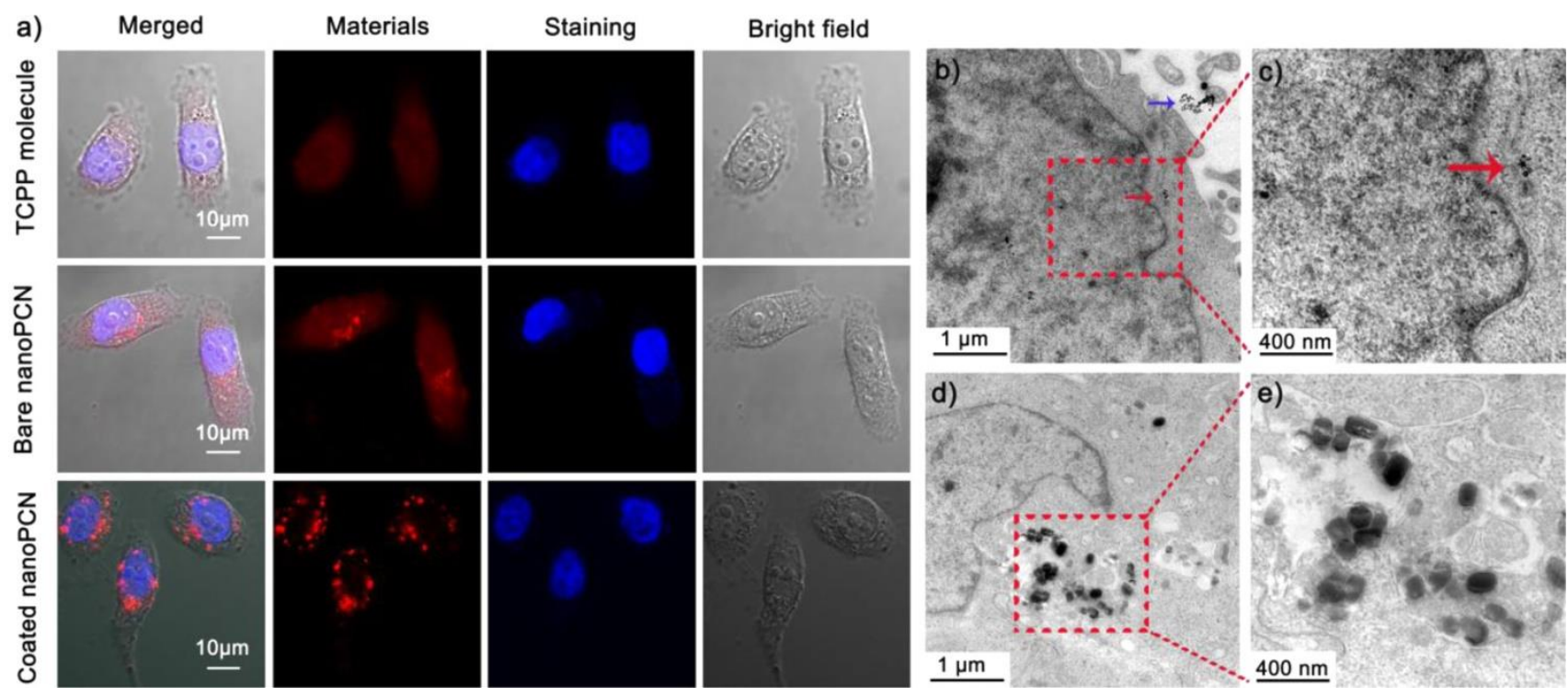

Figure 15. a) Confocal fluorescence microscopy of SMMC-7721 cells after incubation with TCPP (free ligand), bare PCN-223, and PCN-223@DOPC/DOPC. Bio-TEM images of b) and c) bare PCN-223 compared to d) and e) PCN-223@DOPC/DOPC, showing enhanced intracellular stability of PCN223@DOPC/DOPC. Reproduced with permission from ref [90] copyright (2017) American Chemical Society.

We have analysed the internalisation of bare and surface functionalised UiO-66, loaded with fluorescent calcein, by $\mathrm{J} 774$ mouse macrophages, finding that in general, surface functionalised MOFs are internalised by macrophages to a higher extent than analogous bare MOFs, with a similar trend to HeLa cell internalisation efficiency [74]. Only PEG coating decreases macrophage uptake compare to the bare MOF, indicating that this coating might be desirable for selective anticancer treatment, as it decreases recognition by immune system cells. Internalisation of biotin-coated UiO-66 by HeLa cells was remarkably reduced compared to the naked NMOF. In fact, cal@UiO-66-Biot cell uptake did not significantly decrease at $4{ }^{\circ} \mathrm{C}$ compared to when cells were treated with the functionalised MOF at $37^{\circ} \mathrm{C}$, indicating that there is no efficient active transport.

Targeting peptides have also been utilised to enhance MOF uptake by particular cell lines. DOX@UiO-66-Py-PGA-PEG-F3 (where the fluorescence of doxorubicin serves to track the location of NMOFs inside the cell) internalisation by human breast adenocarcinoma MDAMB-231 cells was found to be remarkably higher than DOX@UiO-66-Py-PGA-PEG, as 
determined by flow cytometry measurements and confocal microscopy. This is because MDA-MB-231 cells over express the nucleolin receptor $(n+)$, which is targeted by the F3 peptide attached to the MOF [100]. In contrast, both targeted and non-targeted NMOFs were internalised considerably less by L929 mouse fibroblast cells, which do not over express the nucleolin receptor ( $\mathrm{n}-$ ). DOX fluorescence was mainly located in the cytoplasm, with some co-localisation in the lysosome when fluorescein isothiocyanate (FITC) modified MOFs were examined. The authors observed that for DOX@UiO-66-Py-PGA-PEG-F3, an internalisation plateau occurs within the first $0.25 \mathrm{~h}$ of incubation, in which a similar amount of internalised MOF and MOF binding to the cells surface was found. It was found that once internalised, during the next $24 \mathrm{~h} 30 \%$ of the NMOF can be externalised by cells through exocytosis processes.

Targeting galactose-specific liver receptors resulted in an increased internalisation of $\mathrm{Zr}$-fum (loaded with resorufin) and UiO-67 (loaded with Rhodamine 6G) by HepG2 liver cancer cells after galactosylamine coating, while cells incubated with uncoated analogue samples did not show appreciable uptake of the MOFs. Importantly, the targeting effect was evidenced by the fact that internalisation of the coated MOFs by HepG2 cells (which over express the receptor) is higher than by healthy FL83B mouse liver cells [95]. Folate targeting has also been used to enhance uptake of MOFs by cancer cells, and will be discussed in the context of receptor-mediated endocytosis in Section 6.2.

Investigation of the fate of DDSs after cell internalisation can also provide key information to explain biological activity. For example, endosomal escape is a key feature for efficient siRNA delivery. Lin and co-workers performed co-localisation studies with human ovarian cancer SKOV-3 cells using confocal laser assisted microscopy, demonstrating siRNA and lysosome separation after $2 \mathrm{~h}$ incubation time [87]. The authors postulate that when siRNA@UiO becomes entrapped in the endosomes, the presence of high endogenous phosphate concentration and the acidic $\mathrm{pH}$ of those will result in structure degradation, and zirconium ions will disrupt the endosome structure, thus facilitating siRNA release.

\subsection{Endocytosis Mechanisms}

Nanoparticles are generally internalised by cells through active transport such as endocytosis, including clathrin-mediated, caveolae-mediated, and non-mediated endocytosis, and macropinocytosis, among others (Figure 16) [114, 119-122]. While nanoparticles internalised through clathrin-mediated endocytosis are finally delivered to 
lysosomes, which can result in degradation and inefficient cytosolic release of their cargo, nanoparticles internalised through caveolae-mediated endocytosis can escape lysosome capture, typically resulting in faster cytosolic release, reaching the desired cell organelles in a more efficient manner and hence displaying higher therapeutic efficiency [123]. Macropinocytosis, whilst unselective, can result in uptake of large quantities of foreign material, some of which may also escape lysosomal degradation and excretion.

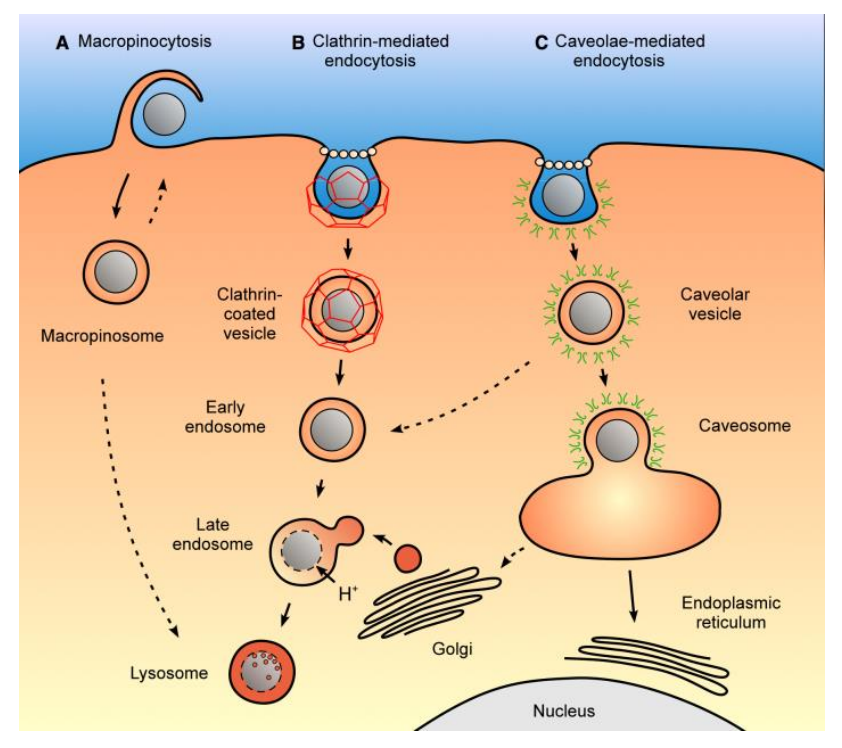

Figure 16. Common endocytosis pathways observed for nanomaterials. Reproduced with permission from ref [122] copyright (2009) Springer Nature.

The use of inhibitors of particular cell uptake pathways can allow internalisation pathways of MOFs to be studied by FACS. In 2016, Fairen-Jimenez et al. first reported the study of internalisation of calcein-loaded UiO-66 by HeLa cells, using inhibitors to suppress specific endocytosis routes [124]. Uptake of cal@UiO-66 was drastically decreased when cells were incubated with the MOFs at $4{ }^{\circ} \mathrm{C}$ rather than $37^{\circ} \mathrm{C}$, confirming that cell internalisation occurs predominantly by active transport. The authors observed that UiO-66 generally undergoes cell internalisation through clathrin-mediated endocytosis, with minor contributions of the macropinocytosis process. Only a minor contribution of the caveolae route was found when the size of the particles was increased from $150 \mathrm{~nm}$ to $260 \mathrm{~nm}$. The clathrin-mediated route forms an early endosome, which is later transformed into a lysosome [125-127], while nanoparticles internalised through caveolae-mediated route are able to escape the early endosome, by the alternative formation of a caveosome that will release its content to the cytosol in a more efficient way [123, 128]. Macropinocytosis is a process in which cells uptake large quantities of fluids [129]. Thus, the therapeutic efficiency of nanoparticles internalised by clathrin-mediated route is expected to be generally lower than for those 
internalised by the caveolae-route. The authors also performed fluorescence co-localisation studies in which they observed a lower degree of lysosome-MOF co-localisation for the bigger nanoparticles, correlating well with the proposed endocytosis routes.

Further studies on the UiO-66 isoreticular series examined the effect of particle size and linker substitution, which modifies the external surface chemistry presented by the particles, on endocytosis efficiency and routes [118]. UiO-66 again tended to favour clathrin-mediated endocytosis with minor contributions from macropinocytosis and caveolae-mediated endocytosis at larger sizes, although the smallest sample (ca $50 \mathrm{~nm}$ ) was internalised by clathrin- and caveolae-independent endocytosis mechanisms (Figure 17a). Functionalised MOFs with more polar surfaces, such as UiO-66- $\mathrm{NH}_{2}$ and UiO-66- $\mathrm{NO}_{2}$, were taken up by HeLa cells in greater quantities, as determined by FACS using calcein-loaded nanoparticles. These more polar MOFs were predominantly internalised by clathrin-mediated endocytosis, in contrast to less polar, unfunctionalised materials (e.g. UiO-67), which had lower overall uptake, but primarily by caveolae-mediated endocytosis (Figure 17b).

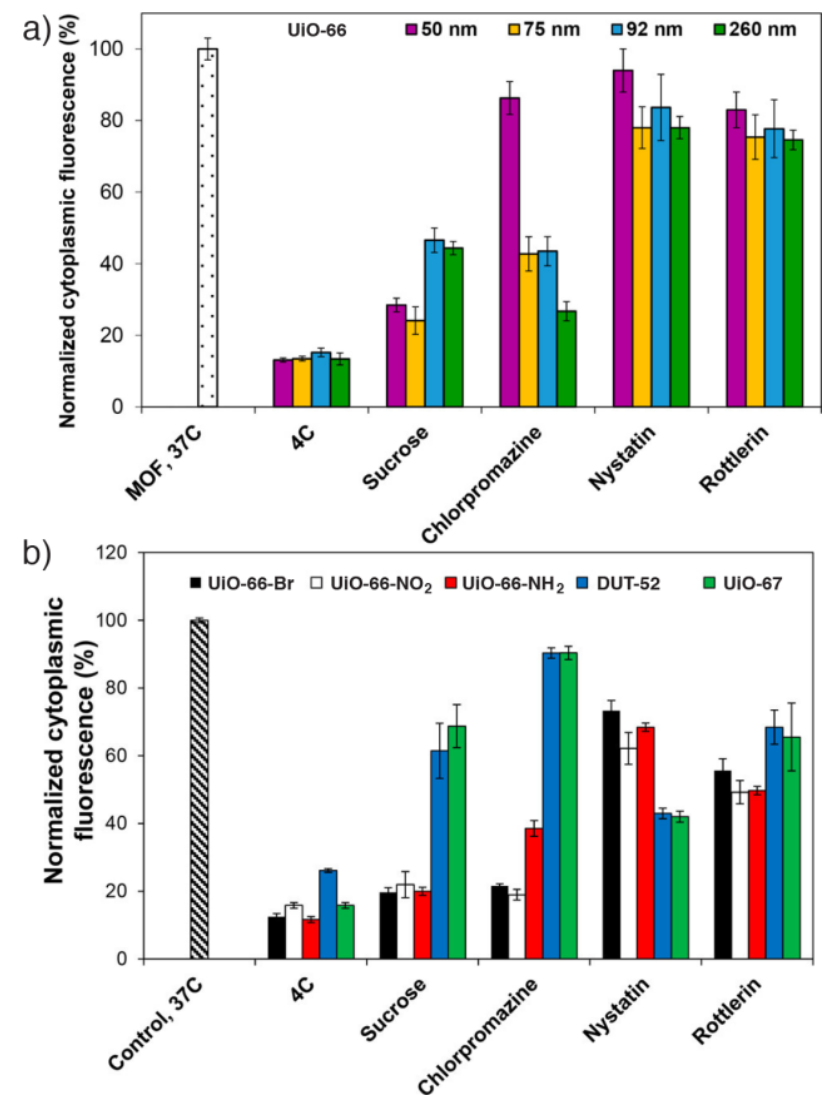

Figure 17. Cell internalisation routes of calcein loaded MOFs as determined by FACS for a) different sized nanoparticles of UiO-66 (Zr-L1) and b) nanoparticles of members of the isoreticular UiO-66 series. Modified with permission from ref [118] copyright (2017) American Chemical Society. 
Fairen-Jimenez et al. reported the HeLa cell internalisation routes of $\mathbf{N U}-\mathbf{1 0 0 0}$ and compared it to amorphised NU-901 [112]. Whilst pristine, calcein loaded NU-1000 was taken up primarily by clathrin-mediated routes, with potentially a small contribution by caveolaemediated uptake, the amorphised sample showed a more significant decrease in cellular fluorescence when incubated with nystatin but also with chlorpromazine, suggesting caveolae-mediated uptake with some contribution from clathrin-mediated endocytosis. The authors also visualised cell internalisation and intracellular location of the MOFs using structured illumination microscopy (SIM), finding the NMOFs to be located mainly at vesicles. They observed that NMOFs start to be internalised after one hour, increasing the uptake gradually up to $24 \mathrm{~h}$.

Changes in particle surface chemistry will tune interactions with cells, and so we have investigated the HeLa cell endocytosis routes of UiO-66 after postsynthetic decoration with a variety of surface functionalities [73, 74]. MOFs functionalised with polymer chains by the click modulation protocol were very sensitive to the nature of the polymer. cal@UiO-66-L1PolyLact and cal@UiO-66-L2-PNIPAM were more efficiently internalised by HeLa cells compared to bare UiO-66, but no remarkable inhibition of mediated uptake routes was found while high suppression of cell uptake occurred upon sucrose pre-treatment, indicating that both might be internalised through clathrin- and/or non-mediated routes. Postsynthetic surface PEGylation resulted in enhanced uptake, while significant caveolae-mediated endocytosis was observed only for cal@UiO-66-L1-PEG2000 compared to cal@UiO-66-L1PEG550, meaning that the length of the PEG chains determines endocytosis pathways.

Postsynthetic coating with folic acid resulted in internalisation of cal@UiO-66-FA by HeLa cells through the caveolae-mediated route. This is so because HeLa cells overexpress the folate receptor (FR), which is mainly located in the caveolae invaginations [130]. Hence, UiO-66 cell internalisation was remarkably higher after folate coating compared to the bare MOF, due to folate targeting, and no notable clathrin-mediated uptake for internalisation of folate-coated MOFs was observed. Heparin coating also promoted caveolae-mediated cell internalisation of UiO-66, although clathrin-mediated route plays an important role on its cell uptake. A related study with folate coated PCN-224-FA showed that its internalisation by HeLa cells decreases when an excess of free folate was added, as a consequence of free folate biding to the FR, thus decreasing uptake and suggesting cell internalisation occurs through receptor-mediated endocytosis, although the specific uptake routes were not studied [83]. Folate-mediated endocytosis has also been proposed as the major route of internalisation of UiO-66- $\mathbf{N H}_{2}-\mathbf{F A}-\mathbf{5 - F A M}$, as HepG2 cells, which overexpress the FR, 
display strong green fluorescence after incubation with the folate-coated MOF $\left(0.1 \mathrm{mgmL}^{-1}\right.$ for 2 h), while HL-7702 human liver cells, which do not overexpress the folate receptor display no green fluorescence under the same conditions. In addition, HepG2 cells incubated with UiO-66- $\mathbf{N H}_{2}-5-F A M$, i.e. without folate coating, show no appreciable green fluorescence [94].

The endocytosis pathways of $\mathbf{Z r}$-fum- $\mathbf{H}_{6}$-GFP have been studied using the inherent fluorescence of the his-tagged green fluorescent protein. The cells were pre-incubated for 30 minutes with different concentration of the various inhibitors - in this case amiloride to suppress macropinocytosis [131], genistein to inhibit caveolae-mediated endocytosis [132], and chlorpromazine to inhibit clathrin-mediated uptake - and then incubated with the NMOFs for $2 \mathrm{~h}$. Using different concentrations of inhibitors allows assessment of doseresponsive inhibition to confirm the importance of the inhibited uptake route (Figure 18). The authors found that the peptide-coated NMOFs are mainly internalised by macropinocytosis, although minor contributions of the caveolae-mediated route is also observed. In general, higher levels of inhibition were found when cells were pre-treated with higher concentration of the inhibitors.

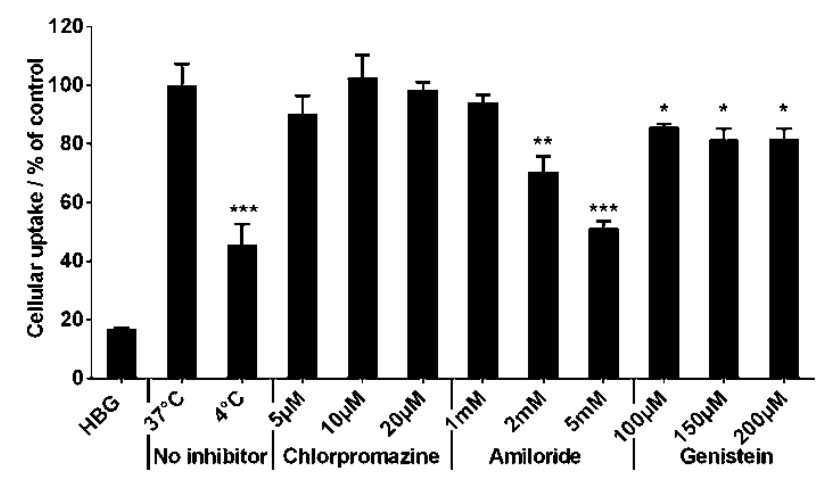

Figure 18. Cellular uptake of $\mathrm{Zr}$-fum coated with his-tagged green fluorescent protein in the presence of different inhibitors as measured by flow cytometry. Reproduced with permission from ref [85] copyright (2017) American Chemical Society.

Control of surface chemistry is clearly required to enhance endocytosis efficiency, but also to alter uptake pathways, whether by mimicking the chemistry of certain receptor sites (e.g. by PEGylation) or by directly targeting (e.g. folate receptors). Uptake by immune cells is also of great importance when considering an in vivo treatment, but examples of MOF internalisation by macrophages in the literature are relatively rare, and further work is clearly needed to understand this process and enhance NMOFs potential as DDS, by improving their uptake by cancerous cells while reducing immune cell recognition. Considering the 
amount of work into studying and enhancing cell internalisation of Zr MOFs by endocytosis processes, there is very little research into determining and understanding the exocytosis processes, which may also play an important role in their therapeutic efficiency. The exocytosis of other nanoparticulate materials has been studied in vitro, and shown that it tends to occur for longer incubation times, especially if the nanoparticles present in the incubation media are removed [133]. Being able to extend the time that the nanoparticles are present inside cells, or suppressing exocytosis processes while enhancing endocytosis processes, could be of vital importance to enhance the therapeutic effect of MOF-based systems.

\subsection{Biocompatibility of Zr MOFs}

The therapeutic efficiency of any DDS is strictly correlated to its ability to cross the cell membrane and successfully deliver the drug to the various cell compartments. As described in the previous sections, both cell internalisation rates and routes are of crucial importance for efficiency drug delivery, as well as low toxicity of the DDS and its ability to deliver active cargo into cells. Typically, in vitro cell proliferation experiments, such as (3-(4,5dimethylthiazol-2-yl)-5-(3-carboxymethoxyphenyl)-2-(4-sulfophenyl)-2H-tetrazolium) (MTS) and 3-(4,5-dimethylthiazol-2-yl)-2,5-diphenyltetrazolium bromide (MTT) assays after incubation of cells with the DDSs, are used as key initial evaluators of the effect of factors such as surface modification and drug loading.

It is important to note that comparisons between absolute values for cell proliferation determined from different laboratories can be significantly affected by experimental parameters such as MOF particle size, morphology, preparation method, residual solvent, and other variables such as the age of cells and how many times they have been passaged. For example, HeLa cells are known to mutate, and hence results might drastically differ between passages and labs [134]. Half inhibitory concentration $\left(\mathrm{IC}_{50}\right)$ values for the archetypal Zr MOF UiO-66 towards HeLa cervical cancer cells have been variously measured to be $1.50 \pm 0.15 \mathrm{mgmL}^{-1}(261 \pm 12 \mathrm{~nm}$, HCl modulation, MTS assay, $24 \mathrm{~h}$ incubation) [110], $0.40 \pm 0.01 \mathrm{mgmL}^{-1}(100 \pm 20 \mathrm{~nm}, \mathrm{HCl}$ modulation, MTT assay, $24 \mathrm{~h}$ incubation) [135], and $>1 \mathrm{mgmL}^{-1}$ (77 $\pm 24 \mathrm{~nm}$, DCA modulation, MTS assay, $72 \mathrm{~h}$ incubation) [74]. Nevertheless, these are still relatively high concentrations compared to expected clinically relevant doses. UiO-66, UiO-66- $\mathrm{NH}_{2}$ and $\mathrm{UiO}-67$ have also been found to be compatible with MCF-7 breast cancer cells up to $0.2 \mathrm{mgmL}^{-1}$, but of the trio, UiO-66- $\mathrm{NH}_{2}$ was found to be somewhat cytotoxic towards HepG2 liver cancer cells at this concentration 
[50]. The amino groups are expected to be protonated under physiological conditions; the more efficient internalisation of positively charged nanoparticles by cells, due to the negative potential of the cell membrane [114], could be one of the reasons why the cytotoxicity is more pronounced. ZJU-800 has also been proven non-cytotoxic in rat neuroblastic pheochromocytoma PC12 cells after incubation with a solution of $0.1 \mathrm{mgmL}^{-1}$ of NMOF for $24 \mathrm{~h}[111]$.

The biocompatibility of empty Zr MOFs has also been investigated before and after surface modifications. For example, the effect of UiO-66-NH-Q and capped UiO-66-NH-Q-Cp5 in HEK293 normal human kidney cells has been assessed using the MTT protocol, incubating

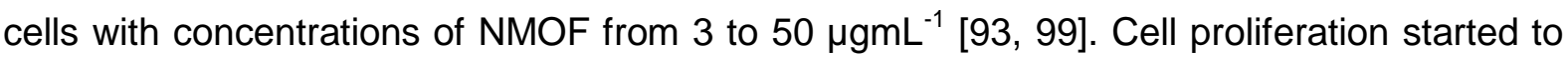
decrease when treated with a $25 \mu_{\mathrm{gmL}}^{-1}$ solution of UiO-66-NH-Q, while no effect on cell viability was observed after Cp5 capping for concentrations of MOF up to $50 \mu \mathrm{gmL}^{-1}$, again possibly as a consequence of the positive charges of amine-terminated UiO-66-NH-Q.

The biocompatibility of bare PCN-223 towards SMMC-7721 human hepatocellular carcinoma and HeLa cells was enhanced after PBLs coating [90], with nanoPCN-223@DOPC/DOPC being non-cytotoxic at concentrations of $0.4 \mathrm{mgmL}^{-1}$, while treatment with the same concentration of bare MOF decreased cell viability to $\sim 70 \%$, even though its cell internalisation efficiency is lower than for the coated MOF. A number of other Zr MOFs have been tested for in vitro biocompatibility as part of greater investigations into therapeutic activity (both photodynamic and through drug delivery) and will be described in the following sections.

\subsection{Photodynamic Therapy with Zr MOFs}

Photodynamic therapy (PDT) is based on the use of a photosensitizer that, after excitation with light, can transfer its excited state to neighbouring oxygen resulting in the generation of singlet oxygen $\left({ }^{1} \mathrm{O}_{2}\right)$ and reactive oxygen species (ROS), killing surrounding cells. Among sensitizers, porphyrin molecules have proven to be some of the most efficient. Hence, their incorporation into MOFs can result in targeted accumulation, which is necessary for selective cytotoxicity, and an enhancement of their therapeutic effect. Aggregation-based quenching is known to be one of the major problems that reduces generation of singlet oxygen species, and incorporation of sensitizers into MOFs has been proposed as an alternative to reduce this quenching effect, while favouring diffusion of singlet oxygen species out of the MOF matrix $[35,36]$. A number of examples of Zr-MOFs as PDT agents have emerged recently, 
mostly involving porphyrin-based samples, and showing very promising results that are represented in Table 5.

Table 5. Examples of Zr MOFs used for PDT.

\begin{tabular}{|c|c|c|c|c|c|}
\hline Sample & $\begin{array}{l}\text { Light Source } \\
\left(\mathrm{mWcm}^{-2}\right)\end{array}$ & Cell Lines & $\begin{array}{l}\text { Time } \\
(\min )\end{array}$ & PDT Efficacy & Ref \\
\hline UiO-PDT & Visible light (80) & $\begin{array}{l}\text { CT26, C26 } \\
\text { B16F10 }\end{array}$ & 10 & $\begin{array}{c}\text { CT26 IC } \mathrm{IC}_{50}=0.70 \mu \mathrm{gmL}^{-1} \\
\text { C26 IC } \\
\text { B16F10 IC }=1.15 \mu \mathrm{ImL}_{50}=0.51 \mathrm{gmL}^{-1}\end{array}$ & [100] \\
\hline $\begin{array}{c}\text { PCN-224 } \\
\text { PCN-224-FA }\end{array}$ & $\begin{array}{l}\text { Laser, } 420 \mathrm{~nm} \\
\text { and } 630 \mathrm{~nm}(100)\end{array}$ & HeLa, A549 & 30 & $\begin{array}{l}\text { 2-fold increase compared to linker; } \\
\text { Folate-targeting of HeLa cells }\end{array}$ & [83] \\
\hline 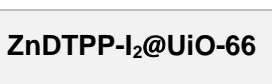 & $\begin{array}{l}\text { Green LED, } 540 \\
\mathrm{~nm}(20)\end{array}$ & HepG2 & 10 & $\begin{array}{l}<50 \% \text { proliferation at } 10 \mu \mathrm{gmL}^{-1} \mathrm{MOF} \text {; } \\
<25 \% \text { proliferation at } 40 \mu \mathrm{gmL}^{-1} \mathrm{MOF}\end{array}$ & [79] \\
\hline $\begin{array}{l}\text { UiO-66-TPP-SH } \\
\text { UiO-66-TCPP }\end{array}$ & $\begin{array}{l}\text { Laser, } 660 \mathrm{~nm} \\
\quad(100)\end{array}$ & HeLa & 10 & $\begin{array}{l}\text { UiO-66-TPP-SH higher phototoxicity } \\
\text { than UiO-66-TCPP and free TPP-SH }\end{array}$ & [80] \\
\hline PCN224-UCNP & $\begin{array}{l}\text { Laser, } 980 \mathrm{~nm}, \\
\quad(15900)\end{array}$ & MB-MDA-462 & 10,20 & $\begin{array}{l}<20 \% \text { proliferation at } 100 \mu \mathrm{gmL}^{-1} \\
\text { targeted MOF }\end{array}$ & [136] \\
\hline $\begin{array}{l}\text { Mn-doped } \\
\text { UiO-66-PEG }\end{array}$ & MW Irradiation & HepG2 & 2 & $25 \%$ proliferation at $62 \mu \mathrm{gmL}^{-1} \mathrm{MOF}$ & [96] \\
\hline
\end{tabular}

It is important that the PDT system only induces cytotoxicity under irradiation to limit offtarget effects. UiO-PDT, coated with a bodipy chromophore, induced no cytotoxicity towards mouse colon carcinoma C26 cells, murine colon carcinoma CT26 cells, and B16F10 mouse melanoma cells when incubated for $24 \mathrm{~h}$ at concentrations up to $1 \mathrm{mgmL}^{-1}$ in the dark [86]. As UiO-PDT can generate ${ }^{1} \mathrm{O}_{2}$ under light irradiation (Figures $19 \mathrm{a}$ and $19 \mathrm{~b}$ ) with similar efficiencies to I2-BDP (the free linker), determined by measurement of the degradation of 1,3-diphenylisobenzofuran (DPBF) by UV-Vis spectroscopy, the in vitro phototoxicity of UiO66-PDT (0-0.625 $\left.\mathrm{mgmL}^{-1}\right)$ could be assessed using the MTT assay with CT26, C26 and B16F10 cells (Figures 19c and 19d).

The authors observed that free I2-BDP has $\mathrm{IC}_{50}>15 \mu \mathrm{gmL}^{-1}$ in the dark, which decreases to $\mathrm{IC}_{50}<0.8 \mathrm{\mu gmL}^{-1}$ when irradiated at a power density of $80 \mathrm{mWcm}^{-2}$ for $10 \mathrm{~min}$ under visible light for the studied cell lines. UiO-PDT has similar cytotoxicity values to free I2-BDP under light irradiation, with $\mathrm{IC}_{50}$ values of $0.70,1.15$ and $0.51 \mu \mathrm{gmL}^{-1}$ for $\mathrm{B} 16 \mathrm{~F} 10, \mathrm{CT} 26$ and C26 cells, in turn, despite the higher cell internalisation of UiO-66-PDT compared to I2-BDP, as determined by FACS. The fact that I2-BDP is present at $30 \%$ loading in UiO-PDT, coupled with the free bodipy molecule potentially undergoing passive diffusion and thus being located in the cytoplasm rather than in vesicles, might be the reason why there is not a more pronounced cytotoxic effect when cells are incubated UiO-PDT, together with the fact that free linker has a slightly better ability to generate ${ }^{1} \mathrm{O}_{2}$. 

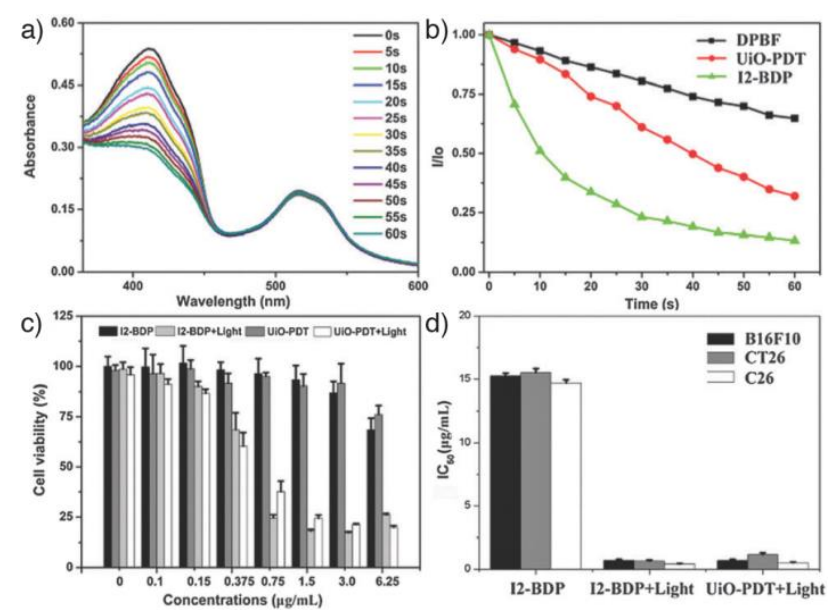

Figure 19. UV/Vis spectroscopic measurement (degradation of DPBF) of singlet oxygen $\left({ }^{1} \mathrm{O}_{2}\right)$ generation by UiO-PDT in DMF (LED, $20 \mathrm{mWcm}^{-2}, 60 \mathrm{~s}$ ). (b) Quantification of ${ }^{1} \mathrm{O}_{2}$ generation ability showing the degradation of DPBF over time: DPBF control, DPBF in the presence of UiO-PDT, and free I2-BDP after light irradiation. (c) In vitro cytotoxicities (MTT assay) of free I2-BDP and UiO-PDT towards B16F10 cells before and after light irradiation (visible light, $80 \mathrm{mWcm}^{-2}, 10 \mathrm{~min}$ ). (d) $\mathrm{IC}_{50}$ values of I2-BDP and UiO-PDT with and without light irradiation for different cell lines. Modified with permission from ref [86] copyright (2016) The Royal Society of Chemistry.

The potential of five samples of PCN-224 of different particle sizes as PDT devices was also tested on HeLa cells, and therapeutic efficiency was consistent with the cell uptake results [83]. Particles of $90 \mathrm{~nm}$ size, which were the most efficiently internalised size fraction, were also the most cytotoxic under light irradiation (laser, $420 \mathrm{~nm}$ and $630 \mathrm{~nm}$ ), while no remarkable effect on cell proliferation was found in dark. PCN-224 exhibits a two-fold increase in cytotoxicity compared to the free TCPP linker, suggesting that incorporation into the MOF scaffold enhances efficiency. HeLa cells overexpress the folate receptor, and thus coating the MOF with folic acid resulted in an enhancement of the therapeutic efficiency of PCN-224-FA in comparison to the unmodified MOF. A control experiment, in which FR negative cells (human lung carcinoma A549 cells) were treated with PCN-224-FA and bare PCN-224 was performed, showing no enhancement in either cell internalisation or PDT efficacy upon folate coating.

Zn-TDPP-I ${ }_{2} @ U i$-66 was found to have higher ${ }^{1} \mathrm{O}_{2}$ production efficiency than an analogous sample without iodine atoms, attributed to the heavy atom effect. Importantly, the Zn-TDPP$\mathrm{I}_{2}$ doped MOF exhibited higher ${ }^{1} \mathrm{O}_{2}$ generation than free $\mathrm{Zn}$-TDPP $-\mathrm{I}_{2}$. In vitro PDT against HepG2 liver cancer cells was investigated by the MTT cell proliferation assay. Zn-TDPP$\mathrm{I}_{2} @ U i O-66$ was proven biocompatible, with $\sim 87 \%$ cell viability when cells where treated with $60 \mu \mathrm{g} / \mathrm{mL}$ in dark, while a remarkable decrease in cell proliferation was found upon LED light 
irradiation $\left(\lambda=\sim 540 \mathrm{~nm}\right.$ ), with $50 \%$ cell viability for a concentration of $10 \mu \mathrm{gmL}^{-1}$ of MOF, and less than $25 \%$ at a concentration of $40 \mathrm{\mu gmL}^{-1}$ [79].

UiO-66 surface functionalised with a thiol-modified porphyrin, UiO-66-TPP-SH, was postulated to increase therapeutic efficiency based on the fact that ROS are highly reactive and have short half-lives [80]. Therefore, PDT can only directly and efficiently affect the cells that are proximal to the ROS producing area, and so location of the photosensitizer on the external surface of NMOFs might be a key factor to enhance PDT efficiency. In fact, ${ }^{1} \mathrm{O}_{2}$ generation by UiO-66-TPP-SH was more efficient than for the porphyrin (TPP-SH) alone (Figures 20a and 20b), indicating that surface-decorated TPP-SH on the MOF surfaces were well separated, and their agglomeration and self-quenching of the excited states were effectively avoided. Additionally, UiO-66-TPP-SH has higher ${ }^{1} \mathrm{O}_{2}$ generation than an analogous sample TCPP@UiO-66, in which TCPP was trapped in the core of the structure during synthesis; TCPP located inside the matrix might be inefficient due to singlet oxygen diffusion issues. ${ }^{1} \mathrm{O}_{2}$ generation inside HeLa cells under laser irradiation (Figure 20c) was assessed by the 2',7'-dichlorodihydrofluorescein diacetate (DCFH-DA) assay and found to correlate well with the UV/Vis spectroscopic analysis.

MTT assays (0-15 $\mu \mathrm{gmL}^{-1}$ MOF and $0-0.56 \mu \mathrm{gmL}^{-1}$ of equivalent porphyrin, Figures $20 \mathrm{~d}$ and e) confirmed the MOF to be biocompatible with no cytotoxicity in the dark. In agreement with ${ }^{1} \mathrm{O}_{2}$ generation efficiency, a decrease in proliferation of $\sim 70 \%$ occurred upon light irradiation (100 mW for $10 \mathrm{~min}$ ) after incubation with $15 \mu \mathrm{gmL}^{-1}$ of UiO-66-TPP-SH, while UiO-66-TCPP displayed a decrease of only $\sim 41 \%$ under the same conditions. TPP-SH had no dark cytotoxicity and, even at high concentrations of $5 \mathrm{\mu gmL}^{-1}$, only decreased cell proliferation by $12 \%$ under light irradiation, highlighting the enhancement in its phototoxicity when attached to the external surface of UiO-66 [80]. 

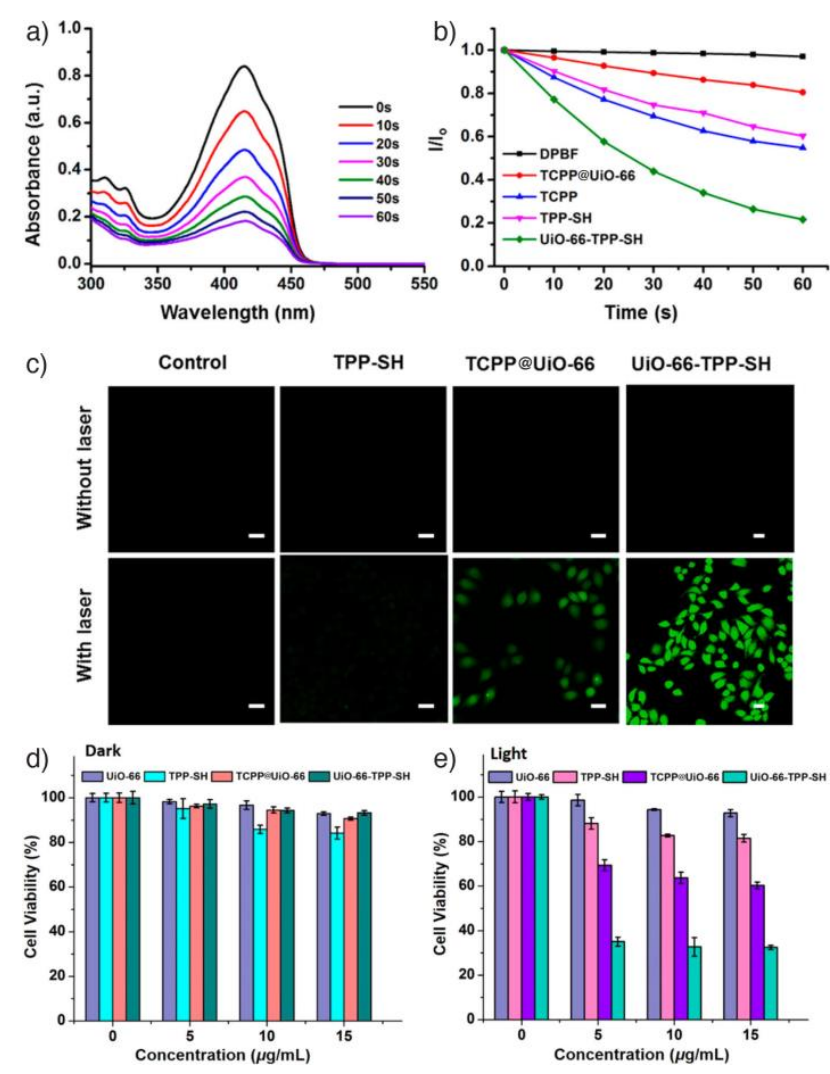

Figure 20. a) Time-dependent UV/Vis spectroscopic measurement (degradation of DPBF) of ${ }^{1} \mathrm{O}_{2}$ generation by UiO-66-TPP-SH in DMF (2.5 $\mu \mathrm{M}$ porphyrin equiv, $660 \mathrm{~nm}$ laser, $\left.20 \mathrm{mWcm}^{-2}, 60 \mathrm{~s}\right)$. b) Comparison of DPBF degradation, a consequence of ${ }^{1} \mathrm{O}_{2}$ generation, by TPP-SH $(2.5 \mu \mathrm{M})$, TCPP $(2.5$ $\mu \mathrm{M})$, UiO-66-TPP-SH (2.5 $\mu \mathrm{M}$ porphyrin equiv), and TCPP@UiO-66 (2.5 $\mu \mathrm{M}$ porphyrin equiv) compared to a control of free DPBF. c) Intracellular ${ }^{1} \mathrm{O}_{2}$ generation induced by TPP-SH $\left(15 \mu \mathrm{gmL}^{-1}\right.$, $18 \mu \mathrm{M}$ porphyrin equiv), TCPP@UiO-66 (15 $\mathrm{gmL}^{-1}, 0.56 \mu \mathrm{M}$ porphyrin equiv), and UiO-66-TPP-SH (15 $\mathrm{\mu gmL}^{-1}, 0.56 \mu \mathrm{M}$ porphyrin equiv) in HeLa cells $\left(660 \mathrm{~nm}, 100 \mathrm{mWcm}^{-2}, 5 \mathrm{~min}\right.$ ) using 2',7'dichlorodihydrofluorescein diacetate (DCFH-DA) assay. Scale bar $=50 \mu \mathrm{m}$. HeLa cell proliferation (MTT assay) for $2 \mathrm{~h}$ incubation with UiO-66, TPP-SH, TCPP@UiO-66, and UiO-66-TPP-SH d) without, and e) with irradiation (660 nm laser, $100 \mathrm{mWcm}^{-2}, 10 \mathrm{~min}$ ). Modified with permission from ref [80] copyright (2018) American Chemical Society.

Inorganic units have also been incorporated to Zr MOFs for PDT. PCN-224 was surface modified with DNA strands by a sequential coordination / amide coupling / SPAAC protocol, and the single strands were hybridised with complementary sequences to attach $\mathrm{NaFY}_{4}: \mathrm{Yb} / \mathrm{Er}$ upconverting nanoparticles (UCNPs) to give PCN-224-UCNP [136]. The hybrid was found to generate ${ }^{1} \mathrm{O}_{2}$ under near-infrared (NIR) irradiation (laser, $\lambda=980 \mathrm{~nm}, 500 \mathrm{~mW}$, $15.9 \mathrm{Wcm}^{-2}$ ) using the fluorescent Singlet Oxygen Sensor Green assay, with increasing ratios of UCNP to MOF increasing ${ }^{1} \mathrm{O}_{2}$ generation. The MOF was subsequently PEGylated with thiol-modified PEG2000, and MTT assays showed that MB-MDA-468 human breast 
cancer cell proliferation was not negatively affected up to concentrations of $150 \mu \mathrm{gmL}^{-1}$. Assessment of PDT efficiency was carried out on the same cells after incubation with 100 $\mu \mathrm{gmL}^{-1}$ of MOF for $4 \mathrm{~h}$, followed by NIR laser irradiation for 10 or $20 \mathrm{~min}$, and a further $12 \mathrm{~h}$ incubation. MTT assays showed no adverse effect from MOFs without UCNPs, with or without irradiation, but PCN-224-UCNP samples showed $50-60 \%$ decreases in proliferation after irradiation, with irradiation time not significantly affecting the results. Further increases in PDT efficiency $(70-80 \%$ decrease in proliferation) could be achieved by attaching epidermal growth factor receptor affibodies - small targeting proteins - to the free amines of the UCNPs through succinimidyl 4-( $N$-maleimidomethyl) cyclohexane-1-carboxylate groups on the affibodies, demonstrating the power of the targeting approach.

Whilst PDT uses electromagnetic irradiation to generate ROS that kill surrounding cells, an example has also been shown to use microwave (MW) irradiation to promote their formation. Mn-doped UiO-66-PEG was studied for microwave dynamic therapy and for microwave thermal therapy [96]. While no increase in temperature was found in water containing the MOF after irradiation $(1.8 \mathrm{~W}, 450 \mathrm{MHz})$ for $5 \mathrm{~min}$, the temperature of $\mathrm{NaCl}$ solution $(0.9 \%)$ containing the MOF rose rapidly, meaning that ions play a key role in the increase of temperature under MW irradiation, probably due to the strong inelastic collision between ions and the framework. The MOF showed peroxidase-like activity, catalysing the conversion of $\mathrm{H}_{2} \mathrm{O}_{2}$ to ${ }^{\circ} \mathrm{OH}$ under MW irradiation, increasing with both irradiation time and MOF and $\mathrm{H}_{2} \mathrm{O}_{2}$ concentrations, whereas controls without MOF show no ${ }^{\circ} \mathrm{OH}$ generation.

Infrared thermal imaging was used to monitor the temperature of HepG2 cells during the MTT cell proliferation assay, showing an increase to $45^{\circ} \mathrm{C}$ after 2 min at MW irradiation of $0.9 \mathrm{~W}$ when cells are incubated with $62 \mathrm{\mu gmL}^{-1}$ of MOF. After $24 \mathrm{~h}$ of MOF incubation (63 $\mu \mathrm{gmL}^{-1}$ ) with HepG2 cells without $\mathrm{MW}$ irradiation, $80 \%$ cell proliferation was observed, demonstrating good biocompatibility, while incubation with the same concentration of MOF under MW irradiation resulted in only $\sim 25 \%$ cell proliferation. A control in which cells were immersed in a water bath at $45{ }^{\circ} \mathrm{C}$ resulted in cell proliferation of $>80 \%$, suggesting that the cytotoxic effect is due to incubation with the MOF under mild MW irradiation. To elucidate the mechanism, the authors used 2,7-dichlorofluorescein diacetate (DCFH-DA), a reactive oxygen species index probe that can be oxidized in the presence of ROS and exhibits green fluorescence upon excitation at $520 \mathrm{~nm}$. Quantification of hydroxyl radicals in HepG2 cells with or without irradiation upon incubation with the MOFs was performed, showing indeed that cytotoxicity is a result of ROS generation upon incubation with the MOF under MW irradiation. Control groups showed no fluorescence, and only a small green fluorescence 
signal was found in the control of MOF without irradiation, while strong fluorescence was observed in the cell treated the MOF and irradiation.

\subsection{Drug Delivery from Zr MOFs}

The biocompatibility of Zr-MOFs, combined with their high storage capacities, excellent stabilities and controlled release of cargo, has led to many reports into both in vitro and in vivo anticancer activity. As a first port of call, the efficiency of therapeutic cargo delivery into cells is monitored in vitro, often by comparing cell proliferation in the presence of the drugloaded MOF with that of the free drug and the empty MOF. A summary of the most relevant in vitro studies carried out with Zr MOFs is given in Table 6.

The therapeutic efficiency of UiO-66-AL, coated on its surface with the drug alendronate, was tested in human breast cancer MCF-7 and human liver carcinoma HepG2 cells using the MTT assay [84]. The authors found that after $24 \mathrm{~h}$ of incubation, the free drug had a higher effect than the loaded NMOFs, while after $48 \mathrm{~h}$, incubation with UiO-66-AL decreased cell proliferation to a slightly higher extent than when cells were treated with a solution of the same free drug concentration (Figures 21a-c). These results could indicate slow uptake of the MOF or particles reaching different intracellular locations after different time periods, but it is also important to consider that if the MOF itself degrades during the incubation time, the free drug subsequently present in the growth media could then be internalised through passive diffusion and thus inhibit cancer cell growth.

a-Cyano-4-hydroxycinnamic acid ( $\alpha-\mathrm{CHC}$ ) has been proposed as an anticancer drug [137], and can be loaded postsynthetically into Zr MOFs. An investigation of the delivery of $\alpha-\mathrm{CHC}$ into HeLa cells by UiO series MOFs showed that cell proliferation was dependent on the endocytosis pathways of the MOFs [105]. As UiO-66 is internalised through clathrinmediated endocytosis, $\boldsymbol{\alpha}-\mathbf{C H C} @ U i 0-66$ (31\% w/w $\alpha-\mathrm{CHC}$ loading) did not have a negative effect on HeLa cells after incubation for $24 \mathrm{~h}$, but as UiO-67 partially undergoes caveolaemediated endocytosis, incubation with $\alpha$-CHC@UiO-67 (20\% w/w a-CHC loading, 0.25-1 $\mathrm{mgmL}^{-1}$ ) decreased cell proliferation to $<70 \%$ for the concentrations studied, while the empty MOF was non-cytotoxic. 

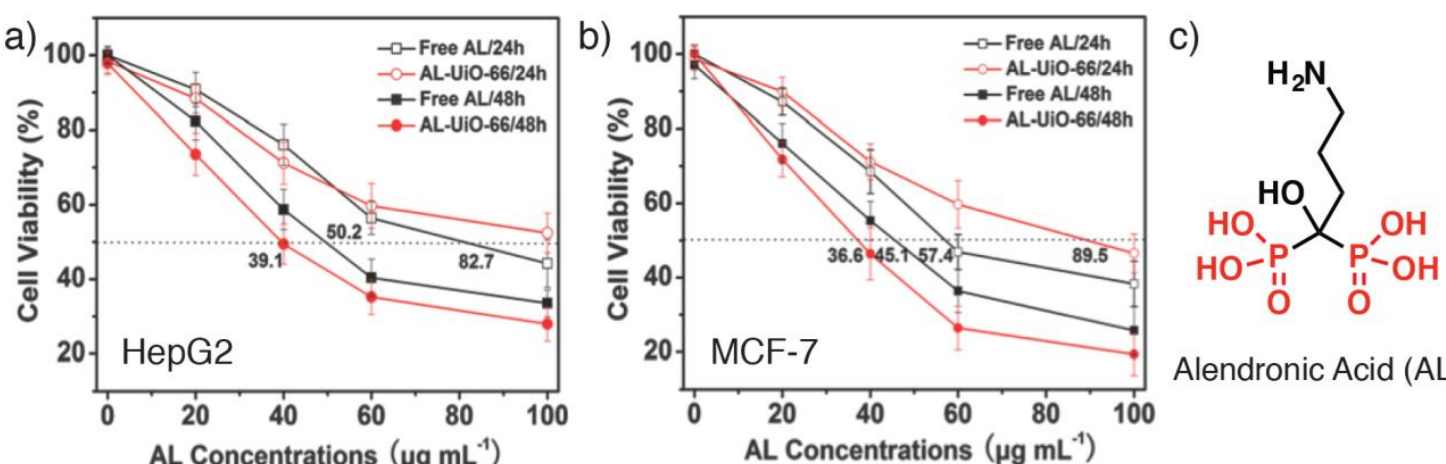

Alendronic Acid $(A L)$
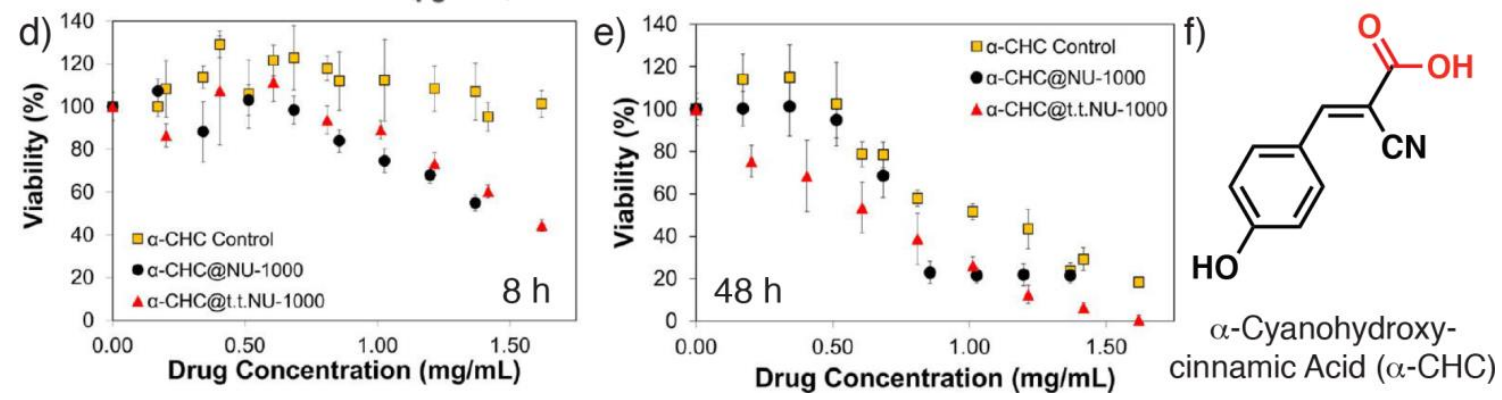

Figure 21. Cell proliferation assays (MTT) for a) HepG2, and b) MCF-7 cells after incubation with free alendronate (AL) and AL@UiO-66. Modified with permission from ref [84] copyright (2014) The Royal Society of Chemistry. c) Chemical structure of alendronic acid with its coordinating units highlighted. Cell proliferation assays (MTS) for HeLa cells after incubation with free $\alpha$-cyanohydroxycinnamic acid $(\alpha-\mathrm{CHC})$ and $\alpha-\mathrm{CHC} @ N U-1000$ before and after thermal amorphisation for d) $8 \mathrm{~h}$, and e) $48 \mathrm{~h}$. Modified with permission from ref [112] copyright (2017) American Chemical Society. f) Chemical structure of $\alpha-\mathrm{CHC}$ with its coordinating units highlighted.

Due to the larger porosities of NU-1000 and NU-901, $\alpha-\mathrm{CHC}$ loadings of up to $81 \% \mathrm{w} / \mathrm{w}$ have been reached. The therapeutic effect in HeLa cells of $\alpha-\mathrm{CHC}$ loaded NU-1000 and NU901 before and after amorphisation through temperature treatment was studied using the MTS assay and compared to a control in which the cells were incubated with a solution of the same concentration of free drug [112]. Although both $\alpha-C H C @ N U-1000$ and $\alpha-C H C @ t t-$ NU-1000 induce higher cell cytotoxicity than the free drug, there is no real difference between pristine and amorphised MOF after $8 \mathrm{~h}$ incubation. The enhancement in cytotoxicity compared to the free drug could be a consequence of its greater internalisation when loaded in the DDS compared to passive diffusion, and to the internalisation of the MOF through caveolae-mediated endocytosis, enabling endosomal escape. After $48 \mathrm{~h}$ of incubation time a notable difference upon temperature treatment was found, especially for lower concentrations of the temperature-treated NU-1000. While the free drug and $a-C H C @ N U-$ 1000 did not induce any cytotoxicity up to $0.6 \mathrm{mgmL}^{-1}$ drug concentration, cell proliferation decreased to $\sim 80 \%$ for $0.2 \mathrm{mgmL}^{-1} \alpha-\mathrm{CHC}$ loaded in thermally treated NU-1000, while $\alpha-$ $\mathrm{CHC} @ \mathrm{tt}-\mathrm{NU}-1000$ killed all cells at a drug concentration of $1.60 \mathrm{mgmL}^{-1}$ of drug (Figures 
21d-21f). Similar behaviour is observed for a-CHC@NU-901 and a-CHC@tt-NU-901, which have the same effect on HeLa cell viability after $11 \mathrm{~h}$ of incubation, again showing considerably more cytotoxicity than the free drug, while after $48 \mathrm{~h}$ of treatment, the efficacy of the thermally treated sample difference is more pronounced at lower concentrations. The authors also used structured illumination microscopy (SIM) to visualise cellular uptake of calcein loaded MOFs in real time.

Table 6. Examples of in vitro drug delivery from Zr MOFs.

\begin{tabular}{|c|c|c|c|c|}
\hline MOF & Drug Loading & Cell line & Drug Delivery Efficacy & Ref \\
\hline UiO-66-AL & $\begin{array}{c}\mathrm{AL} \\
51.4 \% w / w\end{array}$ & $\begin{array}{l}\text { MCF-7 } \\
\text { HepG2 }\end{array}$ & $\begin{array}{l}\text { Higher cytotoxicity than the free } \\
\text { drug }\end{array}$ & {$[84]$} \\
\hline $\begin{array}{l}\text { NU-1000 } \\
\text { NU-901 }\end{array}$ & $\begin{array}{c}\alpha-\mathrm{CHC} \\
\sim 81 \% w / w\end{array}$ & HeLa & $\begin{array}{c}\text { Higher cytotoxicity than the free } \\
\text { drug; } \\
\text { Enhancements from thermal } \\
\text { amorphisation }\end{array}$ & [112] \\
\hline $\begin{array}{l}\text { UiO-66-X } \\
\text { DUT-52 } \\
\text { UiO-67 }\end{array}$ & $\begin{array}{c}\alpha-\mathrm{CHC} \\
\sim 30 \% w / w\end{array}$ & HeLa & $\begin{array}{l}\text { Cytotoxicity accordingly with } \\
\text { endocytosis routes of } \\
\text { internalisation }\end{array}$ & [105] \\
\hline $\begin{array}{l}\text { UiO-66 } \\
\text { UiO-66-Hep } \\
\text { UiO-66-Biot }\end{array}$ & $\begin{array}{c}\text { DCA } \\
10-20 \% w / w\end{array}$ & HeLa & $\begin{array}{l}\text { No cytotoxicity, related to } \\
\text { endocytosis studies }\end{array}$ & {$[74]$} \\
\hline $\begin{array}{c}\text { UiO-66-FA } \\
\text { UiO-66-L1-PolyLact } \\
\text { UiO-66-L1-PEG2000 } \\
\text { UiO-66-L2-PNIPAM }\end{array}$ & $\begin{array}{c}\text { DCA } \\
10-20 \% w / w\end{array}$ & $\begin{array}{c}\text { HeLa } \\
\text { MCF-7 } \\
\text { HEK293 } \\
\text { J774 } \\
\text { Human Iymphocytes }\end{array}$ & $\begin{array}{l}\text { Higher anticancer efficiency } \\
\text { than the free drug; } \\
\text { Surface dependent selective } \\
\text { anticancer cytotoxicity related to } \\
\text { endocytosis routes }\end{array}$ & {$[73],[74]$} \\
\hline $\begin{array}{l}\text { UiO-66-X } \\
\text { DUT-52 } \\
\text { UiO-67 }\end{array}$ & $\begin{array}{c}\text { DCA } \\
\sim 7-26 \% w / w\end{array}$ & MCF-7 & $\begin{array}{l}\text { Higher anticancer efficiency } \\
\text { than the free drug related to } \\
\text { endocytosis routes }\end{array}$ & [78] \\
\hline $\begin{array}{l}\text { UiO-66-X } \\
\text { DUT-52 } \\
\text { UiO-67 }\end{array}$ & $\begin{array}{c}\text { DCA } ~ 7-26 \% w / w \\
5-F U \sim 1-4 \% w / w\end{array}$ & MCF-7 & $\begin{array}{l}\text { Synergistic DCA and 5-FU } \\
\text { enhanced cytotoxicity; } \\
\text { Cytotoxicity related to } \\
\text { endocytosis routes }\end{array}$ & [78] \\
\hline UiO-66-NH ${ }_{2}-\mathrm{FA}-5-\mathrm{FAM}$ & $\begin{array}{c}5-\mathrm{FU} \\
\text { Up to } 26 \% w / w\end{array}$ & HepG2 & $\begin{array}{l}\text { No apparent enhancement in } \\
\text { cytotoxicity compared to the } \\
\text { free drug }\end{array}$ & [94] \\
\hline $\begin{array}{l}\text { Zr-fum-H }- \text { Tags } \\
\text { (Bak, Bad, KLK) } \\
\text { Cytc }\end{array}$ & $\begin{array}{l}\text { Pro-apoptosis } \\
\text { peptides } \\
\text { Cytochrome c } \\
\text { protein }\end{array}$ & HeLa & $\begin{array}{c}\text { Higher cytotoxicicty than free } \\
\text { peptides }\end{array}$ & [85] \\
\hline siRNA-UiO-Cis & $\begin{array}{l}\text { siRNA; } \\
\text { Cisplatin } \\
12.3 \% \mathrm{w} / \mathrm{w}\end{array}$ & $\begin{array}{l}\text { SKOV-3 } \\
\text { MCF-7 } \\
\text { H460 } \\
\text { A2780 }\end{array}$ & $\begin{array}{l}\text { siRNA gene silencing; } \\
\text { Enhanced cytotoxicity towards } \\
\text { cis-platin resistant cell lines }\end{array}$ & [87] \\
\hline $\begin{array}{l}\text { UiO-68- } \mathrm{N}_{3} \text {-DNA } \\
\text { conjugates }\end{array}$ & $\begin{array}{c}\text { DOX } \\
52.8 \mu \text { mols } \\
\text { DOX.per gram of } \\
\text { MOF }\end{array}$ & $\begin{array}{l}\text { MDA-MB-231 } \\
\text { MFC-10A }\end{array}$ & $\begin{array}{l}\text { Higher anticancer efficiency } \\
\text { than the free drug; } \\
\text { Stimuli-responsive cytotoxicity } \\
\text { towards cancer cells; } \\
\text { Nucleolin targeting enhances } \\
\text { cytotoxicity }\end{array}$ & {$[98]$} \\
\hline $\begin{array}{c}\mathrm{Zr}_{89} \mathrm{UiO}-66-\mathrm{Py}-\mathrm{PGA}- \\
\text { PEG-F3 }\end{array}$ & $\begin{array}{c}\text { DOX } \\
50 \% w / w\end{array}$ & $\begin{array}{l}\text { MDA-MB-231 } \\
\text { L929 }\end{array}$ & $\begin{array}{c}\text { Enhanced cytotoxicity by } \\
\text { nucleolin targeting (F3 peptide) }\end{array}$ & {$[100]$} \\
\hline $\begin{array}{c}\text { DOX@ } \\
\mathrm{Fe}_{3} \mathrm{O}_{4} @ U i O-66-\mathrm{NH}_{2}\end{array}$ & DOX & $\begin{array}{l}\text { HeLa } \\
\text { 3T3 }\end{array}$ & Selective anticancer cytotoxicity & [141] \\
\hline
\end{tabular}


We have investigated the therapeutic efficiency of a series of surface functionalised UiO-66 MOFs where the anticancer probe molecule, dichloroacetic acid (DCA), can been loaded during synthesis by using it as a modulator [73]. As DCA is a pyruvate dehydrogenase kinase inhibitor, it is only cytotoxic if it can cross the cell membrane and reach the cytosol, hence it is an excellent probe molecule for drug delivery from MOFs, as its $I_{50}$ value is the milimolar range, and therapeutic enhancement will indicate good cellular internalisation. Additionally, defect incorporation of drugs during synthesis is a protocol that is also compatible with further drug loading or surface functionalisation. Initially, it was found that the change in HeLa endocytosis pathway induced by PEGylation of UiO-66 meant that DCA@UiO-66-L1-PEG2000, which is internalised by caveolae-mediated endocytosis, decreased HeLa cell proliferation to $\sim 50 \%$ when incubated with $1 \mathrm{mgmL}^{-1} \mathrm{MOF}$, whereas DCA@UiO-66, which is internalised by clathrin-mediated endocytosis, had no effect. The efficacy of the intracellular delivery of DCA is highlighted by the fact that the $\mathrm{IC}_{50}$ of the free drug is close to $3 \mathrm{mgmL}^{-1}$ [138], yet delivery of $\sim 0.1 \mathrm{mgmL}^{-1}$ DCA in DCA@UiO-66-L1PEG2000 induces significant cytotoxicity.

The surface chemistry of the MOF can also be modified by linker functionalisation. An isoreticular series of Zr MOFs with different linkers were prepared by DCA modulation; only minor cytotoxic effects towards MCF-7 breast cancer cells were found for DCA@UiO-66-Br and DCA@UiO-66-NO $\mathrm{N}_{2}$, whereas DCA@DUT-52 and DCA@UiO-67 were the most therapeutically efficient MOFs despite their lower DCA content, suggesting that caveolaemediated endocytosis, which plays a more important role for the latter two MOFs, enhances cytotoxicity (Figure 22a). DCA@UiO-66- $\mathrm{NH}_{2}$ also showed high therapeutic efficacy, possibly as a consequence of the positive charge of the pendant amino groups under physiological conditions. Decreasing particle size from $\sim 150 \mathrm{~nm}$ to $\sim 15-25 \mathrm{~nm}$ can further enhance cytotoxicity somewhat, possibly due to passive diffusion of nanoparticles into cells, but not to the same extent as control of surface chemistry [78].

We have also examined the effect of different polymer coatings of UiO-66 across additional cell lines; MCF-7 breast cancer cells, HEK293 human embryonic kidney cells, J744 macrophages and peripheral blood lymphocytes isolated from the blood of human donors [74]. Similar trends to the HeLa experiments were observed when MCF-7 cells were treated with the bare and PEGylated DCA@UiO-66, but DCA@UiO-66-L1-PEG2000 induced unwanted cytotoxicity to human embryonic kidney HEK293 cells at high doses, without any remarkable negative effects on macrophage or lymphocyte proliferation. Empty UiO-66 coated with thermally-responsive PNIPAM was found to be cytotoxic against HeLa cells at concentrations of MOF of $0.5 \mathrm{mgmL}^{-1}$ during $72 \mathrm{~h}$ of incubation, although empty poly-L- 
lactide coated UiO-66 was biocompatible up to $1 \mathrm{mgmL}^{-1}$. Despite both DCA-loaded samples reducing the proliferation of both cervical and breast cancer cells, they were found to be cytotoxic also for HEK293 kidney cells. Both DCA@UiO-66-L1-PolyLact and DCA@UiO-66L2-PNIPAM induced cytotoxicity and ROS production in $\mathrm{J774}$ macrophages and human peripheral blood lymphocytes, suggesting incompatibility with the immune system. Interestingly, none of the empty samples had notable negative effects on cell growth and ROS production, indicating that it is the synergic effect of the polymers surface coating and DCA which induces cells cytotoxicity, and that the surface coating must be carefully selected to avoid unwanted off-target effects.
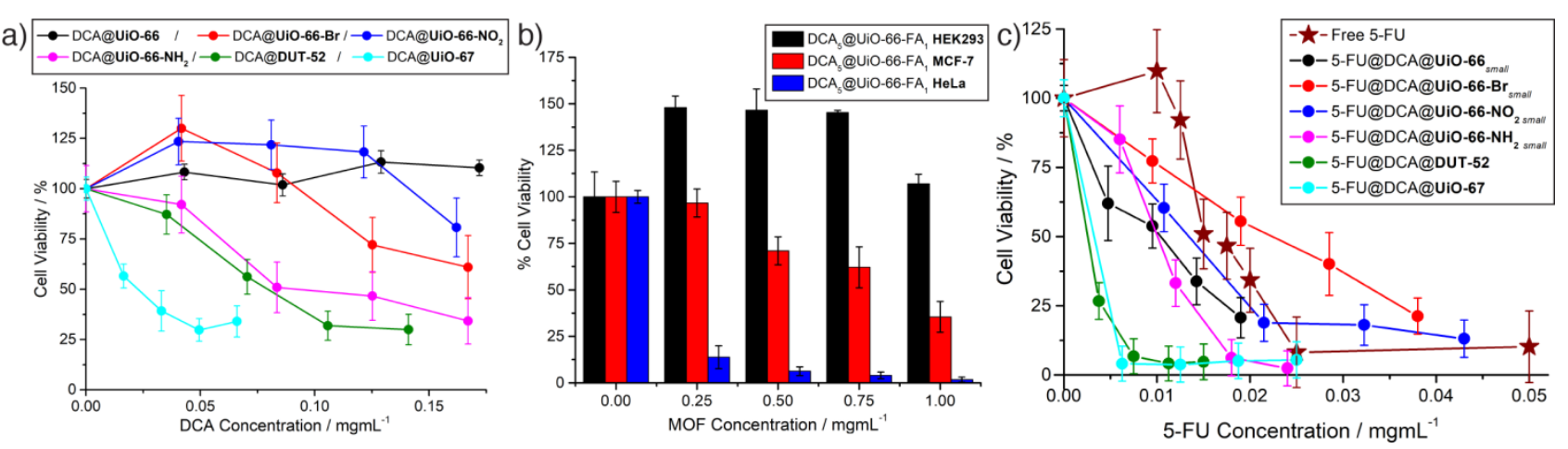

Figure 22. Cell proliferation assays (MTS, 72 h) for a) MCF-7 cells incubated with DCA-loaded members of the UiO-66 isoreticular series, ranked by delivered DCA concentration, b) DCA $@$ @UiO-66$F_{1}(C M)$ incubated with HeLa, MCF-7 and HEK293 cells, showing selective anticancer cytotoxicity, and c) MCF-7 cells incubated with DCA- (coordination modulation) and 5-FU- (postsynthetic) loaded UiO-66 isoreticular series MOFs, ranked by delivered 5-FU concentration and compared to free 5-FU. Modified with permission from ref [78] copyright (2018) The Royal Society of Chemistry and ref [74] copyright (2017) American Chemical Society.

Functionalising nanoparticles with targeting units can increase their cellular uptake efficiencies and direct DDSs to specific sites of disease, potentially reducing off-target effects. We have assessed different methods of functionalising UiO-66 with folic acid, which is a known targeting strategy for several cancers, incorporating folate both during synthesis and postsynthetically [74]. After $72 \mathrm{~h}$ of incubation the empty folate coated MOFs did not induce any negative effect on HeLa cell proliferation up to $1 \mathrm{mgmL}^{-1}$ of NMOF, while DCAloaded, folate-coated MOFs have different dose-responsive effects on cell viability, related to the DCA and folate contents and the stability of the samples. Samples prepared by postsynthetic folate coating of DCA@UiO-66 were less cytotoxic towards HeLa cells, possibly due to free folate being released from the MOF during the incubation time and binding to the folate receptor expressed on the surface of cancer cells, thus decreasing MOF 
uptake. Samples prepared in a one-pot synthesis where folic acid and DCA act as modulators tended to be more cytotoxic, since folic acid can be attached to the $\mathrm{Zr}$ clusters in the defect sites in the core of the structure as well as at the surface. The power of folate targeting was evident in the fact that $\mathbf{D C A}_{5} @ U i$-66-FA $(\mathbf{C M})$, which has a higher folate coating and a lower DCA content, induced more cytotoxicity, despite containing less DCA than $\mathbf{D C A}_{10} @ U i$-66-FA $\mathbf{A}_{\mathbf{2 5}}(\mathbf{C M})$, which has a higher DCA content and a lower folate coating.

The most efficient sample, DCA ${ }_{5} @ U i O-66-F A_{1}$ was also tested against the MCF-7 cell line, which has a lower overexpression of the FR compared to HeLa cells [139], and cell growth was inhibited to lesser extent compare to HeLa cells (Figure 22b). DCA $@$ @UiO-66-FA 1 was biocompatible with HEK293 cells up to $1 \mathrm{mgmL}^{-1}$ of NMOF over $72 \mathrm{~h}$ of incubation, while both empty and DCA-loaded UiO-66-FA were found to be non-cytotoxic towards $\mathrm{J774}$ macrophages and human peripheral blood lymphocytes over $48 \mathrm{~h}$, not generating significant ROS production, and thus confirming the efficiency of folate targeting and suggesting the validity of these DDSs for in vivo treatment.

The use of DCA as a modulator results in UiO-66 nanoparticles loaded with DCA at defect sites but with excellent porosity for postsynthetic storage of additional drugs. This dual-drug strategy was exploited to prepare 5-FU@DCA@MOFs, which were found to affect proliferation of MCF-7 cells much more significantly compared to their precursor DCA@MOFs [78]. Comparison of their effect on cell proliferation to free 5-FU showed surface chemistry dependence, following similar trends to the DCA precursors: 5FU@DCA@UiO-67 and 5-FU@DCA@DUT-52 ( 200 nm) were the most cytotoxic, followed by 5-FU@DCA@UiO-66 and 5-FU@DCA@UiO-66- $\mathrm{NH}_{2}$, all of them significantly more active than free 5-FU, whereas 5-FU@DCA@UiO-66- $\mathbf{N O}_{2}$ had a similar effect on cell proliferation to 5-FU, and performance of 5-FU@DCA@UiO-66-Br was worse than the free drug (Figure 22c). The UiO-66 derivative MOFs with electron withdrawing groups $\left(\mathrm{Br}, \mathrm{NO}_{2}\right)$ were significantly bigger $(\sim 30 \mathrm{~nm})$ than UiO-66 and UiO-66-NH $(\sim 13 \mathrm{~nm})$; the smaller NMOFs are more likely to undergo passive internalisation, and may explain their better efficacy. Importantly, although it has been reported that DCA enhances the effect of 5-FU on cancer cells, the DCA doses required to reach the synergistic effect are at least one order of magnitude higher than the maximum dose reached if the MOFs release their full cargo [140]. This suggests that co-delivery from one DDS is a valid strategy to boost anticancer activity, especially considering that controls in which 5-FU and DCA were incubated with cells, at concentrations delivered by the MOFS, resulted in no enhancement of 5-FU therapeutic efficiency. 
A combination of folate-targeting and 5-FU delivery resulted in the preparation of 5FU@UiO-66- $\mathrm{NH}_{2}-5-F A M-F A$, surface functionalised by amide condensation reactions between the carboxylate groups of the fluorescein (5-FAM) and folic acid (FA) surface reagents. The MOF was proven to be biocompatible to human liver HL-7702 cells, with cell proliferation over $80 \%$ when treated with $0.2 \mathrm{mgmL}^{-1}$ of MOF, while the empty MOF UiO-66$\mathrm{NH}_{2}-5-\mathrm{FAM}-\mathrm{FA}$ and 5-FU exhibited a similar cytotoxic effect. The anticancer activity was assessed using HepG2 cells, in which incubation with 5-FU@UiO-66- $\mathrm{NH}_{2}-5-\mathrm{FAM}-\mathrm{FA}$ had a slightly lesser effect than the same mass of the free drug (cell proliferation $57 \%$ vs $40 \%$, respectively, at a concentration of $0.2 \mathrm{mgmL}^{-1}$ ) despite the targeting effect. This is likely due to the maximum 5-FU loading being reported as $26 \% \mathrm{w} / \mathrm{w}$ for $\mathrm{UiO}-66-\mathrm{NH}_{2}$, although no loading value for 5-FU@UiO-66- $\mathrm{NH}_{2}-5-\mathrm{FAM}-\mathrm{FA}$ is given in the paper [94].

The potential of Zr-fum as a delivery vector for biomolecules was investigated by attaching various pro-apoptotic peptides (Bak, Bad, KLK) and a cytochrome c protein (CytC) which, due to their membrane impermeability, are not able to efficiently cross the cell membrane by themselves, to the NMOF surface using His-tags [85]. The authors observed a 20 -fold increase in the mean cell internal fluorescence of HeLa cells when incubated with Zr-fum$\mathbf{H}_{6} \mathbf{C F}\left(\mathrm{H}_{6} \mathrm{CF}=\right.$ carboxyfluorescein with six histidine residues) and a 30 -fold increase for $\mathbf{Z r}$ fum- $\mathrm{H}_{6}$ GFP $\left(\mathrm{H}_{6}\right.$ GFP $=$ green fluorescent protein modified with six histidine residues) compared to when cells were incubated with solutions of the same concentration of the respective free peptides in growth media, highlighting the efficiency of Zr-fum in internalising biomolecules not able to do so efficiently themselves. Thus, a decrease in HeLa cell viability when treated with the peptide-modified NMOFs was considered a consequence of efficient cytosolic release of the attached peptides. The authors compared the effect on cell growth to those obtained when incubating cells with free peptide or naked $\mathrm{Zr}$-fum for the same period of time. The peptide or protein conjugated MOFs induced remarkably higher cytotoxicity on cells ( $\sim 40 \%$ cell proliferation) compared with the free peptide ( $\sim 9 \%$ cell proliferation), while naked MOF did not exhibit any cytotoxicity, confirming the intracellular delivery of the peptides by the MOF (Figures 23a and 23b).

Lin and co-workers investigated siRNA transfection efficiency mediated by siRNA-UiO-Cis UiO-68 functionalised with siRNA and loaded with cis-platin - in SKOV-3 ovarian cancer cells, which have cis-platin resistance. By siRNA delivery, the authors aimed to inhibit three genes (survivin, Bcl-2 and P-gp) in order to overcome cis-platin resistance. ELISA assays showed that when cells were incubated with siRNA-UiO-66-Cis (either as a pool of siRNA or with siRNA specific to inhibit certain genes) potent gene silencing was induced, while free 
siRNAs on their own did not have the same effect, (Figure 23c), as naked siRNA degradation in biological media occurs quickly, determined by Western blot. These results were mirrored by the therapeutic effect, as when cells incubated with either UiO-Cis or free cis-platin plus a pool of free siRNA had a similar cytotoxic effect to the free drug on its own (cis-platin $\mathrm{IC}_{50}=53.9 \pm 4.7,53.2 \pm 4.4$ and $45.1 \pm 7.0 \mu \mathrm{M}$ for free cis-platin, UiO-Cis and free cis-platin/pool siRNA respectively), whereas when cells were incubated with siRNA-UiO-Cis or free cis-platin and siRNA-UiO, remarkably lower $I_{50}$ values (cis-platin $I_{50}=4.7 \pm 1.8$ and $6.6 \pm 0.3 \mu \mathrm{M}$, in turn) were found, as a consequence of efficient siRNA delivery [87].
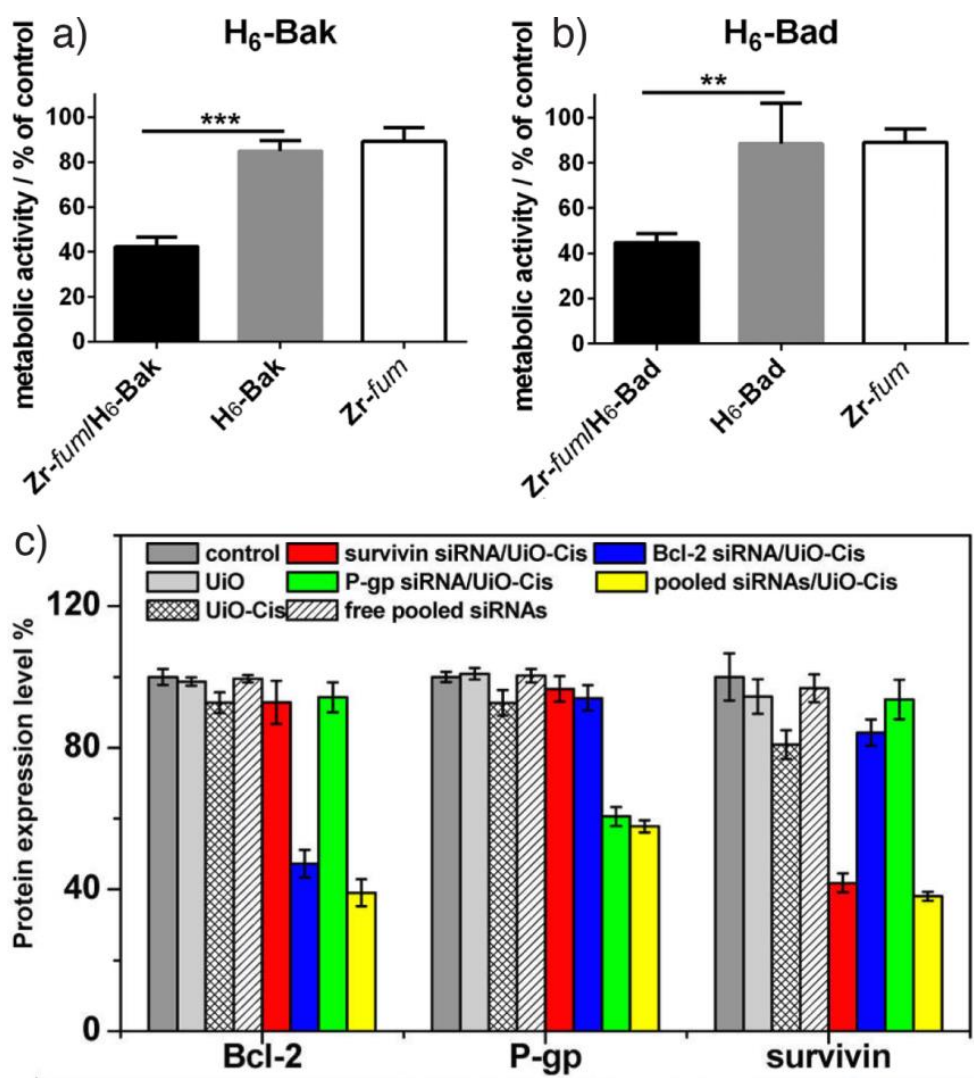

Figure 23. MTS cell proliferation assays for delivery of his-tagged pro-apoptotic peptides into HeLa cells by $\mathrm{Zr}$-fum for a) $\mathrm{H}_{6}$-Bak, and b) $\mathrm{H}_{6}$-Bad at $10 \mu \mathrm{M}$ peptide concentration. Modified with permission from ref [85] copyright (2017) American Chemical Society. c) Gene silencing in SKOV-3 cells assessed by decrease in protein expression as a result of delivery of $30 \mathrm{nM}$ siRNA by siRNA-UiO-Cis compared to controls. Modified with permission from ref [87] copyright (2014) American Chemical Society.

Importantly, no cytotoxicity was found for siRNA-UiO, confirming that it is the co-delivery of siRNA and cis-platin that induces cytotoxicity towards SKOV-3 cells. Experiments using cisplatin sensitive cell lines, such as human ovarian carcinoma A2780, human breast carcinoma MCF-7 and human lung carcinoma H460 cells, demonstrated that both UiO-Cis 
and siRNA-UiO-Cis had similar levels of cytotoxicity, strongly suggesting that siRNA and cisplatin co-delivery using UiO-68 as a DDS could overcome cis-platin resistance of certain cancer cells through the combined effect of therapeutics and gene silencing. Through Annexin $\mathrm{V}$ conjugate staining and DNA ladder assays, siRNA-UiO-Cis induced cytotoxicity was proved to occur due to apoptosis rather than necrosis.

The cytotoxicity of various doxorubicin (DOX) loaded UiO-68- $\mathbf{N}_{3}$-DNA conjugates has also been assessed against MDA-MB-231 cells by measurement of time-dependent apoptosis (IncuCyte® Red cytotoxicity assay) [98]. The empty MOFs induced less than $20 \%$ cell death after $42 \mathrm{~h}$, while the DOX-loaded MOF functionalised with a $\mathrm{pH}$-responsive cytosine-rich DNA sequence induced around $50 \%$ cell apoptosis for the same incubation time. Addition of the AS1411 aptamer, which binds to the nucleolin receptor that is overexpressed on the surface of cancer cells, to the doxorubicin-loaded MOF induced $100 \%$ cell death for the same incubation time, as a consequence of targeting. Surface functionalisation with $\mathrm{Mg}^{2+}-$ dependent DNAzyme subunits separated by ATP-aptamer sequences gave a MOF that did not induce cell death in both MFC-10A breast epithelial cells and MDA-MB-231 breast cancer cells. After DOX-loading, the MOF decreased proliferation of the breast cancer cells to $\sim 70 \%$ after 3 days and $\sim 60 \%$ after 5 days, as intracellular $\mathrm{Mg}^{2+}$ and ATP triggered DOX release, without affecting the growth of the healthy cells (Figures 24a-24c).

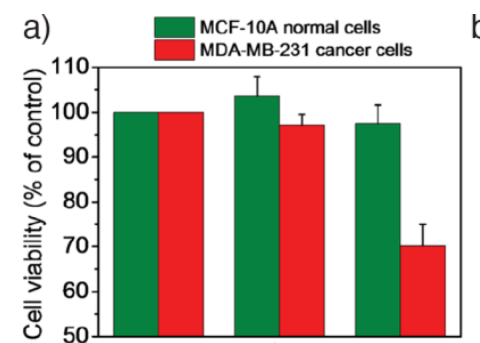

(i)

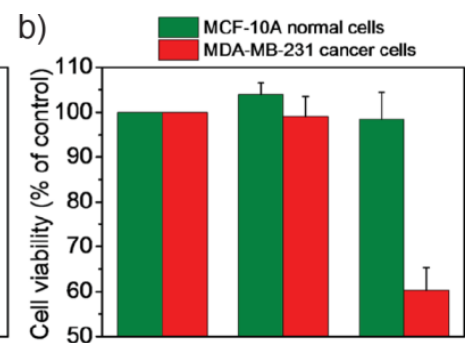

(i) c)

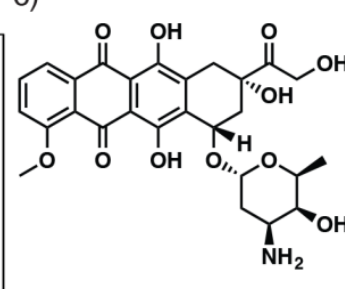

Doxorubicin (DOX)

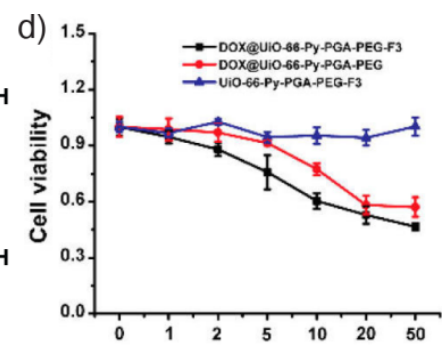

DOX concentration $(\mu \mathrm{g} / \mathrm{mL})$

Figure 24. Cytotoxicity (IncuCyte ${ }^{\circledR}$ Red apoptosis assay) after a) 3 days and b) 5 days of (i) control cells, (ii) empty UiO-68- $\mathrm{N}_{3}$-DNA conjugated with $\mathrm{Mg}^{2+}$ and ATP-responsive DNA sequences, and (iii) doxorubicin loaded analogues. Modified with permission from ref [98] copyright (2017) The Royal Society of Chemistry. c) Chemical structure of doxorubicin. d) Cell viability of MDA-MB-231 cells incubated with DOX@UiO-66-Py-PGA-PEG-F3, DOX@UiO-66-Py-PGA-PEG, and Py-PGA-PEG-F3. Modified with permission from ref [100] copyright (2017) American Chemical Society.

In vitro tumour targeting using the F3 nucleolin targeting peptide was investigated by FACS with ${ }^{89} \mathrm{Zr}$-UiO-66-Py-PGA-PEG-F3 showing that uptake was higher in MDA-MB-231 triplenegative breast cancer cells, which over express the nucleolin receptor $(n+)$, compared to 
L929 fibroblasts, which do not (n-) [100]. The empty MOF did not affect MDA-MB-231 cell growth in concentration range $\left(0-50 \mathrm{\mu gmL}^{-1}\right)$, and the doxorubicin loaded analogue decreased MDA-MB-231 cell viability to a greater extent than an analogue without the F3 peptide, as a consequence of enhanced MOF internalisation through targeting (Figure 24d).

Drug delivery from Zr MOFs has also been combined with imaging in hybrid systems. Coreshell iron oxide-MOF nanoparticles, $\mathrm{Fe}_{3} \mathrm{O}_{4} @ U i \mathrm{U}-66-\mathrm{NH}_{2}$ (core $150 \mathrm{~nm}$; shell 2, 25, $50 \mathrm{~nm}$ ), were synthesised through growth of UiO-66- $\mathrm{NH}_{2}$ on the surface of carboxylate capped $\mathrm{Fe}_{3} \mathrm{O}_{4}$ [141]. The core-shell MOFs exhibited strong superparamagnetic behaviour, retaining the properties of the core iron oxide with only minor decrease in saturation magnetisation from 69.7 emug $^{-1}$ to 51.6 emug $^{-1}$ as a consequence of the MOF coating, suggesting their use as optimal T2-contrast agents. $\mathrm{Fe}_{3} \mathrm{O}_{4} @ U$ UiO-66- $\mathrm{NH}_{2}$ has a high transverse relaxivity $\left(\mathrm{r}_{2}\right)$ of 255.9 $\mathrm{Mms}^{-1}$, considerably higher than some clinical Fe-based $\mathrm{T}_{2}$-weighed contrast agents. The effect of empty and DOX-loaded $\mathrm{Fe}_{3} \mathrm{O}_{4} @ \mathrm{UiO}-66-\mathrm{NH}_{2}$ on HeLa cell proliferation was investigated using the MTT assay. While the empty MOF did not induce cytotoxicity even at concentrations of $0.5 \mathrm{mgmL}^{-1}$, proliferation decreased by $60 \%$ upon $24 \mathrm{~h}$ incubation with DOX@Fe $\mathrm{O}_{4} @ U i \mathrm{O}-66-\mathrm{NH}_{2}$. The MOF possessed similar anticancer activity to DOX when the incubation time was $24 \mathrm{~h}$, but this was enhanced after $48 \mathrm{~h}$. The loaded MOF also did not significantly affect proliferation of healthy mouse fibroblast 3T3 cells at concentrations up to $0.5 \mathrm{mgmL}^{-1}$ of MOF.

A number of protocols have been adapted to induce selective cytotoxicity of MOF-based drug delivery systems, including targeting, stimuli-responsive release mechanisms, and photodynamic agents, while retaining excellent biocompatibility and stability. There is great potential for combining these strategies into dual-mode (e.g. PDT combined with medicinal cargo) or theranostic (imaging and treatment) systems, with materials now being prepared with these applications in mind. It is also evident that examining endocytosis in detail mechanisms, localisations, exocytosis, etc - gives mechanistic information to inform design of materials, as for certain drugs it seems that the endocytosis mechanism is more important than uptake efficiency. There are also a large number of in vitro experiments to assess compatibility with the immune system, which give important information prior to, and possibly in place of, early stage in vivo experiments. 


\section{In Vivo Studies of Zirconium MOFs}

Building on the large and varied in vitro studies in the previous section, a small number of important in vivo experiments with $\mathrm{Zr}$ MOFs have been reported, both for imaging and delivery of therapeutics (Table 7). One of the first studies involved zebrafish embryos, which are often used as models for vertebrate development, and screened a range of MOFs for in vivo toxicity [50]. Both nanoparticulate $\mathrm{UiO}-66$ and $\mathrm{UiO}-67$ were found to have low toxicity towards zebrafish embryos, with yolk sac edema the only observed morphological defects, which correlated well with in vitro experiments. The Zr MOFs were found to have the lowest toxicity of the range studied.

Table 7. Examples of in vivo drug delivery from Zr MOFs.

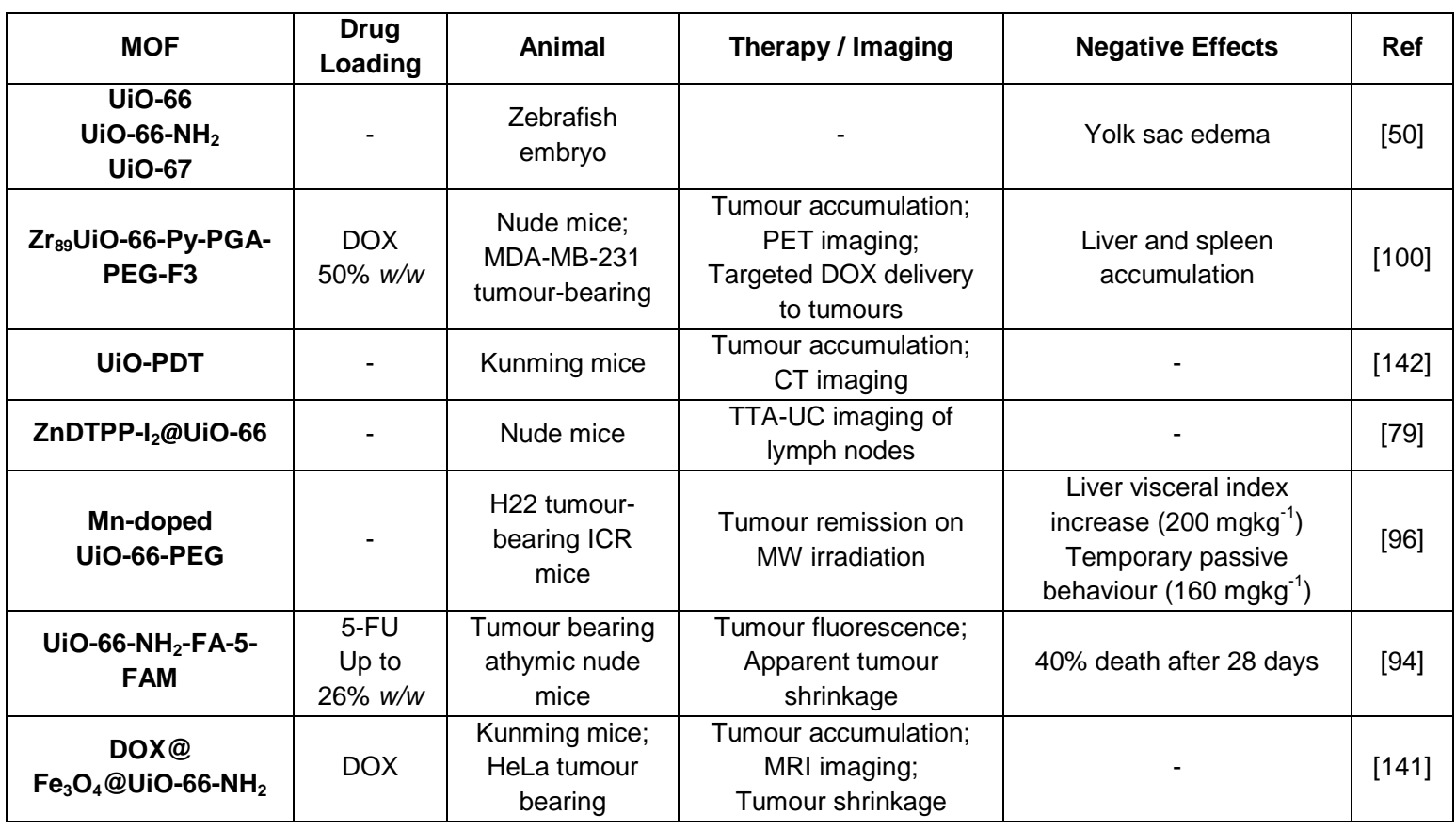

A number of studies using mice have been reported. The distribution and clearance profile of ${ }^{89} \mathrm{Zr}$-UiO-66 in nude mice up to $120 \mathrm{~h}$ post-injection was investigated in vivo [100]. The health of the mice was monitored after treatment of medium doses $\left(10 \mathrm{mgkg}^{-1}\right)$ and high doses $\left(50 \mathrm{mgkg}^{-1}\right.$ ) of UiO-66-Py-PGA-PEG, finding no side effects or acute, medium or chronic toxicity. Positron emission tomography (PET) scans of MDA-MB-231 tumours in tumour-bearing mice were taken at point times of $0.5,2,20,24,48,72,96$ and $120 \mathrm{~h}$. The circulation half-life of ${ }^{89} \mathrm{Zr}$-UiO-66-Py-PGA-PEG was determined through serial blood sampling and found to be $118.8 \mathrm{~min}$, indicating that the PEG surface density might not be high enough to prolong circulation times. Uptake of ${ }^{89} \mathrm{Zr}$-UiO-66-Py-PGA-PEG-F3 in MDAMB-231 tumours-in mice was found to be higher at all time points than ${ }^{89} \mathrm{Zr}$-UiO-66-Py-PGAPEG as a consequence of the F3 targeting peptide (Figure 25). However, after a maximum 
uptake around $2 \mathrm{~h}$ after injection, MOF accumulation in tumour tissue gradually decreases with time. The MOFs were found to be highly accumulated in the liver and spleen, with no major decrease over time. In order to study F3 targeting properties, the NMOFs were administered together with a nucleolin blocking dose $\left(10 \mathrm{mgkg}^{-1}\right)$ five minutes before ${ }^{89} \mathrm{Zr}$ UiO-66-Py-PGA-PEG-F3, causing tumour uptake reduction and thus confirming that targeting through F3 peptide is one of the reasons why tumour uptake is enhanced, while liver and spleen accumulation were not affected. The MOFs have slow clearance from the liver, while no radioactivity was found in the bone or kidney. Tumour-muscle contrast was found to be efficient and as high as $76.3 \pm 3.9$ at $2 \mathrm{~h}$ post-injection, and $19.6 \pm 5.4$ after 120 h. In vivo targeted delivery of doxorubicin (DOX) from DOX@UiO-66-Py-PGA-PEG and DOX@UiO-66-Py-PGA-PEG-F3 was studied by ex vivo fluorescence imaging, showing a 4fold increase in the DOX signal in the tumour upon F3 peptide targeting.
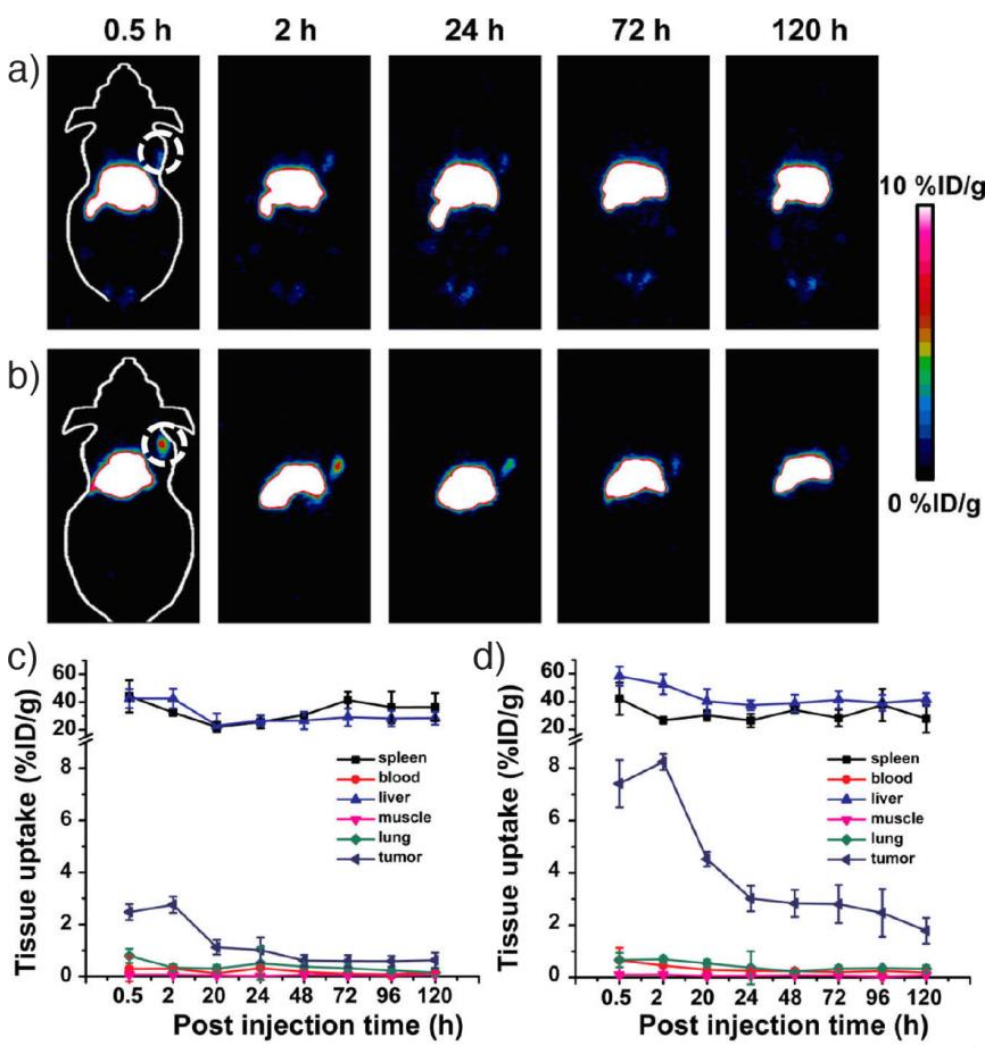

Figure 25. Coronal PET images of MDA-MB-231 tumour-bearing mice (tumour highlighted in dashed circle) after injection with a) ${ }^{89} \mathrm{Zr}$-UiO-66-Py-PGA-PEG and b) ${ }^{89} \mathrm{Zr}$-UiO-66-Py-PGA-PEG-F3. Quantitative region-of-interest analysis of the PET data showing time-activity curves in organs for ${ }^{89} \mathrm{Zr}$ UiO-66-Py-PGA-PEG and b) ${ }^{89} \mathrm{Zr}-\mathrm{UiO}-66-P y-P G A-P E G-F 3$. Both show enhanced tumour uptake by the targeted MOF. Modified with permission from ref [100] copyright (2017) American Chemical Society. 
UiO-PDT has been assessed as an in vivo contrast agent for tumour computed tomography (CT) imaging in mice [142]. The bodipy-modified UiO-66 was tested for in vivo toxicity in Kunming mice, with injection of concentrations of UiO-PDT up to $100 \mathrm{mgkg}^{-1}$ resulting in no significant histological abnormalities across a range of vital organs. Analysis of serum biochemistry showed no hepatic or kidney problems and haematology showed no changes to blood parameters. CT imaging of tumours in Sprague-Dawley rats implanted with cancerous cells showed preferential accumulation of UiO-PDT in the tumours rather than in surrounding tissue and organs, with a maximum signal observed after $24 \mathrm{~h}$.

Pd(II)-TCPP@UiO-68 was demonstrated to be a promising candidate for in vivo TTAupconversion-based imaging; the MOF was found to undergo triplet diffusion/migration in water upon laser excitation $(\lambda=532 \pm 10 \mathrm{~nm}$ ) with a threshold at solar irradiation suggesting upconversion luminescence (UCL) saturation at low irradiation power [82]. The authors postulated that the highly ordered alignment of the immobilized annihilators (the anthracenebased linkers) in the MOF offers efficient diffusion, significantly reducing the nonradioactive decay pathways and resulting in long UCL life time $(1.6 \mathrm{~ms})$, much higher than other reported systems ( 100 $\mu \mathrm{s})$. Pd(II)-TCPP@UiO-68 displayed no cytotoxicity to HeLa cells in the dark, while in vitro imaging showed an intense upconverted luminescence at $\lambda=450 \pm$ $25 \mathrm{~nm}$ when excited at $532 \mathrm{~nm}$. Due to these results, Pd(II)-TCPP@UiO-68 was further studied for in vivo imaging in nude mice. 10 minutes after subcutaneous injection, the control mouse, injected with blank saline, showed no TTA-UC response in the blue emission channel while the mouse treated with MOF exhibited strong upconversion fluorescence with high contrast imaging (signal to noise ratio $\sim 45$ ) under excitation $\left(\lambda=532 \mathrm{~nm}, 20 \mathrm{mWcm}^{-2}\right.$ ). The authors performed real-time imaging of lymph nodes - known to be implicated in cancer metastasis - of nude mice injected in the footpad with the MOF in PBS. Imaging was performed under the excitation of a $532 \mathrm{~nm}$ laser at $5 \mathrm{mWcm}^{-2}$. Immediately after injection, upconversion response was found to be distributed close to the site of injection, whilst after one hour upconversion fluorescence was located in the sentinel node with a signal to noise ratio of 31 , which is a significant response considering the very low excitation power (Figures $26 \mathrm{a}$ and 26b). Additionally, no histological abnormalities were observed in the lymph node, as determined by hematoxylin and eosin stains. 

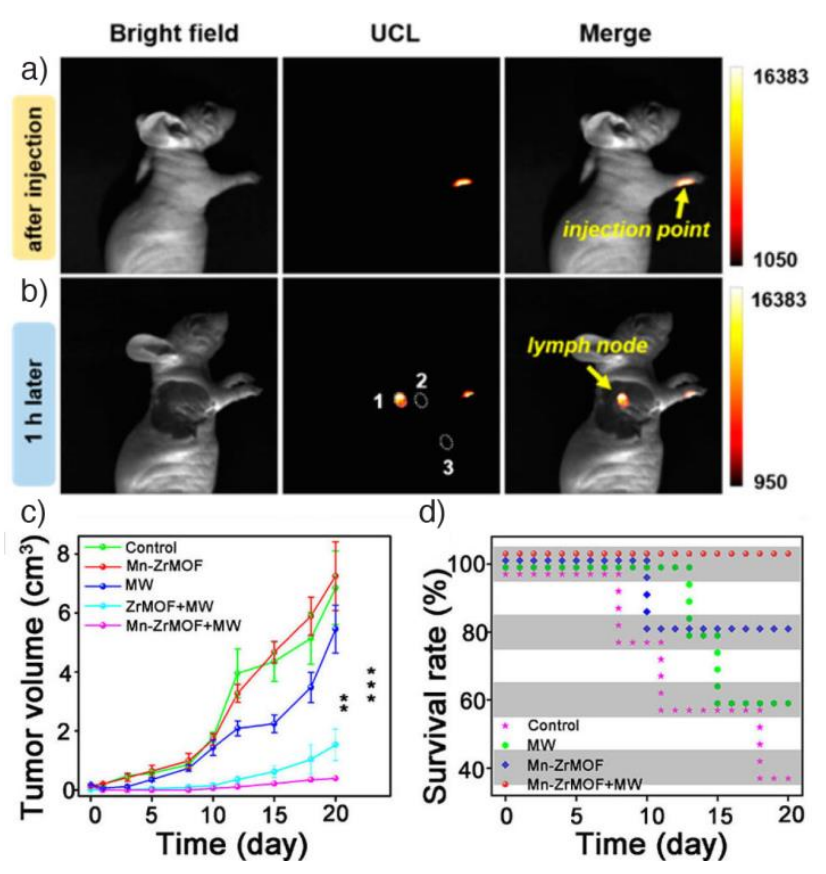

Figure 26. In vivo TTA-UC imaging $\left(\lambda=532 \mathrm{~nm}, 5 \mathrm{mWcm}^{-2}\right)$ of lymph nodes of a nude mouse after footpaw injection (2 $\mathrm{mgmL}^{-1}$ ) of Pd(II)-TCPP@UiO-68 at a) 5 minutes, and b) 60 minutes after injection. Modified with permission from ref [82] copyright (2018) American Chemical Society. c) Decrease in tumour size in ICR mice with $\mathrm{H} 22$ tumour cells after intravenous injection $\left(40 \mathrm{mgkg}^{-1}\right)$ of Mn-doped-UiO-66-PEG and controls followed by MW irradiation $6 \mathrm{~h}$ later (1.8 W, $5 \mathrm{~min}$ ). d) Survival rates of mice after 20 days following different treatments. Modified with permission from ref [96] copyright (2018) American Chemical Society.

The potential of Mn-doped@UiO-66-PEG for microwave dynamic therapy (MWDT) and microwave thermal therapy (MWTT) has been tested in vivo. Toxicity of the MOF towards ICR mice bearing $\mathrm{H} 22$ mouse hepatocellular tumour cells was evaluated after injection with different doses $\left(120,160,200 \mathrm{mgkg}^{-1}\right)$ of MOF dispersed in aqueous $\mathrm{NaCl}$ [96]. White blood cells were analysed and were found to be in the normal range although statistical differences with the control group were found. The visceral index of the liver increased after injection at $200 \mathrm{mg} \mathrm{Kg}^{-1}$, indicating that higher doses of the MOF might affect the liver. Hence $160 \mathrm{mgKg}^{-}$ ${ }^{1}$ was stated as the maximum tolerated dose, for which only passive behaviour and weight loss was observed in mice $24 \mathrm{~h}$ after injection, with no other abnormal behaviour, and the mice returned to normality after $48 \mathrm{~h}$. Biodistribution was evaluated by ICP-OES, showing the highest $\mathrm{Zr}$ content in the tumour $6 \mathrm{~h}$ after administration, after which it decreases. Thus, MW irradiation (1.8 W, $5 \mathrm{~min}$ ) at $6 \mathrm{~h}$ post-injection was chosen. Tumour temperature raised $10{ }^{\circ} \mathrm{C}$ (comparison performed between MW group and group treated with MOF plus MW) as determined by infrared thermal imagining. Significant differences in tumour size 20 days post-injection were observed (Figures $26 \mathrm{c}$ and $26 \mathrm{~d}$ ). While administration of the MOF 
without MW irradiation or MW irradiation on its own resulted in no decrease in tumour size, remission was notable after MOF treatment with MW irradiation, with the tumours almost completely destroyed. A control treated in which mice were treated with UiO-66 without Mn doping confirmed the MWTT and MWDT synergic effect. Although tumours could also reach a high temperature upon treatment with $\mathrm{UiO}-66$ and $\mathrm{MW}$ irradiation, tumour recurrence was observed after 5 days, while it totally disappears for the Mn-doped@UiO-66-PEG; undoped Zr-MOFs only act as a MWTT agent, with a similar MW conversion to the Mn-doped analogue, but not as a MWDT agent, as they do not catalyse the formation of hydroxyl radicals.

Tumour bearing athymic nude mice treated with 5-FU@UiO-66- $\mathbf{N H}_{2}-\mathrm{FA}-5-\mathrm{FAM}$ did not have a good survival rate, as 28 days after treatment only three mice out of five were alive. Significant fluorescence was observed in the tumour and lungs after $12 \mathrm{~h}$, but not in the liver or spleen, which is common with MOFs and other nanomaterials, suggesting either targeted tumour uptake or in vivo release of the fluorescent coating. Although tumour remission of the treated group compared to a PBS-only control was observed, the statistical significance is almost minimal due to the large standard deviations of tumour size of both groups. The authors attribute mice death to the inherent cytotoxicity of 5-fluorouracil and postulate that 5FU@UiO-66- $\mathrm{NH}_{2}$-FA-5-FAM could reduce its toxic effect [94].

The potential of $\mathbf{F e}_{3} \mathrm{O}_{4} @ U$ UiO-66- $\mathrm{NH}_{2}$ core-shell composites as magnetic resonance imaging (MRI) contrast agents was evaluated in vivo in Kunming mice [141]. Significant signal darkening was found in the liver 10 minutes post-injection, and in the tumour after one hour, continuing to increase to $9 \mathrm{~h}$ post-injection time, thus confirming accumulation in tumour tissue after prolonged times. Biodistribution and toxicology studies were performed in vivo to evaluate potential toxic effects, and thus T2-weighted images of Kunming mice were taken $1,7,14$, and 30 days after injection. Since no darkening effect was found in the urinary bladder, while high darkening with time-recovery signal was observed in the liver, $\mathrm{Fe}_{3} \mathrm{O}_{4} @$ @iO-66- $\mathrm{NH}_{2}$ seems to be excreted from the liver rather than from the kidney. The biodistribution of the core-shell NPs was also determined ex vivo by ICP-MS determination of the iron and zirconium levels of the different digested organs in specimens after 1, 7, and 30 days of injection. In concordance with the T2-weighted images, significant accumulation of $\mathrm{Zr}$ and $\mathrm{Fe}$ was found in the liver and spleen. The levels decreased with prolonged times, reaching similar levels to an untreated control after 30 days, although the iron content in the liver was slightly higher than the untreated mice after 30 days (Figure 27a). The body weight and growth of mice was found not to be affected, and blood analysis (Figure 27b) was consistent with the untreated control. In general, it was proven that $\mathrm{Fe}_{3} \mathrm{O}_{4} @ U$ UiO-66- $\mathrm{NH}_{2}$ is 
relatively safe for in vivo treatments. The anticancer therapeutic effect of the core-shell nanoparticles was also measured in vivo towards HeLa bearing tumour mice. While tumours in control mice grew quickly, mice treated with DOX@Fe $\mathrm{O}_{3} @$ @iO-66- $\mathrm{NH}_{2}$ showed a 4-fold decrease in tumour mass, which could be monitored in vivo through MRI (Figures 27c and 27d).
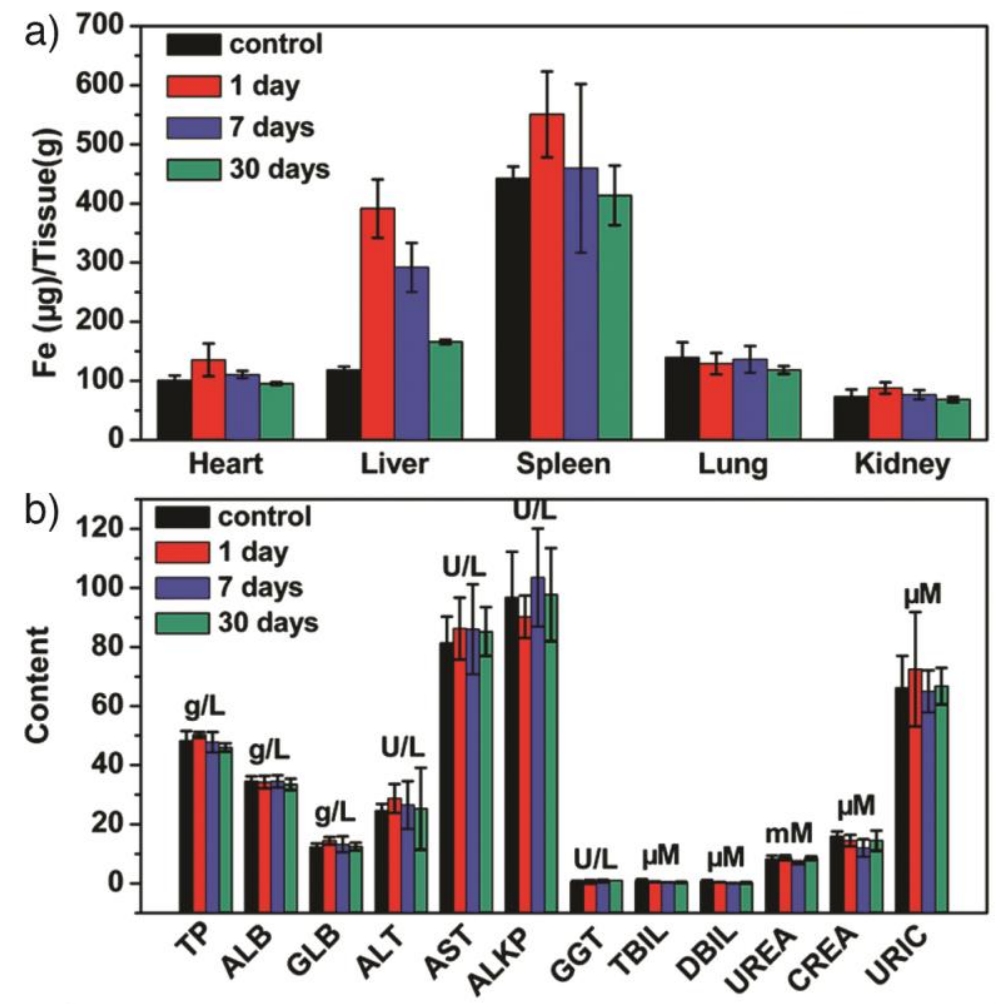

c)

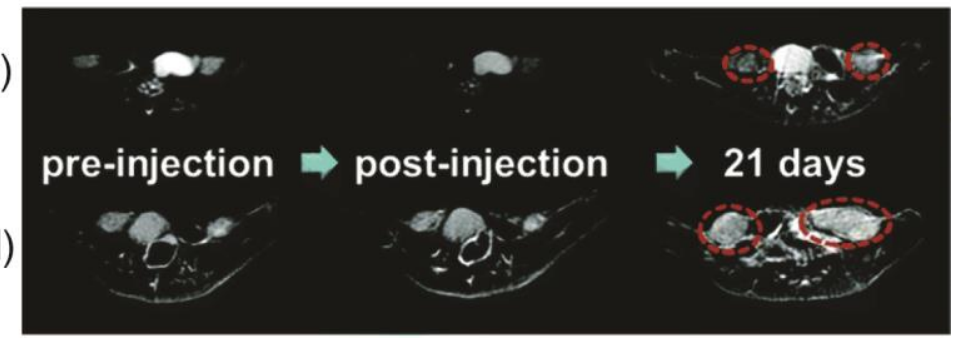

Figure 27. a) In vivo biodistribution of $\mathrm{Fe}$ from $\mathrm{Fe}_{3} \mathrm{O}_{4} @ \mathrm{UiO}-66-\mathrm{NH}_{2}$ in mice organs. b) Biochemistry of mouse blood after treatment with $\mathrm{Fe}_{3} \mathrm{O}_{4} @ \mathrm{UiO}-66-\mathrm{NH}_{2}\left(24 \mathrm{mgkg}^{-1}\right)$. Magnetic resonance images of tumours from HeLa tumour bearing mice after treatment with c) DOX@ $\mathrm{Fe}_{3} \mathrm{O}_{4} @ \mathrm{UiO}-66-\mathrm{NH}_{2}$ compared to d) PBS, showing tumour shrinkage after treatment with the MOF. Modified with permission from ref [141] copyright (2016) The Royal Society of Chemistry.

In vivo studies are important experiments in the development of MOF-based DDSs, giving information on adverse effects, biodistribution, and treatment efficiency [143]. There are, however, a number of in vitro experiments which can give similar information without resorting to early stage animal testing. The studies to date suggest tumour uptake of NMOFs 
by the enhanced permeability and retention effect, but also accumulation in the liver and spleen, which is often a consequence of high macrophage recognition and uptake. Therefore, developing surface functionality that avoids macrophage recognition, while further enhancing cancer cell uptake through targeting units, might be an alternative to overcome accumulation in the body. Additionally, surface modifications that ensure adequate colloidal dispersion and minimal drug release under extracellular conditions, alongside fast surface detachment and consequent degradation under intracellular conditions, might be an alternative to overcome accumulation issues. 


\section{Conclusions}

In a relatively short time period a large volume of research has arisen examining Zr MOFs in drug delivery and other bioapplications. A number of factors have led to this rapid emergence, including the development of protocols for synthetic control over particle size and morphology, the amenability of Zr MOFs to postsynthetic modification, their high storage capacity for drug cargo, their excellent aqueous stability and colloidal dispersion, and their biocompatibility. The complexity of hybrid materials has also rapidly increased, with incorporation of targeting peptides, DNAzymes, and stimuli-responsive release mechanisms leading to in vitro assessment of imaging, drug delivery, and photodynamic therapy, as well as a burgeoning body of in vivo studies. The review has highlighted a number of strategies to enhance physical properties and therapeutic efficiencies; it is expected that many of these are orthogonal with one another and so combined in vivo targeted theranostic devices could be the next development in the field. As well as the large number of studies describing incorporation of primarily organic functionality, metal doping and hybrid nanoparticle devices are beginning to be used for imaging purposes. A number of metal ions can form the hexameric cluster that links most Zr MOFs, and so it is likely that doping of metals such lanthanides for MRI, for example into existing structures will be possible. The compatibility of Zr MOFs with biological entities suggests further bioapplications will also be possible, for example, the intracellular sensing of $\mathrm{HClO}$ by a redox-active UiO-68 derivative [144].

Furthermore, there are isostructural $\mathrm{Hf}$ variants of most $\mathrm{Zr}$ MOFs, and a number have been used in similar settings to their $\mathrm{Zr}$ MOF analogues. For example, both $\mathrm{Zr}$ and $\mathrm{Hf}$ analogues of UiO-66 have been assessed as contrast agents for computed tomography, with promising in vitro and in vivo results from UiO-66(Hf) that had been surface coated with silica and poly(ethylene glycol) [145]. Hf-based porphyrin [146] and chlorin [147] MOFs have been used for PDT, while Hf MOFs have been shown to act as radioenhancers, improving the efficacy of radiotherapy while concurrently delivering therapeutic cargo [148, 149]. With these latest innovations in mind, it is not unreasonable to foresee the use of so-called theranostic MOFs in the near future that (i) contain metals that are active for imaging, (ii) are linked by ligands with activity for PDT or otherwise, (iii) are loaded with different types of therapeutic cargo, and (iv) are surface modified for targeting and biodistribution, enabled by the continuing development of orthogonal protocols for functionalisation and encapsulation alongside the desirable properties of Zr MOFs for bioapplications. 


\section{Acknowledgements}

We thank the Royal Society for receipt of a University Research Fellowship and the University of Glasgow for funding. This project received funding in part from the European Research Council (ERC) under the European Union's Horizon 2020 Programme for Research and Innovation (grant agreement no. 677289, SCoTMOF, ERC-2015-STG).

\section{Abbreviations and Acronyms}

$\begin{array}{ll}\text { 3T3 } & \text { Mouse fibroblast cell line } \\ \text { 5-FAM } & \text { 5-Carboxyfluorescein } \\ \text { 5-FU } & \text { 5-Fluorouracil } \\ \alpha \text {-CHC } & \text { a-Cyanohydroxycinnamic acid } \\ \text { A2780 } & \text { Human ovarian carcinoma cell line } \\ \text { A549 } & \text { Human lung carcinoma cell line } \\ \text { AcOH } & \text { Acetic acid } \\ \text { AL } & \text { Alendronate } \\ \text { ATP } & \text { Adenosine triphosphate } \\ \text { B16F10 } & \text { Mouse skin melanoma cell line } \\ \text { BCDTE } & \text { 1,2-bis(5-(4-carboxyphenyl)-2-methylthien-3-yl)cyclopent-1-ene } \\ \text { BET } & \text { Brunauer-Emmett-Teller } \\ \text { BDC } & \text { Benzenedicarboxylic acid } \\ \text { Biot } & \text { Biotin } \\ \text { BODIPY } & \text { Boron dipyrromethene } \\ \text { BPDC } & \text { Biphenyldicarboxylic acid } \\ \text { C26 } & \text { Mouse colon carcinoma cell line } \\ \text { cal } & \text { Calcein } \\ \text { CF } & \text { Carboxyfluorescein } \\ \text { CHCl } & \text { Chloroform } \\ \text { CM } & \text { Coordination modulation } \\ \text { CP5 } & \text { Decacarboxylato-pillar[5]arene } \\ \text { CT } & \text { Computed tomography } \\ \text { CT26 } & \text { Murine colon carcinoma cell line } \\ \text { CuAAC } & \text { Copper-catalysed azide-alkyne cycloaddition } \\ \text { CytC } & \text { Cytochrome c protein } \\ \text { DBCO } & \text { Dibenzylcyclooctyne } \\ \text { DCA } & \text { Dichloroacetic acid } \\ \text { DCFH-DA } & \text { 2',7'-dichlorodihydrofluorescein diacetate } \\ \text { DDS } & \text { Drug delivery system } \\ \text { DLS } & \text { Dynamic light scattering } \\ \text { DMF } & \text { Dimethylformamide } \\ \text { DNA } & \text { Deoxyribonucleic acid } \\ \text { DOPA } & \text { 1,2-dioleosyl-sn-glycero-3-phosphate } \\ \text { DOPC } & \text { 1,2-dioleoyl-sn-glycero-3-phospho-choline } \\ \text { DOX } & \text { Doxorubicin } \\ \text { DPBF } & \text { 1,3-diphenylisobenzofuran } \\ \text { DS } & \text { Diclofenac Sodium } \\ \text { DTPP-l2 } & \text { 5,15-Di(4-methoxycarbonylphenyl)-10,20-bis(4-iodophenyl)-porphine } \\ & \end{array}$




\begin{tabular}{|c|c|}
\hline $\begin{array}{l}\text { EDC } \\
\text { EPR }\end{array}$ & $\begin{array}{l}\text { 1-Ethyl-3-(3-dimethylaminopropyl)carbodiimide } \\
\text { Enhanced permeability and retention }\end{array}$ \\
\hline EDX & $\begin{array}{l}\text { Enhanced permeability and retentıon } \\
\text { Energy dispersive X-ray }\end{array}$ \\
\hline FA & Folic acid \\
\hline FACS & Fluorescence assisted cell sorting \\
\hline FITC & Fluorescein isothiocyanate \\
\hline FL83B & Mouse liver hepatocyte cell line \\
\hline FMN & Flavin mononucleotide \\
\hline FT-IR & Fourier transform infra-red \\
\hline FR & Folate receptor \\
\hline GFP & Green fluorescent protein \\
\hline $\mathrm{H} 22$ & Mouse hepatocellular carcinoma cell line \\
\hline $\mathrm{H} 460$ & Human lung carcinoma cell line \\
\hline HBG & HEPES buffered glucose \\
\hline $\mathrm{HCl}$ & Hydrochloric acid \\
\hline HEK293 & Human embryonic kidney cell line \\
\hline HeLa & Human cervical cancer cell line \\
\hline Hep & Heparin \\
\hline HepG2 & Human liver carcinoma cell line \\
\hline HEPES & 4-(2-Hydroxyethyl)-1-piperazineethanesulfonic acid \\
\hline HL-7702 & Human liver hepatocyte cell line \\
\hline I2-BDP & $\begin{array}{l}\text { 3-(2',6'-Diiodo-1',3',5',7'-tetramethyl-4',4'-difluoro-4'-bora-3'a,4'a-diaza-s- } \\
\text { indacen-8'-yl) propanoic acid }\end{array}$ \\
\hline $\mathrm{IC}_{50}$ & Half inhibitory concentration \\
\hline ICP-MS & Inductively coupled plasma optical emission spectroscopy \\
\hline ICP-OES & Inductively coupled plasma mass spectrometry \\
\hline ICR & Institute of Cancer Research \\
\hline L929 & Mouse fibroblast cell line \\
\hline $\mathrm{LD}_{50}$ & Median lethal dose \\
\hline MCF-7 & Human breast carcinoma cell line \\
\hline MDA-MB-231 & Triple negative human breast cancer cell line \\
\hline MDA-MB-468 & Human breast cancer cell line \\
\hline MFC-10A & Human breast epithelial cell line \\
\hline MOF & Metal-organic framework \\
\hline MTS & $\begin{array}{l}\text { (3-(4,5-dimethylthiazol-2-yl)-5-(3-carboxymethoxyphenyl)-2-(4- } \\
\text { sulfophenyl)-2H-tetrazolium) }\end{array}$ \\
\hline MTT & 3-(4,5-dimethylthiazol-2-yl)-2,5-diphenyltetrazolium bromide \\
\hline MRI & Magnetic resonance imaging \\
\hline MW & Microwave \\
\hline MWDT & Microwave dynamic therapy \\
\hline MWTT & Microwave termal therapy \\
\hline NHS & $N$-hydroxysuccinimide \\
\hline NIR & Near infrared \\
\hline NMOF & Nanoparticulate metal-organic framework \\
\hline NMR & Nuclear magnetic resonance \\
\hline NP & Nanoparticle \\
\hline PBLs & Phospholipid bilayers \\
\hline PBS & Phosphate buffered saline \\
\hline PC12 & Rat neuroblastic pheochromocytoma cell line \\
\hline PCL-TPGS & $\begin{array}{l}\text { Poly( } \varepsilon \text {-caprolactone)-alpha tocopheryl polyethylene glycol } 1000 \\
\text { succinate }\end{array}$ \\
\hline PDT & Photodynamic therapy \\
\hline PEG & Poly(ethylene glycol) \\
\hline PET & Positron emission tomography \\
\hline PNIPAM & Poly(N-isopropylacrylamide) \\
\hline
\end{tabular}




$\begin{array}{ll}\text { PolyLact } & \text { Poly-L-Lactide } \\ \text { PS } & \text { Postsynthetically } \\ \text { PSM } & \text { Postsynthetic modification } \\ \text { PXRD } & \text { Powder X-ray diffraction } \\ \text { Py-PGA-PEG } & \text { poly(Y-glutamic acid)-pyrene(30\%)-poly(ethylene glycol) } \\ \text { ROS } & \text { Reactive oxygen species } \\ \text { SBU } & \text { Secondary building unit } \\ \text { SEM } & \text { Scanning electron microscopy } \\ \text { SIM } & \text { Structured illumination microscopy } \\ \text { siRNA } & \text { Small interfering ribonucleic acid } \\ \text { SKOV-3 } & \text { Human ovarian cancer cell line } \\ \text { SLE } & \text { Surface ligand exchange } \\ \text { SMMC-7721 } & \text { Human hepatocellular carcinoma cell line } \\ \text { SPAAC } & \text { Strain-promoted azide-alkyne cycloaddition } \\ \text { STEM } & \text { Scanning tunnelling electron microscopy } \\ \text { TCPP } & 5,10,15,20-\text { Tetrakis(4-carboxyphenyl)porphyrin } \\ \text { TEA } & \text { Triethylamine } \\ \text { TGA } & \text { Thermogravimetric analysis } \\ \text { TPP-SH } & \text { 5-(4-(S-ethylthiolester)thiocarbonylphenyl)-10,15,20-tris(4-chlorophenyl)- } \\ & \text { porphyrin } \\ \text { TTA-UC } & \text { Triplet-triplet annihilation upconversion } \\ \text { UCNPS } & \text { Upconverting nanoparticles } \\ \text { UV-Vis } & \text { Ultraviolet-visible spectroscopy } \\ \text { XPS } & \text { X-ray photoelectron spectroscopy }\end{array}$

\section{References}

[1] A. Jemal, F. Bray, M. Center Melissa, J. Ferlay, E. Ward, D. Forman, CA Cancer J. Clin., 61 (2011) 69-90.

[2] M.E. Gindy, R.K. Prud'homme, Expert Opin. Drug Deliv., 6 (2009) 865-878.

[3] J.D. Rocca, D. Liu, W. Lin, Acc. Chem. Res., 44 (2011) 957-968.

[4] D. Peer, J.M. Karp, S. Hong, O.C. Farokhzad, R. Margalit, R. Langer, Nat. Nanotechnol., 2 (2007) 751-760.

[5] J. Shi, P.W. Kantoff, R. Wooster, O.C. Farokhzad, Nat. Rev. Cancer, 17 (2017) 20-37.

[6] X. Huang, C.S. Brazel, J. Control. Release, 73 (2001) 121-136.

[7] D. Cunha, M. Ben Yahia, S. Hall, S.R. Miller, H. Chevreau, E. Elkaïm, G. Maurin, P. Horcajada, C. Serre, Chem. Mater., 25 (2013) 2767-2776.

[8] K.M.L. Taylor, A. Jin, W. Lin, Angew. Chem. Int. Ed., 47 (2008) 7722-7725.

[9] M.A. Dobrovolskaia, S.E. McNeil, Nat. Nanotechnol., 2 (2007) 469-478.

[10] J. Xie, C. Xu, N. Kohler, Y. Hou, S. Sun, Adv. Mater., 19 (2007) 3163-3166.

[11] J.L. Perry, K.G. Reuter, M.P. Kai, K.P. Herlihy, S.W. Jones, J.C. Luft, M. Napier, J.E. Bear, J.M. DeSimone, Nano Lett., 12 (2012) 5304-5310.

[12] E. Bellido, T. Hidalgo, M.V. Lozano, M. Guillevic, R. Simón-Vázquez, M.J. Santander-Ortega, Á. González-Fernández, C. Serre, M.J. Alonso, P. Horcajada, Adv. Healthc. Mater., 4 (2015) 1246-1257. [13] K. Kim, M. Yu, X. Zong, J. Chiu, D. Fang, Y.-S. Seo, B.S. Hsiao, B. Chu, M. Hadjiargyrou, Biomaterials, 24 (2003) 4977-4985.

[14] W.H. De Jong, W.I. Hagens, P. Krystek, M.C. Burger, A.J.A.M. Sips, R.E. Geertsma, Biomaterials, 29 (2008) 1912-1919.

[15] H. Furukawa, K.E. Cordova, M. O’Keeffe, O.M. Yaghi, Science, 341 (2013).

[16] P. Horcajada, R. Gref, T. Baati, P.K. Allan, G. Maurin, P. Couvreur, G. Férey, R.E. Morris, C. Serre, Chem. Rev., 112 (2012) 1232-1268.

[17] M. Javadi, W.G. Pitt, C.M. Tracy, J.R. Barrow, B.M. Willardson, J.M. Hartley, N.H. Tsosie, J. Control. Release, 167 (2013) 92-100. 
[18] S. Sur, A.C. Fries, K.W. Kinzler, S. Zhou, B. Vogelstein, Proc. Natl. Acad. Sci. USA, 111 (2014) 2283-2288.

[19] I.R. Vlahov, C.P. Leamon, Bioconjug. Chem., 23 (2012) 1357-1369.

[20] J. Lu, M. Liong, Z. Li, J.I. Zink, F. Tamanoi, Small, 6 (2010) 1794-1805.

[21] M. Longmire, P.L. Choyke, H. Kobayashi, Nanomedicine, 3 (2008) 703-717.

[22] G. Jarockyte, E. Daugelaite, M. Stasys, U. Statkute, V. Poderys, T.-C. Tseng, S.-H. Hsu, V. Karabanovas, R. Rotomskis, Int. J. Mol. Sci., 17 (2016) 1193.

[23] R.C. Huxford, J.D. Rocca, W. Lin, Curr. Opin. Chem. Biol., 14 (2010) 262-268.

[24] K.M.L. Taylor-Pashow, J.D. Rocca, Z. Xie, S. Tran, W. Lin, J. Am. Chem. Soc., 131 (2009) 14261-14263.

[25] K. Deng, Z. Hou, X. Li, C. Li, Y. Zhang, X. Deng, Z. Cheng, J. Lin, Sci. Rep. 5 (2015) 7851.

[26] R. Riccò, W. Liang, S. Li, J.J. Gassensmith, F. Caruso, C. Doonan, P. Falcaro, ACS Nano, 12 (2018) 13-23.

[27] K. Liang, R. Ricco, C.M. Doherty, M.J. Styles, S. Bell, N. Kirby, S. Mudie, D. Haylock, A.J. Hill, C.J. Doonan, P. Falcaro, Nat. Commun., 6 (2015) 7240.

[28] X. Lian, Y. Fang, E. Joseph, Q. Wang, J. Li, S. Banerjee, C. Lollar, X. Wang, H.-C. Zhou, Chem. Soc. Rev., 46 (2017) 3386-3401.

[29] S. Li, M. Dharmarwardana, R. P. Welch, Y. Ren, C. M. Thompson, R. A. Smaldone, J.J. Gassensmith, Angew. Chem. Int. Ed., 55 (2016) 10691-10696.

[30] K. Liang, J.J. Richardson, J. Cui, F. Caruso, C.J. Doonan, P. Falcaro, Adv. Mater., 28 (2016) 7910-7914.

[31] P. Horcajada, C. Serre, M. Vallet-Regí, M. Sebban, F. Taulelle, G. Férey, Angew. Chem. Int. Ed., 45 (2006) 5974-5978.

[32] M. Giménez-Marqués, T. Hidalgo, C. Serre, P. Horcajada, Coord. Chem. Rev., 307 (2016) $342-$ 360.

[33] C. Doonan, R. Riccò, K. Liang, D. Bradshaw, P. Falcaro, Acc. Chem. Res., 50 (2017) 1423-1432.

[34] J. Della Rocca, D. Liu, W. Lin, Acc. Chem. Res., 44 (2011) 957-968.

[35] M. Lismont, L. Dreesen, S. Wuttke, Adv. Funct. Mater., 27 (2017) 1606314.

[36] G. Lan, K. Ni, W. Lin, Coord. Chem. Rev., (2017).

[37] P. Horcajada, T. Chalati, C. Serre, B. Gillet, C. Sebrie, T. Baati, J.F. Eubank, D. Heurtaux, P. Clayette, C. Kreuz, J.-S. Chang, Y.K. Hwang, V. Marsaud, P.-N. Bories, L. Cynober, S. Gil, G. Ferey, P. Couvreur, R. Gref, Nat. Mater., 9 (2010) 172-178.

[38] P. Horcajada, H. Chevreau, D. Heurtaux, F. Benyettou, F. Salles, T. Devic, A. Garcia-Marquez, C. Yu, H. Lavrard, C.L. Dutson, E. Magnier, G. Maurin, E. Elkaim, C. Serre, Chem. Commun., 50 (2014) 6872-6874.

[39] A.C. McKinlay, R.E. Morris, P. Horcajada, G. Férey, R. Gref, P. Couvreur, C. Serre, Angew. Chem. Int. Ed., 49 (2010) 6260-6266.

[40] S. Rojas, T. Devic, P. Horcajada, J. Mater. Chem. B, 5 (2017) 2560-2573.

[41] S. Sene, M.T. Marcos-Almaraz, N. Menguy, J. Scola, J. Volatron, R. Rouland, J.-M. Grenèche, S. Miraux, C. Menet, N. Guillou, F. Gazeau, C. Serre, P. Horcajada, N. Steunou, Chem, 3 (2017) 303322.

[42] Y. Bai, Y. Dou, L.-H. Xie, W. Rutledge, J.-R. Li, H.-C. Zhou, Chem. Soc. Rev., 45 (2016) 23272367.

[43] H.A. Schroeder, J.J. Balassa, J. Chron. Dis., 19 (1966) 573-586.

[44] Zirconium and its compounds [MAK Value Documentation, 1999], in: The MAK-Collection for Occupational Health and Safety, Wiley-VCH Verlag GmbH \& Co. KGaA, 2002.

[45] J.B. DeCoste, G.W. Peterson, H. Jasuja, T.G. Glover, Y.-g. Huang, K.S. Walton, J. Mater. Chem. A, 1 (2013) 5642-5650.

[46] J.E. Mondloch, M.J. Katz, N. Planas, D. Semrouni, L. Gagliardi, J.T. Hupp, O.K. Farha, Chem. Commun., 50 (2014) 8944-8946.

[47] H.-L. Jiang, D. Feng, K. Wang, Z.-Y. Gu, Z. Wei, Y.-P. Chen, H.-C. Zhou, J. Am. Chem. Soc., 135 (2013) 13934-13938.

[48] R.J. Marshall, R.S. Forgan, Eur. J. Inorg. Chem., 2016 (2016) 4310-4331.

[49] D. Cunha, C. Gaudin, I. Colinet, P. Horcajada, G. Maurin, C. Serre, J. Mater. Chem. B, 1 (2013) 1101-1108.

[50] À. Ruyra, A. Yazdi, J. Espín, A. Carné-Sánchez, N. Roher, J. Lorenzo, I. Imaz, D. Maspoch, Chem. Eur. J., 21 (2014) 2508-2518.

[51] J.H. Cavka, S. Jakobsen, U. Olsbye, N. Guillou, C. Lamberti, S. Bordiga, K.P. Lillerud, J. Am. Chem. Soc., 130 (2008) 13850-13851.

[52] S.J. Garibay, S.M. Cohen, Chem. Commun., 46 (2010) 7700-7702. 
[53] M. Kandiah, M.H. Nilsen, S. Usseglio, S. Jakobsen, U. Olsbye, M. Tilset, C. Larabi, E.A. Quadrelli, F. Bonino, K.P. Lillerud, Chem. Mater., 22 (2010) 6632-6640.

[54] A. Schaate, P. Roy, T. Preuße, S.J. Lohmeier, A. Godt, P. Behrens, Chem. Eur, J., 17 (2011) 9320-9325.

[55] J. Lippke, B. Brosent, T. von Zons, E. Virmani, S. Lilienthal, T. Preuße, M. Hülsmann, A.M. Schneider, S. Wuttke, P. Behrens, A. Godt, Inorg. Chem., 56 (2017) 748-761.

[56] C.V. McGuire, R.S. Forgan, Chem. Commun., 51 (2015) 5199-5217.

[57] D. Feng, Z.-Y. Gu, Y.-P. Chen, J. Park, Z. Wei, Y. Sun, M. Bosch, S. Yuan, H.-C. Zhou, J. Am. Chem. Soc., 136 (2014) 17714-17717.

[58] D. Feng, W.-C. Chung, Z. Wei, Z.-Y. Gu, H.-L. Jiang, Y.-P. Chen, D.J. Darensbourg, H.-C. Zhou, J. Am. Chem. Soc., 135 (2013) 17105-17110.

[59] J.E. Mondloch, W. Bury, D. Fairen-Jimenez, S. Kwon, E.J. DeMarco, M.H. Weston, A.A. Sarjeant, S.T. Nguyen, P.C. Stair, R.Q. Snurr, O.K. Farha, J.T. Hupp, J. Am. Chem. Soc., 135 (2013) 1029410297.

[60] C.-W. Kung, T.C. Wang, J.E. Mondloch, D. Fairen-Jimenez, D.M. Gardner, W. Bury, J.M. Klingsporn, J.C. Barnes, R. Van Duyne, J.F. Stoddart, M.R. Wasielewski, O.K. Farha, J.T. Hupp, Chem. Mater., 25 (2013) 5012-5017.

[61] T. Islamoglu, K.-i. Otake, P. Li, C.T. Buru, A.W. Peters, I. Akpinar, S.J. Garibay, O.K. Farha, CrystEngComm, (2018).

[62] M.J. Katz, Z.J. Brown, Y.J. Colon, P.W. Siu, K.A. Scheidt, R.Q. Snurr, J.T. Hupp, O.K. Farha, Chem. Commun., 49 (2013) 9449-9451.

[63] A. Schaate, P. Roy, A. Godt, J. Lippke, F. Waltz, M. Wiebcke, P. Behrens, Chem. Eur. J., 17 (2011) 6643-6651.

[64] F. Vermoortele, B. Bueken, G. Le Bars, B. Van de Voorde, M. Vandichel, K. Houthoofd, A. Vimont, M. Daturi, M. Waroquier, V. Van Speybroeck, C. Kirschhock, D.E. De Vos, J. Am. Chem. Soc., 135 (2013) 11465-11468.

[65] M.R. DeStefano, T. Islamoglu, S.J. Garibay, J.T. Hupp, O.K. Farha, Chem. Mater., 29 (2017) 1357-1361.

[66] R.J. Marshall, C.L. Hobday, C.F. Murphie, S.L. Griffin, C.A. Morrison, S.A. Moggach, R.S. Forgan, J. Mater. Chem. A, 4 (2016) 6955-6963.

[67] W. Liang, D.M. D'Alessandro, Chem. Commun., 49 (2013) 3706-3708.

[68] N. Stock, S. Biswas, Chem. Rev., 112 (2012) 933-969.

[69] S. Tai, W. Zhang, J. Zhang, G. Luo, Y. Jia, M. Deng, Y. Ling, Micropor. Mesopor. Mater., 220 (2016) 148-154.

[70] S. Hermes, T. Witte, T. Hikov, D. Zacher, S. Bahnmüller, G. Langstein, K. Huber, R.A. Fischer, J. Am. Chem. Soc., 129 (2007) 5324-5325.

[71] A. Umemura, S. Diring, S. Furukawa, H. Uehara, T. Tsuruoka, S. Kitagawa, J. Am. Chem. Soc., 133 (2011) 15506-15513.

[72] T. Rijnaarts, R. Mejia-Ariza, R.J.M. Egberink, W. van Roosmalen, J. Huskens, Chem. Eur. J., 21 (2015) 10296-10301.

[73] I. Abánades Lázaro, S. Haddad, S. Sacca, C. Orellana-Tavra, D. Fairen-Jimenez, R.S. Forgan, Chem, 2 (2017) 561-578.

[74] I. Abánades Lázaro, S. Haddad, J.M. Rodrigo-Muñoz, C. Orellana-Tavra, V. del Pozo, D. FairenJimenez, R.S. Forgan, ACS Appl. Mater. Interfaces, 10 (2018) 5255-5268.

[75] E. Blanco, H. Shen, M. Ferrari, Nat. Biotechnol., 33 (2015) 941-951.

[76] G.C. Shearer, S. Chavan, S. Bordiga, S. Svelle, U. Olsbye, K.P. Lillerud, Chem. Mater., 28 (2016) 3749-3761.

[77] M. Taddei, Coord. Chem. Rev., 343 (2017) 1-24.

[78] I. Abanades Lazaro, S. Abanades Lazaro, R.S. Forgan, Chem. Commun., 54 (2018) 2792-2795.

[79] L.-L. Zhou, Q. Guan, Y.-A. Li, Y. Zhou, Y.-B. Xin, Y.-B. Dong, Inorg. Chem., 57 (2018) 31693176.

[80] J.-L. Kan, Y. Jiang, A. Xue, Y.-H. Yu, Q. Wang, Y. Zhou, Y.-B. Dong, Inorg. Chem., 57 (2018) 5420-5428.

[81] J. Park, Q. Jiang, D. Feng, H.-C. Zhou, Angew. Chem. Int. Ed., 55 (2016) 7188-7193.

[82] J. Park, M. Xu, F. Li, H.-C. Zhou, J. Am. Chem. Soc., 140 (2018) 5493-5499.

[83] J. Park, Q. Jiang, D. Feng, L. Mao, H.-C. Zhou, J. Am. Chem. Soc., 138 (2016) 3518-3525.

[84] X. Zhu, J. Gu, Y. Wang, B. Li, Y. Li, W. Zhao, J. Shi, Chem. Commun., 50 (2014) 8779-8782.

[85] R. Röder, T. Preiß, P. Hirschle, B. Steinborn, A. Zimpel, M. Höhn, J.O. Rädler, T. Bein, E. Wagner, S. Wuttke, U. Lächelt, J. Am. Chem. Soc., 139 (2017) 2359-2368.

[86] W. Wang, L. Wang, Z. Li, Z. Xie, Chem. Commun., 52 (2016) 5402-5405. 
[87] C. He, K. Lu, D. Liu, W. Lin, J. Am. Chem. Soc., 136 (2014) 5181-5184.

[88] S. Wang, W. Morris, Y. Liu, C.M. McGuirk, Y. Zhou, J.T. Hupp, O.K. Farha, C.A. Mirkin, Angew. Chem. Int. Ed., 54 (2015) 14738-14742.

[89] S. Wang, C.M. McGuirk, M.B. Ross, S. Wang, P. Chen, H. Xing, Y. Liu, C.A. Mirkin, J. Am. Chem. Soc., 139 (2017) 9827-9830.

[90] J. Yang, X. Chen, Y. Li, Q. Zhuang, P. Liu, J. Gu, Chem. Mater., 29 (2017) 4580-4589.

[91] L.-S. Wang, L.-C. Wu, S.-Y. Lu, L.-L. Chang, I.T. Teng, C.-M. Yang, J.-A. Ho, ACS Nano, 4 (2010) 4371-4379.

[92] S. Nagata, K. Kokado, K. Sada, Chem. Commun., 51 (2015) 8614-8617.

[93] L.-L. Tan, H. Li, Y. Zhou, Y. Zhang, X. Feng, B. Wang, Y.-W. Yang, Small, 11 (2015) 3807-3813.

[94] X. Gao, R. Cui, G. Ji, Z. Liu, Nanoscale, 10 (2018) 6205-6211.

[95] U. Ryu, J. Yoo, W. Kwon, K.M. Choi, Inorg. Chem., 56 (2017) 12859-12865.

[96] C. Fu, H. Zhou, L. Tan, Z. Huang, Q. Wu, X. Ren, J. Ren, X. Meng, ACS Nano, 12 (2018) 22012210.

[97] W. Morris, W.E. Briley, E. Auyeung, M.D. Cabezas, C.A. Mirkin, J. Am. Chem. Soc., 136 (2014) 7261-7264.

[98] W.-H. Chen, X. Yu, A. Cecconello, S. Yang Sung, R. Nechushtai, I. Willner, Chem. Sci., 8 (2017) 5769-5780.

[99] L.-L. Tan, N. Song, S.X.-A. Zhang, H. Li, B. Wang, Y.-W. Yang, J. Mater. Chem. B, 4 (2016) 135140.

[100] D. Chen, D. Yang, C.A. Dougherty, W. Lu, H. Wu, X. He, T. Cai, M.E. Van Dort, B.D. Ross, H. Hong, ACS Nano, 11 (2017) 4315-4327.

[101] R.C. Huxford, K.E. deKrafft, W.S. Boyle, D. Liu, W. Lin, Chem. Sci., 3 (2012) 198-204.

[102] W.J. Rieter, K.M.L. Taylor, W. Lin, J. Am. Chem. Soc., 129 (2007) 9852-9853.

[103] M. Filippousi, S. Turner, K. Leus, P.I. Siafaka, E.D. Tseligka, M. Vandichel, S.G. Nanaki, I.S. Vizirianakis, D.N. Bikiaris, P. Van Der Voort, G. Van Tendeloo, Int. J. Pharm., 509 (2016) 208-218.

[104] L. He, M. Brasino, C. Mao, S. Cho, W. Park, A.P. Goodwin, J.N. Cha, Small, 13 (2017) 1700504.

[105] C. Orellana-Tavra, R.J. Marshall, E.F. Baxter, I.A. Lazaro, A. Tao, A.K. Cheetham, R.S. Forgan, D. Fairen-Jimenez, J. Mater. Chem. B, 4 (2016) 7697-7707.

[106] E. Bellido, M. Guillevic, T. Hidalgo, M.J. Santander-Ortega, C. Serre, P. Horcajada, Langmuir, 30 (2014) 5911-5920.

[107] W. Morris, S. Wang, D. Cho, E. Auyeung, P. Li, O.K. Farha, C.A. Mirkin, ACS Appl. Mater. Interfaces, 9 (2017) 33413-33418.

[108] B. Van de Voorde, I. Stassen, B. Bueken, F. Vermoortele, D. De Vos, R. Ameloot, J.-C. Tan, T.D. Bennett, J. Mater. Chem. A, 3 (2015) 1737-1742.

[109] K. Jiang, L. Zhang, Q. Hu, Q. Zhang, W. Lin, Y. Cui, Y. Yang, G. Qian, Chem. Eur. J., 23 (2017) 10215-10221.

[110] C. Orellana-Tavra, E.F. Baxter, T. Tian, T.D. Bennett, N.K.H. Slater, A.K. Cheetham, D. FairenJimenez, Chem. Commun., 51 (2015) 13878-13881.

[111] K. Jiang, L. Zhang, Q. Hu, D. Zhao, T. Xia, W. Lin, Y. Yang, Y. Cui, Y. Yang, G. Qian, J. Mater. Chem. B, 4 (2016) 6398-6401.

[112] M.H. Teplensky, M. Fantham, P. Li, T.C. Wang, J.P. Mehta, L.J. Young, P.Z. Moghadam, J.T. Hupp, O.K. Farha, C.F. Kaminski, D. Fairen-Jimenez, J. Am. Chem. Soc., 139 (2017) 7522-7532.

[113] C. Deutsch, J.S. Taylor, D.F. Wilson, Proc. Natl. Acad. Sci. USA, 79 (1982) 7944-7948.

[114] I. Canton, G. Battaglia, Chem. Soc. Rev., 41 (2012) 2718-2739.

[115] T.-G. Iversen, T. Skotland, K. Sandvig, Nano Today, 6 (2011) 176-185.

[116] J. Rejman, V. Oberle, I.S. Zuhorn, D. Hoekstra, Biochem. J., 377 (2004) 159-169.

[117] K. Greish, Meth. Mol. Biol., 624 (2010) 25-37.

[118] C. Orellana-Tavra, S. Haddad, R.J. Marshall, I. Abánades Lázaro, G. Boix, I. Imaz, D. Maspoch,

R.S. Forgan, D. Fairen-Jimenez, ACS Appl. Mater. Interfaces, 9 (2017) 35516-35525.

[119] H. Gao, W. Shi, L.B. Freund, Proc. Natl. Acad. Sci. USA, 102 (2005) 9469-9474.

[120] M. Gonzalez-Gaitan, H. Stenmark, Cell, 115 (2003) 513-521.

[121] I. Mellman, Annu. Rev. Cell Dev. Biol., 12 (1996) 575-625.

[122] H. Hillaireau, P. Couvreur, Cell. Mol. Life Sci., 66 (2009) 2873-2896.

[123] A.L. Kiss, E. Botos, J. Cell. Mol. Med., 13 (2009) 1228-1237.

[124] C. Orellana-Tavra, S.A. Mercado, D. Fairen-Jimenez, Adv. Healthc. Mater., 5 (2016) 2261-2270.

[125] O. Harush-Frenkel, N. Debotton, S. Benita, Y. Altschuler, Biochem. Biophys. Res. Commun.,

353 (2007) 26-32.

[126] S. Mayor, R.E. Pagano, Nat. Rev. Mol. Cell Biol., 8 (2007) 603-612. 
[127] H.T. McMahon, E. Boucrot, Nat. Rev. Mol. Cell Biol., 12 (2011) 517-533.

[128] J. Shin, S.N. Abraham, Immunology, 102 (2001) 2-7.

[129] J.P. Lim, P.A. Gleeson, Immunol. Cell Biol., 89 (2011) 836-843.

[130] G.A. Mansoori, K.S. Brandenburg, A. Shakeri-Zadeh, Cancers, 2 (2010) 1911-1928.

[131] M. Koivusalo, C. Welch, H. Hayashi, C.C. Scott, M. Kim, T. Alexander, N. Touret, K.M. Hahn, S. Grinstein, J. Cell Biol., 188 (2010) 547-563.

[132] J. Rejman, A. Bragonzi, M. Conese, Mol. Ther., 12 (2005) 468-474.

[133] N. Oh, J.H. Park, Int. J. Nanomed., 9 (2014) 51-63.

[134] J.J.M. Landry, P.T. Pyl, T. Rausch, T. Zichner, M.M. Tekkedil, A.M. Stütz, A. Jauch, R.S. Aiyar, G. Pau, N. Delhomme, J. Gagneur, J.O. Korbel, W. Huber, L.M. Steinmetz, G3 (Bethesda), 3 (2013) 1213.

[135] C. Tamames-Tabar, D. Cunha, E. Imbuluzqueta, F. Ragon, C. Serre, M.J. Blanco-Prieto, P. Horcajada, J. Mater. Chem. B, 2 (2014) 262-271.

[136] W. Liu, Y.-M. Wang, Y.-H. Li, S.-J. Cai, X.-B. Yin, X.-W. He, Y.-K. Zhang, Small, 13 (2017) 1603459-n/a.

[137] L. Hamdan, Z. Arrar, Y. Al Muataz, L. Suleiman, C. Négrier, J.K. Mulengi, H. Boukerche, PLoS One, 8 (2013) e72953.

[138] M.M. Badr, N.A. Qinna, F. Qadan, K.Z. Matalka, OncoTargets Ther., 7 (2014) 193-201.

[139] D. Feng, Y. Song, W. Shi, X. Li, H. Ma, Anal. Chem., 85 (2013) 6530-6535.

[140] J. Tong, G. Xie, J. He, J. Li, F. Pan, H. Liang, J. Biomed. Biotechnol., 2011 (2011) 740564.

[141] H.-X. Zhao, Q. Zou, S.-K. Sun, C. Yu, X. Zhang, R.-J. Li, Y.-Y. Fu, Chem. Sci., 7 (2016) 52945301.

[142] T. Zhang, L. Wang, C. Ma, W. Wang, J. Ding, S. Liu, X. Zhang, Z. Xie, J. Mater. Chem. B, 5 (2017) 2330-2336.

[143] T. Simon-Yarza, A. Mielcarek, P. Couvreur, C. Serre, Adv. Mater., 0 (2018) 1707365.

[144] Y.-A. Li, S. Yang, Q.-Y. Li, J.-P. Ma, S. Zhang, Y.-B. Dong, Inorg. Chem., 56 (2017) 1324113248.

[145] K.E. deKrafft, W.S. Boyle, L.M. Burk, O.Z. Zhou, W. Lin, J. Mater. Chem., 22 (2012) 1813918144.

[146] K. Lu, C. He, W. Lin, J. Am. Chem. Soc., 136 (2014) 16712-16715.

[147] K. Lu, C. He, W. Lin, J. Am. Chem. Soc., 137 (2015) 7600-7603.

[148] K. Ni, G. Lan, C. Chan, B. Quigley, K. Lu, T. Aung, N. Guo, P. La Riviere, R.R. Weichselbaum, W. Lin, Nat. Commun., 9 (2018) 2351.

[149] K. Lu, C. He, N. Guo, C. Chan, K. Ni, G. Lan, H. Tang, C. Pelizzari, Y.-X. Fu, M.T. Spiotto, R.R. Weichselbaum, W. Lin, Nat. Biomed. Eng., 2 (2018), 600-610. 